\title{
Impacts of Indigenous Subsistence Hunting on Wildlife Abundance in the Río Plátano Biosphere Reserve, Honduras
}

By Yannick Cabassu, B.Sc.

\begin{abstract}
A thesis submitted to:
The Faculty of Graduate Studies and Research
\end{abstract}

In partial fulfillment of the

Requirements for the degree of

Masters of Science

Department of Geography and Environmental Studies

Carleton University

Ottawa, Ontario, Canada

April 2010

(C) Yannick Cabassu, 2010 


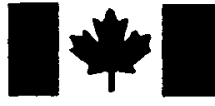

Library and Archives

Canada

Published Heritage

Branch

395 Wellington Street

Ottawa ON K1A ON4

Canada
Bibliothèque et

Archives Canada

Direction du

Patrimoine de l'édition

395 , rue Wellington

Ottawa ON K1A 0N4

Canada
Your file Votre référence
ISBN: 978-0-494-68615-7
Our file Notre référence
ISBN: $978-0-494-68615-7$

\section{NOTICE:}

The author has granted a nonexclusive license allowing Library and Archives Canada to reproduce, publish, archive, preserve, conserve, communicate to the public by telecommunication or on the Internet, loan, distribute and sell theses worldwide, for commercial or noncommercial purposes, in microform, paper, electronic and/or any other formats.

The author retains copyright ownership and moral rights in this thesis. Neither the thesis nor substantial extracts from it may be printed or otherwise reproduced without the author's permission.
AVIS:

L'auteur a accordé une licence non exclusive permettant à la Bibliothèque et Archives Canada de reproduire, publier, archiver, sauvegarder, conserver, transmettre au public par télécommunication ou par l'Internet, prêter, distribuer et vendre des thèses partout dans le monde, à des fins commerciales ou autres, sur support microforme, papier, électronique et/ou autres formats.

L'auteur conserve la proprièté du droit d'auteur et des droits moraux qui protège cette thèse. Ni la thèse ni des extraits substantiels de celle-ci ne doivent être imprimés ou autrement reproduits sans son autorisation.
In compliance with the Canadian Privacy Act some supporting forms may have been removed from this thesis.

While these forms may be included in the document page count, their removal does not represent any loss of content from the thesis.
Conformément à la loi canadienne sur la protection de la vie privée, quelques formulaires secondaires ont été enlevés de cette thèse.

Bien que ces formulaires aient inclus dans la pagination, il n'y aura aucun contenu manquant. 


\begin{abstract}
This study presents field research done over a 12-week-period to investigate the impacts of indigenous subsistence hunting on wildlife in the cultural zone of the Río Plátano Biosphere Reserve in eastern Honduras. A total of $312 \mathrm{~km}$ of repeat transects were used to compare the relative abundance of 21 species in the hunted area around an indigenous village in the cultural zone of the reserve (180 $\mathrm{km}$ of transects), with a nearby, non-hunted area $(132 \mathrm{~km}$ of transects) of the reserve. Abundance of wildlife was also measured as a function of distance from the settlement. Statistical analysis reveals that abundance is significantly greater for the majority of game species in the non-hunted site. A participatory mapping exercise showed that hunters use an area of $107 \mathrm{~km}^{2}$ around the village. Overall, abundance of wildlife increases positively with distance away from the settlement within this zone.
\end{abstract}




\section{Acknowledgements}

I would like to extend my full gratitude to several individuals in both Honduras and Canada who have encouraged me throughout this long journey to carry out this research. First, I would like to thank the Village Council and the villagers of Las Marías in the the Río Plátano Biosphere Reserve for receiving me so warmly and allowing me to pursue this research in their village. I am particularly indebted to the Mejía family, especially to Bonifacio and Teresa for letting me stay under their roof and share their meals. Teresa, thank you so much for your warmth, smiles, and "para el buen café" which was always waiting for me after these long exhausting days in the field.

Many thanks to MOPAWI, namely Adalberto Padilla, Osvaldo Munguia, Sara and Margarita for providing me with important information and great logistical support. Special thanks to Carlos Molinero for introducing me to the field. This thesis would not have been possible without the local research assistants who participated in this project. I am most particularly thankful to Gabriel Suenza for his immense ecological and cartographical knowledge, professionalism, and courage. Carlos Martinez was not only excellent help in the field, but provided me with great company. Thank you for helping me when I fell on my machete. Bonifacio Mejía provided me with great logistical assistance in Las Marias, Juan Gabriel and Daniel Suenza, Misel, and Mario Mejia did 
excellent work. I would like offer a special note of gratitude the nurse in Las Marías: she gave me the best 21 stiches without anesthetic I have ever received.

I cannot thank enough Marc Dunn, for providing me with invaluable advice and for opening his house and receiving me so warmly. Thank you to Rosa Ponce for all her help and friendship in Tegucigalpa.

In Canada I am particularly grateful to my supervisors. Professor Derek Smith for his continued dedication and support throughout this long thesis, for his advice and great editing skills. Thank you to Professor Michael Pisaric for his recommendations and guidance on the structure of the thesis. Thank you to Natalie Pressburger and to the late Hazel Anderson for their great support while in Ottawa. This thesis was made possible thanks to a Carleton University Graduate Bursary and a Duncan M. Anderson Memorial Bursary.

This thesis is dedicated to my wife, Pamela Greenwell. I could not have made it without you. Thank you for all the enormous support and encouragement you have given me along this long journey. I love you! My two little girls, Naomi and Audrey were a constant source of inspiration and warmth on this rocky road, and their eternal smiles and laughs make every day better 


\section{TABLE OF CONTENTS}

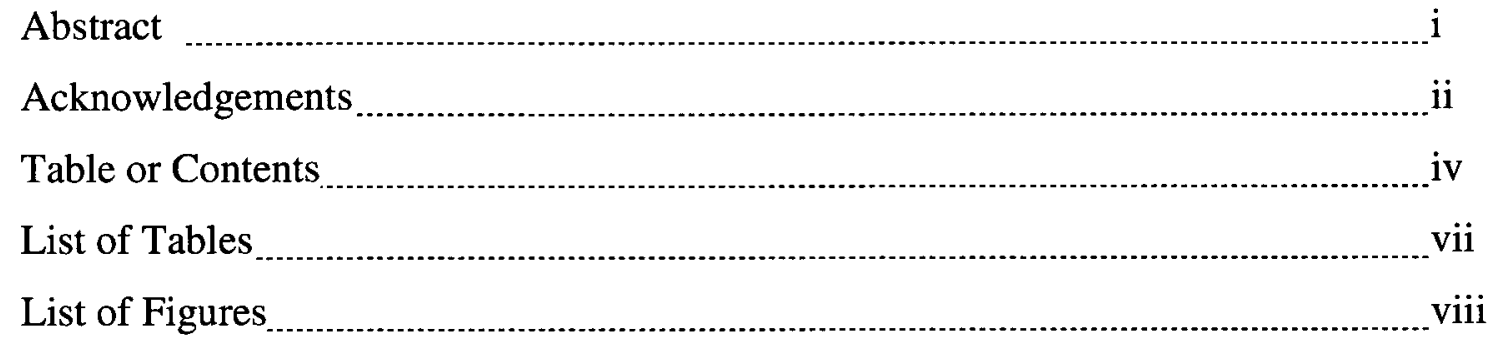

\section{Chapter 1}

Introduction

1.1. Indigenous hunting in biosphere reserves: Are they hunting within sustainable limits?

1.2. Research objectives

1.3. Thesis organization

\section{Chapter 2}

Indigenous Hunting and Factors Affecting the Sustainability of Hunting in

Neotropical Forests .................................................................................................. 8

2.1. Principal Threats Affecting Neotropical Wildlife

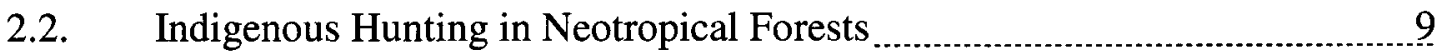

2.3. Geographic Distribution of Hunters and Game Species Around

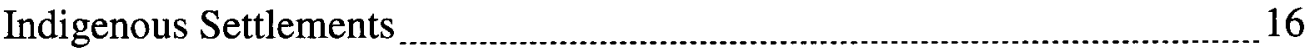

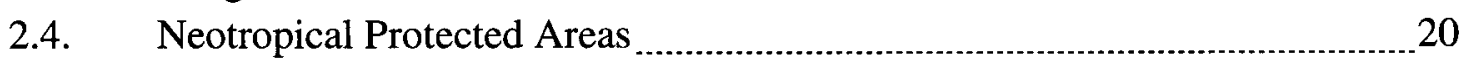

2.5. Consequences of Wildlife Extraction

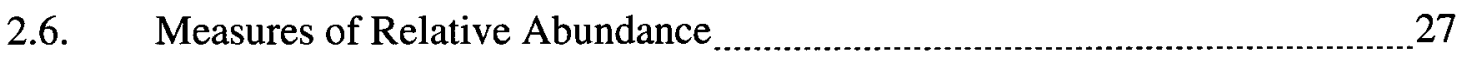

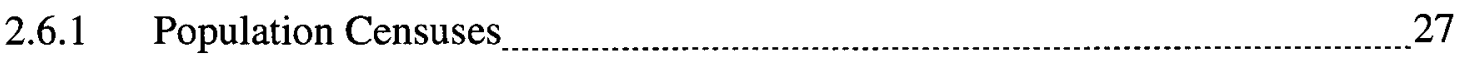

2.6.2. Population Indices and Tracks as a Measure of Relative Abundance _......... 30

\section{Chapter 3}

Study Area and Research Methodology ..............................................................34

3.1. Study Area

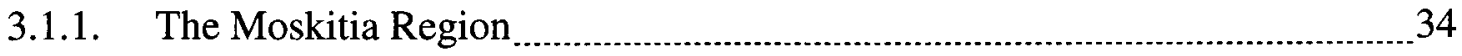

3.1.2. The Río Plátano Biosphere Reserve ............................................................. 36 
3.1.3. Biodiversity of the reserve

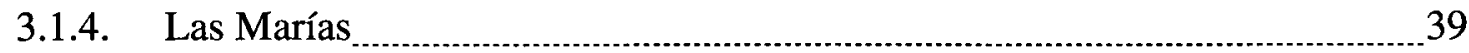

3.2. Data Collection and Analysis Methods Area

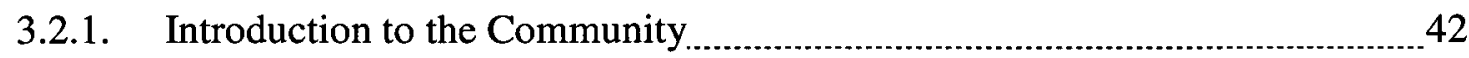

3.2.2. Training of Local Research Assistants in Field Methods ___ _ 43

3.3. Field Methods Applied

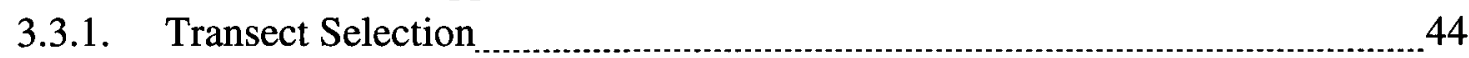

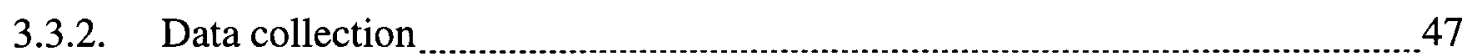

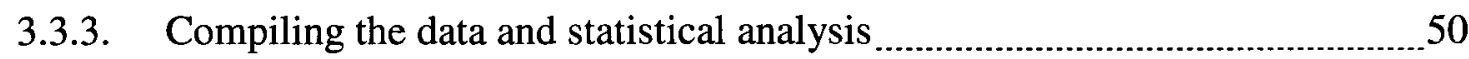

3.3.4. Collecting Complementary Observations on Indigenous Hunting

Activities

\section{Chapter 4}

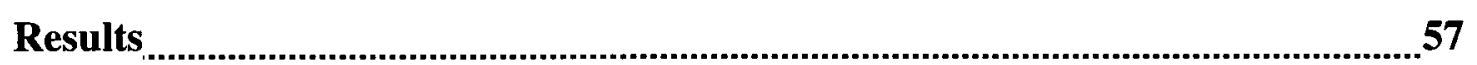

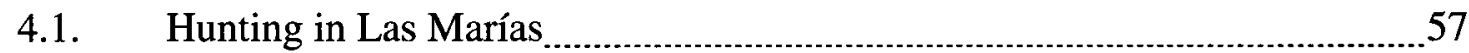

4.2. Delineation of the Principal Hunting Grounds _____ 58

4.3. Comparative Analysis of the Hunted and Non-hunted Region …...................62

4.3.1. Comparing the Abundance of Game and Non-game species in the

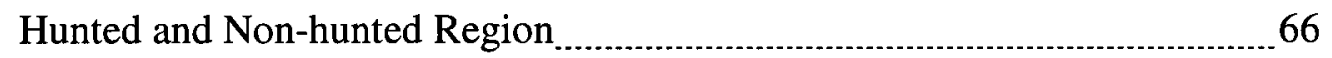

4.3.2. Comparative Abundance of Individual Species _ _ _ _ _ $\quad 71$

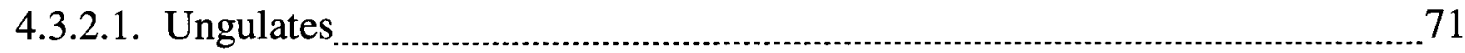

4.3.2.2. Medium-Sized Game Species

4.3.2.3. Birds

4.3.2.4. Primates

4.3.2.5. Felids _..._..._._.

4.3.2.6. Anteaters

4.4. Wildlife Abundance as a Function of Distance Away from the Village ..........91

\section{Chapter 5}

Discussion

5.1 Relative Abundance of Wildlife in Hunted and non-hunted Sites .................101

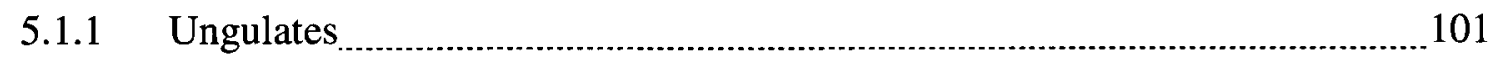

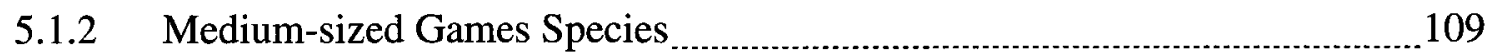

5.1.3 Birds

5.1.4 Primates

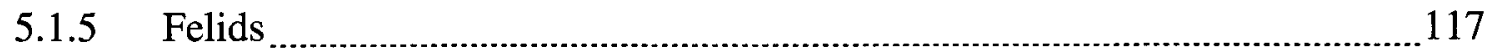


5.1.6 Anteaters

5.2 Wildlife distribution in relation to distance from settlement .........................122

5.3 Geographical distribution of wildlife in the hunted territory ......................... 128

5.4 Effectiveness of the Cultural Zone of the Biosphere Reserve at protecting

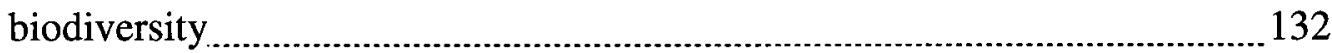

\section{Chapter 6}

Conclusion

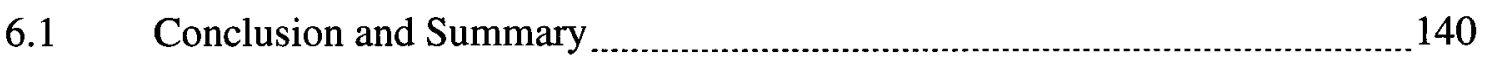

6.2 Key Recommendations $\ldots$

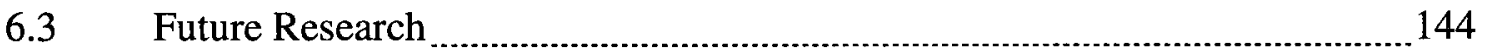

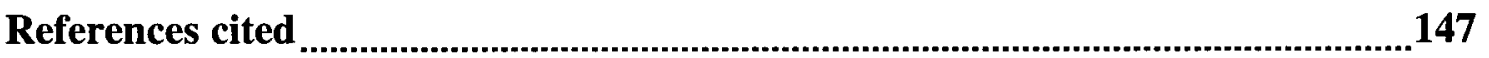




\section{LIST OF TABLES}

Table 2.1: Principal neotropical game species.........................................................14

Table 3.1: Species at risk encountered in the RPBR. ………….................................39

Table 3.2: Game and non-game species included in this study ...............................48

Table 4.1: Percentage of land type occupancy along the transects in the hunted and non-hunted area..........................................................................63

Table 4.2: Total observations and observations per kilometre of each game and non-game species in the non-hunted and hunted areas.

Table 4.3: Statistical tests comparing the abundance of ungulate species in the hunted and non-hunted area ...............................................................73

Table 4.4: Statistical tests comparing the abundance of medium-sized species in the hunted and non-hunted area .........................................................77

Table 4.5: Statistical tests comparing the abundance of birds in the hunted and

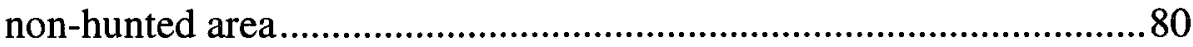

Table 4.6: Statistical tests comparing the abundance of primates in the hunted and non-hunted area.....

Table 4.7: Statistical tests comparing the abundance of felids in the hunted and

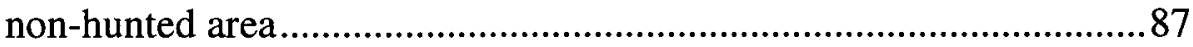

Table 4.8: Statistical tests comparing the abundance of anteaters in the hunted and non-hunted area .....................................................................90

Table 4.9: : Number of observations made around the village of Las Marías for each game and non-game species at various distances from the village.

Table 5.1: Average body mass $(\mathrm{kg})$ of the game species and the distance segment in which they were most abundant around Las Marías. ..... 127

Table 5.2: IUCN classification for ame and non-game species and hunting level around the village of Las Marías. 


\section{LIST OF FIGURES}

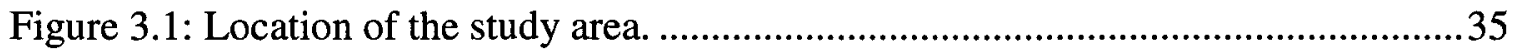

Figure 3.2: Transects location in the hunted area and the non-hunted or lightly hunted area (approximate locations). .46

Figure 3.3: Statistical procedures used to analyze wildlife abundance in hunted and non-hunted area. 53

Figure 4.1: Map of principal hunting grounds around Las Marías designed by the villagers.

Figure 4.2: Principal hunting grounds around Las Marías, 2006 (approximate delineation).

Figure 4.3: Box plot for the total number of wildlife observations per kilometre in the hunted area (Las Marías) and the non-hunted area (nucleus zone). .65

Figure 4.4: Number of observations per kilometre for each game species in the hunted and non-hunted areas.

Figure 4.5: Box plot for the observations per kilometre of game species in the hunted area (Las Marías) and the non-hunted area (nucleus zone). 68

Figure 4.6: Number of observations per kilometre for each non-game species in the hunted and non-hunted areas.

Figure 4.7: Boxplot for the observations per kilometre of non-game species in the hunted and non-hunted area.

Figure 4.8: Box plots for the observations per kilometre of each of the five ungulates studied in the hunted and non-hunted area: a) tapir, b) collared peccary, c) white-lipped peccary, d) white-tailed deer, and e) red brocket deer.

Figure 4.9: Box plots for the number of observation per kilometre for each of the four medium-sized game species studied at the two research sites: a) nine-banded armadillo, b) white-nosed coati, c) paca, d) agouti.

Figure 4.10: Box plots for the number of observations per kilometre of a) great curassow, and b) crested guan.

Figure 4.11: Box plots for the number of observation per kilometre of

primates: a) Central American spider monkey, b) white-faced capuchin, and c) mantled howler monkey.

Figure 4.12: Box plots of the relative abundance of felids (obs $/ \mathrm{km}$ ) in the hunted and non-hunted zone: a) jaguar, b) puma, c) ocelot, and d) small felids.

Figure 4.13: Box plots of the relative abundance of anteaters (obs $/ \mathrm{km}$ ) in the hunted and non-hunted zones.

Figure 4.14: Number of observations for game species, non-game species and total species for each segment of land surveyed $(0-2 \mathrm{~km}, 2-4 \mathrm{~km}$, and 4-6 $\mathrm{km}$ from Las Marías).

Figure 4.15: Observations of game (top) and non-game species (bottom) as a function of distance $(0-2 \mathrm{~km}, 2-4 \mathrm{~km}$, and 4-6 km) from the village of Las Marías. 


\section{Chapter 1:}

Introduction

This thesis presents field research on the spatial distribution of wildlife abundance around the village of Las Marías in the Río Plátano Biosphere Reserve, Honduras. The principal objective of this study is to provide a better understanding of the impacts of indigenous hunting on game populations for a more effective management of biosphere reserves and other protected areas of Central America. More specifically, the purpose of the research is to examine the spatial patterns of hunting and its impact on wildlife abundance, primarily by documenting and comparing the abundance of game species around an indigenous settlement and at another site where hunting does not occur, in order to assess the impacts of hunting on game populations. This research also examines the spatial patterns of hunting by measuring wildlife abundance at various distances from the village, to test the hypothesis that wildlife abundance is inversely correlated to distance from indigenous settlement due to greater hunting pressure closer to where hunters live. Patterns of wildlife abundance around indigenous settlements in protected areas remain poorly understood (Smith 2008), yet are important in estimating the level of hunting these areas can sustain. How far from the village are species affected? Are there large areas of game depletion around indigenous communities? What species are the most affected? Does hunting change the structure of wildlife communities? The intent of this study is to provide insight into these questions.

For this research, a comparative analysis of the relative abundance of twenty game and non-game species (mammals and birds) was conducted at two sites (hunted and non-hunted) 
in the Río Plátano Biosphere Reserve in eastern Honduras over the summer of 2006. A total of $312 \mathrm{~km}$ of repeat transects were observed: $180 \mathrm{~km}$ in the cultural zone around the indigenous village of Las Marías, where hunting is permitted, and $132 \mathrm{~km}$ in the more strictly protected nucleus zone of the reserve where hunting does not occur. The number of direct and indirect observations made along the transect lines were used as indices of relative abundance and analyzed using statistical tests such as one way analysis of variance (ANOVA) and Welch modified two sample $t$-test for normally distributed data, and Kruskal Wallis chi-square test and Wilcoxon Rank Sum test for data not normally distributed. This research was complemented by qualitative observations on hunting practices and a delineation of the principal hunting grounds used by the Pech and Miskito villagers of Las Marías using a participatory mapping approach.

It is hoped that this research will contribute to a better understanding of the relationships between game abundance and indigenous hunting practices in protected areas in neotropical rain forest regions and increase our awareness of the spatial patterns of game animals in hunted areas both in general, and on a species by species basis.

1.1. Indigenous hunting in biosphere reserves: Are they hunting within sustainable limits?

Wild animals are hunted by most indigenous groups living in tropical forests because they are an important source of food (Nietschmann 1973; Redford and Robinson 1987), are sold for income (Peres 2000), have social and cultural value (Bennet and Robinson 2000), 
and because they occasionally damage agricultural crops (Smith 2005). Hunting is especially important to people who live in remote areas as they often have little or no access to other sources of meat for consumption. Prescott-Allen and Prescott-Allen (1982), for example, calculated that a fifth of all animal protein consumed in 62 countries came from fish and wildlife (see Bennet and Robinson 2000). Wildlife was found to provide $66 \%$ of the meat protein for the Aché Indians of Paraguay (Kaplan and Kopishke 1992), and continues to be an important food source to the indigenous Miskito communities of Kurpha and Tukrun in Honduras (Dunn 2004).

Neotropical hunters use a wide array of tools to harvest wildlife and the technologies used can have significantly different impacts on different species. Traditional weapons include bows with poisoned or non-poisoned arrows, spears, catapults (Fitzgibbon et al. 2000; Hill and Padwe 2000), blowguns (Mena et al. 2000), as well as snares and traps (Smith 2005). The use of dogs and firearms, however, is becoming more prevalent for many of these groups (Robinson and Redford 1991; Mena et al. 2000). Hunters harvest a wide range of wild animals, but tend to prefer larger mammals (Robinson and Redford 1991).

Numerous protected areas have been established on land traditionally inhabited by indigenous people in Central America (Herlihy 1997). Hunting and resource extraction by local people in such areas is commonly allowed as they depend on these resources for survival and development. It is also commonly believed that traditional peoples have a better understanding of the land and are better able to manage their resources in a sustainable manner because they have done so in the past (Galetti 2000). This vision is commonly shared by international development agencies and national governments alike 
and has been the basis for the creation of biosphere reserves by the United Nation's Educational, Scientific and Cultural Organization's (UNESCO 2005). As such, the biosphere reserves created within this programme intend to fulfil three basic functions: to conserve biological diversity for long-term purposes; to foster economic and human development which is socio-culturally and ecologically sustainable; and to provide scientific and educational support to conservation and development issues. Balancing the use and conservation of natural resources, however, remains challenging, in part because our understanding of the impacts of hunting and other forms of forest resource use remains far from complete.

While integrating local people into the management of an area's wildlife appears practical, the effectiveness of protecting biological resources in these areas for long-term purposes has at times been questioned. The belief that indigenous peoples always manage their land in a sustainable manner has been challenged by several conservation biologists (e.g., Peres 2000; Redford and Sanderson 2000) and has been the subject of heated debate between conservation biologists and anthropologists. While the former tend to argue that local people frequently over-harvest wildlife in protected areas (Galetti 2000; Redford and Sanderson 2000; Terborgh 2000), the latter refute that evidence (Colchester 2000; Schwartzman et al. 2000) and insist that indigenous peoples' right to develop in their territories should be given priority (Chicchón 2000; Colchester 2000; Schwartzman et al. 2000). Although both groups agree there is a need to conserve biological diversity and protect indigenous people's rights, they have not found common ground on how to attain this goal. Therefore, there is a need to better understand the factors involved in the 
sustainability of subsistence hunting in neotropical environments, especially in protected areas.

Today, the great majority of protected areas in Latin America are inhabited by indigenous peoples (Alcorn 1994). While studies that have looked at the effects of subsistence indigenous hunting on wildlife populations remain relatively few, they frequently indicate a changing trend in resource management techniques used by indigenous people shifting away from traditional techniques, and several studies have given evidence of indigenous overhunting of at least some species (Peres 1990; Robinson and Redford 1991; Redford 1992; Alvard 1994; Bodmer 1994; Peres 1994; Alvard et al. 1997; Souza Mazurek et al. 2000; Ohl-Schacherer et al. 2007). If the goal of protected areas is to conserve wildlife for future generations, then we need to understand whether protected areas on indigenous lands really serve as safe havens for wildlife populations. The research presented here attempts to provide insights into this question.

\subsection{Research objectives}

The over-arching objective of this thesis is to investigate the effects of subsistence hunting on wildlife abundance in the cultural zone of the Río Plátano Biosphere Reserve, Honduras. This is accomplished by: 
1. comparing the relative abundance of eleven game species between the village of Las Marias in the cultural zone of the biosphere and a similar non-hunted site in the nucleus zone;

2. comparing the relative abundance of nine non-game species between the village of Las Marias in the cultural zone of the biosphere and a non-hunted site in the nucleus zone to investigate if non-game species follow the same trends as game species; and

3. comparing the spatial variations of game abundance within a six-kilometre radius around the village of Las Marías.

The thesis also includes complementary observations on the cultural dimensions of hunting in the region, including a map of the boundaries of areas used by hunters, a description of hunting practices and other subsistence activities, and some anecdotal observations on local interpretations of wildlife ecology. This qualitative research was secondary in nature, and conducted in a less systematic way, but nevertheless provides some assistance in the interpretation of the game abundance findings.

\subsection{Thesis organization}

This thesis is presented in six chapters. This chapter describes the goals of the research, provides a brief introduction of indigenous subsistence hunting in biosphere reserves. Chapter 2 reviews the principal factors affecting the sustainability of hunting in neotropical forests. This section provides a description of the principal threats acting on neotropical 
forests and wildlife, and evaluates the patterns of indigenous hunting and the geographic distribution of hunters and game species around indigenous settlements. The remainder of Chapter 2 examines the effects of hunting on game populations and assesses the state of protected areas in neotropical regions. Chapter 3 describes the study area in the Río Plátano Biosphere Reserve and the Moskitia region and the research methods used. Chapter 4 presents the empirical results on wildlife abundance in the hunted and the non-hunted area and wildlife abundance as a function of distance from the village. This chapter also presents the delineation of the Pech and Miskito hunting grounds around Las Marías. Chapter 5 provides a discussion of the findings, in particular an evaluation of effects of subsistence hunting on the abundance of wildlife in the Río Plátano Biosphere Reserve. Chapter 6 presents the main conclusions of the thesis and discusses avenues for future research stemming from the current investigation but was beyond the scope this study. 


\section{Chapter 2:}

Indigenous Hunting and Factors Affecting the Sustainability of Hunting in Neotropical Forests

\subsection{Principal Threats Affecting Neotropical Wildlife}

Tropical forests are considered among the earth's most biologically diverse ecosystems (Laurance et al. 2003), yet, they are being destroyed or altered at alarming rates (Myers 1988, FAO 2005). The Food and Agriculture Organization (FAO) estimates that 154 million hectares of tropical forest were harvested between 1981 and 1990, of which $48 \%$ was in the Americas (FAO 1993). Between 2000 and 2005, South America lost an average of 4.3 million hectares of forested land per year, destroying the habitat of many wildlife populations (Marchak 1995; FAO 2005). The International Union for the Conservation of Nature, which monitors the risk of extinction for species globally, considers habitat loss, degradation and habitat fragmentation as the main threat to mammals, birds, amphibians and reptiles globally (Vié et al. 2009). In Honduras alone there are four extinct, 42 critically endangered, 37 endangered and 41 vulnerable animal species (Vié et al. 2009) 


\subsection{Indigenous Hunting in Neotropical Forests}

Indigenous peoples of Latin America are too numerous and culturally diverse to be classified into a single category and analyzed as such (Stearman 1992). The indigenous population of the Amazonian basin alone, for example, can be divided into some 400 ethnic groups (Tresierra 1997). Significant variations in the use and management of wildlife and other natural resources by indigenous peoples in neotropical regions are therefore expected (Balée 1992; Redford and Padoch 1992). Indeed, while some neotropical indigenous groups have retained many forms of traditional management of the natural environment, others have reoriented land use activities toward market economies. In Honduras, for instance, the Lencas and Chortis are now acculturated farmers who have lost the majority of their pre-Hispanic roots, including their language and many of their ancient beliefs (Rivas 2000). The Miskitos, Pech and Tawahka, on the other hand, have preserved stronger ties to their roots and many continue to rely on subsistence activities to provide them with food, shelter, and medicine (Rivas 2000; Dunn 2004; Cochran 2005; Suazo-Euceda 2005). Some societies, such as the Akuryo, Heta and Maku of the Northern Amazon still had a nomadic lifestyle in 1986 and subsisted exclusively on hunting and gathering (Sponsel 1986). Therefore, the relation of indigenous groups with their natural environment and their effect on wildlife varies considerably, influenced by factors such as their levels of acculturation, beliefs, and dependence on market economies, among others (Saffirio and Scaglion 1982; Redford and Robinson, 1987; Bodmer 1994; Jorgenson 2000; Leeuwemberg and Robinson 2000; Stearman 2000). While hunting remains important for the majority of indigenous 
groups, it has become a secondary activity for many others (Dunn 2004). The many indigenous groups who continue to rely on subsistence activities, however, share important similarities in their management of wild resources, which allows for some generalities to be drawn.

Many indigenous groups of Central and South America still use traditional techniques such as fishing, hunting, gathering and shifting agriculture for subsistence (Vickers 1991; Balée 1992; Kaplan and Kopishke 1992; Orejuela 1992; Posey 1992; Davis and Walli 1993; Alvard et al. 1997; among others). These traditional techniques of natural resource use are generally considered to be ecologically sustainable. However, unsustainable harvesting of wildlife by indigenous people is common (Peres 1990; Robinson and Redford 1991; Redford 1992; Alvard 1994; Bodmer 1994; Peres 1994; Alvard et al. 1997; Souza Mazurek et al. 2000; Ohl-Schacherer et al. 2007) and is of great concern to conservationists, given that the great majority of protected areas in Latin America are also inhabited by indigenous peoples (Kemf 1993; Terborgh 2000). This dilemma has led to a long and heated debate between those who see indigenous people as a threat to the conservation of wildlife in protected areas and those who see indigenous people as essential players in the conservation of tropical forests (Redford 1991; Alcorn 1993; Redford and Stearman 1993; Robinson 1993; Peres 1994; Harmon 1998; Terborgh 1999; Chicchón 2000; Redford and Sanderson 2000; Schwartzman et al. 2000; Terborg 2000; Peres and Zimmerman 2001; Zimmerman et al. 2001; Shepard 2002; Terborgh and Peres 2002; da Silva et al. 2005; Nepstad et al. 2006). While these debates and studies have improved our understanding of the relation between indigenous people and wildlife, the impacts of hunting remain poorly understood. 
Subsistence hunting is of paramount importance to many indigenous groups of neotropical forests (Redford and Robinson 1987; Vickers 1991). Wild animals are hunted for food (Nietchman 1972; Vickers 1991; Orejuela 1992; Alvard et al. 1997; Leeuwemberg and Robinson 2000; Stearman 2000; Dunn 2004; Smith 2005; Suazo-Euceda 2005), clothing, ornaments, and for medicinal and other products (Robinson and Redford 1991). Some are also sold commercially to provide extra income (Robinson and Redford 1991; Stearman 1992; Bodmer et al. 1994). Wild animals are also killed for personal protection or to prevent crop destruction (Orejuela 1992; Jorgenson 2000; Lee 2000; Dunn 2004; Smith 2005).

Wildlife and the act of hunting are frequently included as integral parts of traditional native cultures (Bennet and Robinson 2000). Ornaments made with feathers and skins, for example, are often considered important for cultural rituals. Many indigenous groups have strong spiritual links to the activity of hunting. The Aché of Paraguay, for example, name their children from animals prepared and consumed by the pregnant mother (Hill and Padwe 2000). While this group is willing to adapt wildlife management techniques that help in reducing the negative effect of hunting within the Mbaracayu reserve, they emphasize that even rare or endangered species must be hunted occasionally so as to preserve important traditional Aché names (Hill and Padwe 2000). Hunting is also a key component of the social organization of many indigenous groups (Reichel-Dolmatoff 1971), bringing prestige to hunters (Ventocilla 1995; Stearman 2000; Smith 2005) or maintaining traditional foodsharing systems (Kaplan and Kopischke 1992; Reichel-Dolmatoff 1996; Hill and Padwe 2000). Hunting is frequently considered enjoyable (Smith 2005), and can also fulfill a set of 
social and psychological needs (Hill and Padwe 2000) in the same ways that hunting parties are organized in industrialized countries.

Indigenous hunters have a sound knowledge of their natural environment (Hill and Hawkes 1983; Yost and Kelley 1983; Orejuela 1992; Baksh 1995). Hunting is usually done by men, but women and children occasionally capture small or medium species (Hill and Hawkes 1983; Yost and Kelley 1983; Kaplan and Kopischke 1992; Leeuwenberg and Robinson 2000; Townsend 2000; Smith 2008). Hunting can be opportunistic, while going to agricultural fields or foraging in the forest, or focused on specific locations known to attract game, such as salt licks and fruiting trees (Kaplan and Kopischke 1992; Orejuela 1992; Smith 2005). Hunters hunt individually or in a group (Kaplan and Kopischke 1992; Constantino et al. 2008; Smith 2008) and use a wide variety of hunting tools. Traditional tools include the spear, bow and arrow, blowgun with dart or hardened mud projectiles, traps, snares and sticks (Kaplan and Kopischke 1992). While these tools are still used by many groups (Alvard et al. 1997; Shepard 2002; Ohl-Schacherer et al. 2007), they are increasingly surpassed by new technologies, such as the machete (Vickers 1991; Kaplan and Kopischke 1992; Mena et al. 2000; Townsend 2000; Jerozolimski and Peres 2003). The use of firearms has also become prevalent in the neotropics (Jerozolimski and Peres 2003). In fact, firearms are now the most important hunting tool for many, if not most, indigenous groups (Yost and Kelley 1983; Mena et al. 2000; Townsend 2000; Jerozolimski and Peres 2003; Smith 2005; Koster 2008). The adoption of modern hunting tools and techniques by indigenous peoples, however, is often cited as the cause of overhunting (Yost and Kelley 1983; Robinson and Redford 1991; Alvard et al 1997; Mena et al. 2000; Stearman 2000; Jerozolimski and Peres 2003; Peres and Palacios 2007). Indigenous people in the 
neotropics often use dogs for hunting (Alvard and Kaplan 1991; Ventocilla 1992; Mena et al. 2000; Townsend 2000; Dunn 2004; Smith 2008), but their effect on wildlife has not been thoroughly studied (Koster 2008a). However, the use of dogs for hunting can have a detrimental effect on wildlife conservation as it can increase harvest rates (Redford and Robinson 1987; Constantino et al. 2008) by augmenting the detection rate of certain species such as tapirs (Alvard and Kaplan 1991; Ventocilla 1995; Koster 2008a). The use of dogs can also be detrimental to non-game species. Koster (2008b), for example, documented that over a summer an indigenous hunter of the Bosawas Reserve in Nicaragua killed four female giant anteaters (Myrmecophaga tridactyla), an endangered species, to protect his dogs. In the village of Aguas Calientes, Peru, I have personally observed a villager kill a coati solely to protect his dogs.

Indigenous peoples generally have a stronger dependence on wildlife than do people of European descent because they rely less on domestic and packaged meat (Redford and Robinson 1991). They also hunt a much wider range of species and include a wide range of smaller species (Ruddle 1970; Redford and Robinson 1987; Stearman 2000). The SionaSecoya of Ecuador, for example eat more than a hundred different species of animals (Vickers 1991), and the Achuar of Ecuador eat some 150 species of mammals and birds (Descola 1986). Table 2.1 presents the most frequently targeted game species in the neotropics. 
Table 2.1: Principal neotropical game species

\begin{tabular}{lll} 
Order & Common English name & Scientific name \\
\hline Perissodactyla & Baird's tapir* & Tapirus bairdii \\
& Lowland tapir & Tapirus terrestris \\
\hline Artiodactyla & Collared peccary* & Tayassu tajacu \\
& White-lipped peccary* & Tayassu pecari \\
& Gray brocket deer & Mazama gouzoubira \\
& Red brocket deer* & Mazama americana \\
& White-tailed deer* & Odocoileus virginianus \\
\hline Primates & Capuchin monkey* & Cebus spp. \\
& Howler monkey* & Alouatta spp. \\
& Spider monkey* & Ateles spp. \\
\hline Rodentia & Capybara & Hydrochaeris hydrochaeris \\
& Agoutis* & Dasyprocta spp. \\
& Acouchis & Myoprocta spp. \\
& Paca* & Agouti paca \\
\hline Xenarthra & Armadillos* & Dasypus spp. \\
& & Cabassous spp. \\
\hline Carnivora & Coatis & Nasua spp. \\
\hline Crocodila & Caimans & Caiman spp. \\
\hline Squamata & Iguanas & Iguana spp. \\
\hline Galliformes & Chachalacas & Ortalis spp. \\
& Curassows & Crax spp., Mitu spp etc... \\
& Guans & Penelope spp \\
\hline
\end{tabular}

* Taxa hunted in eastern Honduras

Indigenous people commonly harvest primates, which are rarely consumed by the Mestizos, the people of mixed European and Indigenous descent. Consistent with optimal foraging theory (Smith 1978; Webster 1986), however, the preferred species of indigenous and non-indigenous peoples of the neotropics are almost consistently large-bodied species (Terborgh et al. 1986; Thiollay 1986; Vickers 1991; Peres 1990; 1999; Carrillo et al. 2000; Robinson and Bennet 2000; Townsend 2000; Peres 2001; Naughton Treves 2002; Peres and lake 2003) because they provide the greatest return in terms of energy invested (Alvard 1995). Prey selection of indigenous people, however, is not solely linked to body mass but is also associated to cultural beliefs, taboos and preferences (Helms 1971; Nietshmann 
1973; Linares 1984; Leeuwemberg and Robinson 2000; Dunn 2004). The Xavante of Central Brazil, for example, do not hunt armadillos (Dasypus spp.), brocket deer (Mazama spp.) or peccaries (Tayassu spp.) for six months after the birth of a child (Leeuwemberg and Robinson 2000). Hunting restrictions imposed by the taboo systems of many indigenous groups are often seen as a self-regulating mechanism that helps reduce hunting pressure (McDonald 1977). Colding and Folke (1997), for example, showed that taboos help in protecting many species classified as threatened by the International Union for the Conservation of Nature. Traditional folklore, myths and taboos, however, are eroding from traditional societies (Peres 2000b). Jerozolimski and Peres (2003) found that taboos only play a secondary role in determining what will be on a hunter's plate and argue that taboos change in relation to the composition of available prey. For example, species such as kinkajous (Potos flavus) and coatis (Nasua nasua), which were previously considered undesirable by the Yuqui of Bolivia are now consumed (Stearman 1990), and the previously "tabooed" brocket deer is now hunted by the Siona-Secoya of Bolivia (Hames and Vickers 1982). Similarly, the Huaorani of Ecuador had a taboo against hunting the tapir, collared peccary (Tayassu tajacu) and red-brocket deer (Mazama americana), but after the introduction of dogs, which allowed hunters to corner these species, the species became prey (Mena et al. 2000). A brief discussion of the factors affecting the spatial distribution of game species and hunting activities is provided below. 
2.3. Geographic Distribution of Hunters and Game Species Around Indigenous Settlements

Indigenous hunters do not wander in random directions in search of prey nor do they attempt to kill any animal that crosses their field of vision (Nietschmann 1972). The structure, composition and amount of game harvested by indigenous hunters are influenced by a range of ecological, cultural, economic and technological factors (Smith 2008), and hunting, in turn, affects the distribution and abundance of game and non-game species. Therefore, comprehending the spatial pattern of indigenous hunting is needed to understand the dynamics of wildlife populations around indigenous settlements. However, studies that have looked at the geographic distribution of hunting around indigenous settlements are few (Vickers 1991; Smith 2008), and to this researcher's knowledge, none has looked at the relative abundance of wildlife as a function of distance from an indigenous settlement.

Spatial delineation of hunting territories is one crucial factor in determining hunting sustainability (Smith 2008). Indeed, calculating the density of a wild game population within a defined area requires, at the very least, knowing the size of the area. Furthermore, wildlife population densities can vary widely across space (Peres 2000a) and are dependent on various factors, including hydrology (Bodmer 1990; Peres 2000a), water hole availability (Vaughan and Weiss 1999; Martínez-Kú 2007), soil types (Janzen 1974; Freese et al 1982), rainfall (Janson et al. 1981; Terborgh 1983; Emmons 1984), plant and animal distributions (Emmons 1984), predator-prey relationships (Terborgh and Winter 1978), availability of shelter (Peres 2000a), vegetation structure and composition (Emmons 1984; Peres 2000a), 
the size and shape of the hunting territory (Salas and Kim 2001) as well as the level of hunting pressure (Peres 2000a).

Hunters generally concentrate their efforts around their settlements, and as a result most of the game is caught near home (Hames 1980; Vickers 1991; Ventocilla 1992; Alvard 1994; Fragoso 1998; Hill and Padwe 2000; Mena et al. 2000; Leeuwenberg and Robinson 2000; Souza Mazurek et al. 2000; Dunn 2004; Sirén et al. 2004; Ohl-Schacherer et al. 2007; Constantino et al. 2008; Smith 2008). The Aché of Paraguay, for example, hunt within a six-kilometre radius of their village (Hill and Padwe 2000); and 75\% of the game caught by the Kuna of Panama was captured within four kilometres (Ventocilla 1992). However, hunting expeditions to distant hunting grounds are not uncommon (Souza Mazurek et al. 2000; Dunn 2004). Although $85 \%$ of the hunt done by the Miskito of Río Patuca region in Honduras is done within ten kilometres of their settlements, hunters sometimes travel as far as 30 kilometres in search of game (Dunn 2004). Access to modes of modernized forms of transportation such as trucks and motorboats can greatly influence the distance at which indigenous people travel for hunting (Jerozolimski and Peres 2003). The Waimiri Atroari in the Brazilian Amazon, for example, travel more than $25 \mathrm{~km}$ with trucks to access farther hunting grounds where game is more abundant (Souza-Mazurek et al. 2000). Hunting areas can also be greatly influenced by the temporal stability of settlements (Hames 1980; Stearman 2000). Nomadic or semi-nomadic groups sometimes relocate when game becomes scarce around the settlement (Stearman 2000). However, many of the traditionally nomadic or semi-nomadic groups have adopted a more sedentary lifestyle (Miliken et al. 1992; Stearman and Redford 1995; Leeuwemberg 1997; Bennet et al. 2000; Stearman 2000). This has important implications for wildlife conservation because human settlements 
usually grow with time (Stearman 2000), increasing both the demand for bushmeat (Bodmer et al. 1997) and the hunting pressure around settlements, which in turn can lead to localized over-exploitation of wildlife (Souza Mazurek et al. 2000; Stearman 2000). In fact, the length of time an area has been harvested is considered a determinant predictor of the structure of a harvest profile (Jerozolimski and Peres 2003). The size of indigenous hunting territories, therefore, can vary widely from group to group (Vickers 1991; Herlihy and Leake 1997; Leeuwenberg and Robinson 2000; Mena et al. 2000; Herlihy 2003; Dunn 2004; Smith 2008). For example, while five neighbouring Buglé and Ngöbe settlements in western Panama use a shared area of $131 \mathrm{~km}^{2}$ for hunting (Smith 2008), the hunting grounds of five Siona-Secoya settlements in Ecuador measured $1,150 \mathrm{~km}^{2}$ (Vickers 1991).

Often, indigenous hunting grounds are envisioned as circular in shape, with the human settlement set in the center, and the populations of wild game increasing with distance away from the center of the village (Mittermeier 1991). Studies that have delineated indigenous hunting grounds around indigenous settlement, however, have shown this is not the case (Vickers 1991; Leeuwemberg and Robinson 2000; Dunn 2004; Leeuwemberg and Robinson 2000; Sirén et al. 2004; Smith 2008; Vickers 1991). For example, the hunting grounds of Miskito in the Río Patuca region of eastern Honduras, have a highly irregular shape and are split in four zones that range from heavily to rarely used as you move away from the village (Dunn 2004). Understanding the shape of a hunting territory may be important as areas of mature forests and other suitable habitat that are not used by hunters within a larger hunting territory may provide important refuge for some game species, providing potential sources of animals that can migrate into hunted areas 
through source-sink dynamics (Joshi and Gadgil 1991; Novaro et al. 2000; Sirén et al. 2004; Naranjo and Bodmer 2007).

Higher hunting pressure around indigenous settlements (Hames 1980; Vickers 1991; Ventocilla 1992; Alvard 1994; Fragoso 1998; Hill and Padwe 2000; Mena et al. 2000; Leeuwenberg and Robinson 2000; Souza Mazurek et al. 2000; Dunn 2004; Sirén et al. 2004; Ohl-Schacherer et al. 2007; Constantino et al. 2008; Smith 2008) frequently brings changes to the community structure of game species (Jerozolimski and Peres 2003). Because large vertebrates are the preferred species, they also tend to be the first set of species to be overharvested from these areas (Peres 1990; Alvard 1993; Bodmer et al. 1994; Jerozolimski and Peres 2003). As a result, catches around settlements tend to progressively change from large- to small-bodied game species (Jerozolimski and Peres 2003). In fact, hunting yields often increase with distance from settlements (Hames and Vickers 1982; Alvard 1994; Souza-Mazurek et al. 2000), and the capture per unit effort around settlements is usually lower than in remote hunting sites (Hames 1980; Alvard 1994; Fragoso 1998; Jerozolimski and Peres 2003), explaining the need for many indigenous groups to make use of distant hunting grounds.

While several of the preferred game species, like spider monkeys (Alouatta palliata), white-lipped peccaries (Tayassu pecari) and large birds like the great curassow (Crax rubra) are frequently associated with forested areas, a whole set of other important game species are associated with agricultural lands (Linares 1976; Smith 2005), highlighting the importance of traditional indigenous land management techniques for the conservation of certain species. Shifting cultivation, also called "slash and burn", is the most popular form of land management used by indigenous people of the neotropics. It is 
an agricultural system in which fields are cropped for fewer years than they are allowed to remain fallow, allowing soils to renew themselves (Ruddle and Manshard 1981). The mosaic landscape this type of agriculture creates is said to increase biological diversity and provide highly suitable habitats for many game species used by indigenous hunters (Linares 1978; Smith 2005). The amount of game harvested from agricultural land is not negligible. Smith (2005), for example, found that $47 \%$ of the game harvested by the Buglé and Ngöbe of western Panama comes from such areas and tall fallow of 5 years or more. He adds that the paca, which was the most important prey species in terms of biomass, was caught more than $75 \%$ of the time in agricultural lands.

\subsection{Neotropical Protected Areas}

Parks and protected areas are widely considered as the best means of protecting biological diversity from unsustainable human activities (Bruner et al. 2001; Terborgh and van Schaik 2002). It is now estimated that about 17 percent of the land in Latin America is under some form of protection status (The World Conservation Center 2007), but the effectiveness of these parks in protecting biological diversity is often questioned (Brandon and Anderson 1998; Terborgh and van Schaik 2002). Most tropical forests are found in the developing world, in countries that are often considered ill-equipped to confront the challenge of biodiversity conservation (Barret et al. 2001). Indeed, weak institutions, rampant corruption, high pressure to exploit natural resources and little economic resources to invest in conservation often prevent developing nations from managing their protected 
areas effectively (Barret et al. 2001). For example, in one year working for the Cerro Azul Méambar National Park, considered one of the best managed parks in Honduras, I witnessed dozens of deliberately set fires, constant agricultural encroachment, illegal hunting, whole areas being clearcut, and a several kilometres-long road being built illegally without concern for slope stability or erosion. I was told of a judge from the Supreme Court saying "I am above the law" when caught by the park authorities for having illegally acquired a portion of the park to transform it into a coffee plantation....and getting away with! I was even told of a park guard who was killed in his own home a few years ago for having discovered a marijuana field in the park. While the park staff is composed of hard-working, dedicated, honest people, there is little they can do to protect the park's biological diversity without stronger financial and institutional help from the government. Clearly, managing protected areas in developing countries of the neotropics is more difficult than in wealthy countries (Cox and Elmqvist 1991).

While nature reserves in industrialized countries are usually devoid of people, parks of neotropical regions are generally inhabited. In fact, about $85 \%$ of the protected areas in Latin America are inhabited by local peoples, mainly indigenous (Kemf 1993). Conservationists, as a result, have had little choice other than to collaborate with indigenous people to create many of the protected areas in neotropical forests (Alcorn 1993). The question of whether parks inhabited by indigenous peoples are effective at conserving biological diversity, however, has created a wide divide between the advocates of peoplefree parks and those who consider that indigenous people help in conserving wildlife diversity (Redford 1991; Alcorn 1993; Redford and Stearman 1993; Robinson 1993; Peres 1994; Harmon 1998; Terborgh 1999; Chicchón 2000; Redford and Sanderson 2000; 
Schwartzman et al. 2000; Terborgh 2000; Peres and Zimmerman 2001; Zimmerman et al. 2001; Shepard 2002; Terborgh and Peres 2002; da Silva et al. 2005; Nepstad et al. 2006). While both groups agree on the undisputable rights of indigenous people to their ancestral lands (Bush 1996), they disagree on whether protected areas inhabited by indigenous peoples will serve their long-term purpose of protecting biological diversity (Terborgh 1999; Redford and Sanderson 2000;, Terborgh 2000; Terborgh and Peres 2002). One side argues that indigenous people "demonstrate a concern for maintaining the ecological processes and the species that mediate those processes" (Alcorn 1993: 425) and that the creation of sparsely populated "Indian lands" helps in preserving large tracks of biologically rich forests by stopping the expansion of deforestation (Schwartzman et al. 2000). Conversely, others argue that while indigenous people do have lower impact than others on their ecosystems, unsustainable harvest of wildlife by indigenous people is frequent (Ventocilla 1996; Peres 2000a,b; Redford and Sanderson 2000). There is also no guarantee that indigenous people will not adopt more destructive, but economically more rewarding techniques of resource management in the future (Redford and Stearman 1993). While much of the debate has occurred within academic circles, it has also influenced international institutions in making managerial decisions, such as the United Nations Educational, Scientific and Cultural Organization (UNESCO), the International Union for the Conservation of Nature (IUCN), and the Convention on Biological Diversity (CBD). UNESCO's Man and the Biosphere (2007), for example, does not solely focus on the conservation of biological resources, but also integrates the social and economic development of local and indigenous communities into its management scheme, which is the case for the Río Plátano Biosphere Reserve. 
Protected areas, then, are not only areas of land set aside for conserving wild resources; they have also become centres of cultural preservation, but the balance between resource use and biodiversity conservation is largely dependent on their ownership and management (Robinson and Richter 1999). This thesis compares the relative abundance of wildlife in the nucleus zone of the RPBR, devoid of human settlements, to its cultural zone, inhabited by indigenous people allowed to practise subsistence activities, and investigates whether a difference in wildlife populations and structure exists between the two areas. The research attempts to improve our understanding of the relationships between indigenous communities and game abundance, and provide insights that inform wildlife management within protected areas.

\subsection{Consequences of Wildlife Extraction}

While the effects of habitat loss and loss of tropical biodiversity have been widely publicized, the amplitude and effects of hunting on tropical ecosystems is only beginning to be understood (Peres 2001, Milner-Gulland et al. 2003). Hunting is virtually ubiquitous in neotropical forests (Redford and Robinson 1987; Ojasti 1996; Robinson and Bodmer 1999) and affects even the largest and most remote protected areas (Peres and Terborgh 1995; Peres 2000a). The International Union for the Conservation of Nature now considers overhunting to be one of the main threats to the conservation of wildlife in tropical forests (Vié et al. 2009), affecting about a third of the birds and mammals listed as threatened by the IUCN (Mace and Reynolds 2001, Mainka 2002). In fact, hunting is so widespread that, globally, it is considered the principal cause of wildlife extinction after habitat destruction 
(Diamond and Case 1986; Atkinson 1989; Reid 1992; Alvard et al. 1997; Bodmer et al. 1997). The effects of hunting, however, remain frequently unnoticed because this activity leaves few visible marks in standing forests (Redford 1992).

Subsistence hunting is the most extensive form of faunal extraction in Latin America (Ojasti 1996). Although it is generally done on a small scale, cumulative extractions caused by this activity across the landscape can be staggering. Peres (2000) estimates the yearly consumption of birds, reptiles and mammals by the rural native and non-native population of the Brazilian Amazonian forest to be between 9.6 and 23.5 million individuals, with mammals representing between 6.4 and 15.8 million individuals. These findings correspond to those of Redford (1993), who estimated, based on the 1980 human population of the Brazilian Amazon, that 19 million vertebrates, including 14 million mammals, were extracted from the same region. He adds that this number could add up to 57 million if we include the seriously wounded animals that escaped hunters.

Hunting can have considerable effects on biological communities. It can significantly reduce wildlife populations (Peres 1990; Alvard 1994; Bodmer 1994; Alvard et al. 1997; Souza-Mazurek et al. 2000) and lead to local extirpation of certain vulnerable species (Peres 1993; Alvard et al. 1997; Alvard 2000), even when practised on a small scale (Thiollay 1986; Peres 1990; Redford, 1992; FitzGibbon et al., 1995; Peres 2000b, 2001). Wildlife extraction can change the composition (Redford 1992) and size structure of whole biological communities (Hart 2000). Large mammals and birds are usually the preferred prey and are the most harvested, followed by reptiles (Ayres and Ayres 1979; Hames 1979; Hames and Vickers 1982; Redford and Robinson 1987; Peres 1990; Glanz 1991; Vickers 1991; Alvard 1993; Souza-Mazurek et al. 2000). As a consequence, they are the most 
affected by overhunting (Peres 2000b) and are often the first to disappear from overhunted areas (Daily et al., 2003; Jerozolimski and Peres 2003). In fact, local extinction events are usually correlated with body mass (Peters and Wassembgerg 1983, Jerozolimski and Peres 2003), in great part because life history traits that characterize many large species (low reproductive rates, low population densities, long generation time and long lifespans) (Hennemann 1983; McKinney 1997) make them especially susceptible to overhunting (Redford and Robinson 1987; Bodmer et al. 1997; Peres 2000a, Jerozolimski and Peres 2003). Not all large species, however, have similar life history traits. While primates are considered particularly sensitive to hunting pressure because of their very low production rates, ungulates, apart from tapirs, have relatively higher reproductive rates than expected based on their body mass and can therefore withstand greater hunting pressure (Robinson and Redford 1991). However, other factors also influence the vulnerability of a species to overharvesting. For example, animals which form large groups, like white-lipped peccaries (Tayassu pecari) and woolly monkeys (Lagothrix lagotricha), can both be driven to local extinction within a few years of continued hunting (Peres 1991; 1996) because hunters can kill a high number of individuals within the group at each encounter. Hunting can also, through density-dependent mechanisms, change the demography of wild species by removing entire sets of important prey or competitor species and allowing the establishment of species with high rates of increase, which are frequently small-bodied (Wilkie and Finn 1990; Silva and Strahl 1991; Bodmer 1995; Bodmer et al. 1997; Lopes and Ferrari 2000; Peres 2000b; Souza-Mazurek et al. 2000; Naughton-Treves et al. 2003). Freese et al. (1982), for example, suggest that tamarins (Sanguinus spp.) in the Peruvian and Bolivian Amazon are more common in overhunted areas where large monkeys have been extirpated 
than in non-hunted areas. The increase in density of collared peccary, paca (Agouti paca) and coati (Nasua narica) on Barro Colorado Island in Panama is believed to be linked to the disappearance of several top predators, most notably jaguars (Panthera onca) and pumas (Puma concolor) (Wright et al. 1994). Subsistence hunters can also have a direct effect on non-game species by competing for the same prey. Pumas and jaguars can be indirectly affected by subsistence hunters because they compete for the same set of prey species (Jorgenson and Redford 1993, Novack 2003). Hunting can also change the structure of game species populations by lowering the population's average age of first reproduction and reducing the proportion of animals in older age classes (Hart 2000). Indeed, hunters often kill game species regardless of their age and sex (Vickers 1994; Mena et al. 2000; Souza Mazurek et al. 2000). Finally, hunting can also have significant repercussions on the floristic composition of an ecosystem because it decreases plant dispersal by removing effective seed dispersers and affects plant competitive interactions by removing important seed predators and seedling browsers (Emmons 1984; Bodmer 1991; Dirzo and Miranda 1991; Redford 1992; Chapman and Chapman 1995; Peres and van Roosmalen 1996; Andresen 2000; Wright et al. 2000; Wright 2003; Peres and Palacios 2007; Terborgh et al. 2008).

While hunting can have significant impacts on wildlife populations and their ecosystems, a reduction in the abundance of game species can also seriously affect human populations. Hunting is an important socioeconomic activity (Robinson and Bennet 2000) as the majority of people who depend on it are also the poorest (Mainka 2002). Unsustainable hunting, therefore, decreases the value of primary forests to local peoples by reducing their extraction capacity (Peres 2000b). Large game vertebrates are also an 
attraction to many ecotourists, and overhunting can decrease the potential economic revenues from ecotourism brought by the presence of wildlife (Peres 2000b).

\subsection{Measures of Relative Abundance}

Estimating the size of a specific or a group of species is generally the first step taken to assess changes in the abundance of wildlife populations or compare sites subjected to different extractive pressures. Two general methods are used to estimate population size: (i) population censuses, which are based on total counts, sample counts or population-ratios, and (ii) the use of indices.

\subsubsection{Population Censuses}

Population censuses entail counting animals in a defined area in order to obtain their numbers. This method is divided in two categories: total counts, which demand an entire count of all the individual animals from a species of interest in a given area, and sample counts, which is essentially the same method as total count but applied to a sample area from which inference about the rest of the studied region is made. Population censuses based on total counts can give a perfect snapshot of the state of a studied population at a given time. Total counts of a wildlife population, however, are possible only under rare "idealized circumstances" (Williams and Vaughan 2001), when, for example, the studied species is conspicuous, its population is low and is restricted to small areas such as small 
islands (Geis 1971). In large areas, however, this method is prohibitive and often inaccurate because of the cost and difficulty of observing mobile and/or secretive animals (Bailey 1984; Caughley and Sinclair 1994). This is especially true in dense tropical forests where animals tend to be more secretive (Thompson 2004) and visibility, and hence detectability of the animal, is limited.

The use of sample counts to estimate populations may be the most common approach to estimating wildlife populations. Total counts are conducted on randomly selected plots, and the resulting data are used as a base to estimate the population of an entire area or to compare some selected plots. This method assumes that the sampled plots are representative of the area being investigated.

The sampled area used to estimate population with sample counts can be either fixed and well-defined, or unbounded. The former is generally preferred when observations are numerous because it is simple to analyze and statistically straightforward. Examples of fixed sample units include quadrats and transect lines with fixed boundaries (e.g., 100 metres on each side of the transect line, or the average flushing distance from the particular species). A common use of transect lines with fixed boundaries includes aerial surveys, which are frequently used by state departments to estimate the populations of large mammals such as deer, antelope or caribou. This technique, however, is not used in forested areas for the obvious lack of visibility caused by the forest canopy.

Transect studies based on the number of direct observations is the most common method of assessing wildlife in tropical forest environments (Painter et al. 1995, Peres 1995, Bodmer et al. 1997, Cullen et al. 2000, Hill and Padwe 2000, Peres 2000b, Peres 2001, Hill et al. 2003, Novack et al. 2005, among others). This method uses either fixed boundaries or 
no boundaries at all. The difference between the two methods lies in the statistical analysis rather than the approach. The advantage of the former, as discussed above, is its simplicity. But since the precision of a statistical estimation is dependent upon the sample size, the studied population, therefore, needs to be sufficiently large. Transects based on unbound boundaries allow researchers to take into account all their observations, thereby increasing the power of their analysis. This method, which is also called distance sampling (Buckland et al. 1993), is therefore useful in tropical forest environments where encounter rates are rare due to low visibility and the "shy" behavior of certain species. The observations made with this technique are usually analyzed using the program DISTANCE developed by Buckland et al. (1993) which is based on the vertical distance of each observation from the transect line.

Line transect sampling based on direct observations of individuals or groups requires a large sample size (Buckland et al. 1993) which may be difficult to obtain because many species of mammals are difficult to monitor due to their small size, coloration and secretive behavior (Engeman and Allen 2000). For this reason, the majority of line transect studies that use direct observations are long term studies (e.g., Peres 2001: 14 years; Hill et al. 2003: 7 years), and even with substantial sampling intensity, the number of observations required to allow reliable calculation of densities frequently fall below the required minimum (e.g., Painter et al. 1995, Chiarello 2000, Lopes and Ferrari 2000). Line transect methods based solely on direct observation of species are therefore inadequate for shortterm studies in tropical forests. This is especially true for species or group of species that are rare and/or inconspicuous. The use of population indices for estimating the relative 
abundance of wildlife in tropical areas is therefore a preferred alternative for short-term studies.

\subsubsection{Population Indices and Tracks as a Measure of Relative Abundance}

In theory and as described above, wildlife managers and ecologists have a wide array of techniques and methods for assessing population density. In practice, however, scientists facing time and financial constraints generally rely on some sort of index to estimate density. As expressed by Dice:

The difficulty of obtaining accurate counts of the number of individual mammals present in a given area has led to attempts to develop indices of abundance for the species concerned. Such indices may or may not be convertible into terms of population density. For many practical uses, however, it is sufficient to know the relative abundance of a particular species in different areas or at different times without having an exact count of the population (1941:402).

A population index is an aspect of the population that is representative of the population density. Ideally, an index has a linear relationship with the species density. For example, if one index or group of indices represents a given density, then the doubling or halving of the number of indices encountered would represent a doubling or halving of the animal density. Indices, however, do not have to be translated into actual density as this would require knowing the proportional relationship between the index and the density of the animal. In other words, it is possible to know that a population has doubled without 
knowing exactly how many animals are in the population. Indices of density, hence, are useful for comparing changes occurring in populations that are geographically separated or for monitoring the same population over a defined time period. Methods for estimating relative abundance of populations using indexes are numerous and include using tracks on transects, track plates, pellet groups, auditory clues and harvest rates. The use of tracks on transects as an index of relative abundance is the most suitable and most common technique used in tropical forests (Fragoso 1987; Lizcano and Cavelier 2000; Cullen et al. 2000; Escamilla et al. 2000; Hill and Padwe 2000; Tobler 2002; Mandujano 2005; Reyna-Hurtado and Tanner 2005 ; 2007) because it allows one to investigate the abundance of several species at the same time. Indeed, while recording tracks of several species along a transect line is feasible, measuring the abundance of species with different behaviours may not be logistically possible with other techniques. Auditory cues, for example, can only be used with vocal species, like birds or howler monkeys, and traps and track plates have to be species specific.

Tracks are frequently used to estimate abundance under the assumption that there is a positive relationship between the abundance of tracks encountered in a specific area and the actual population size, and that this relationship remains constant over time (Thompson et al. 1998). In other words, this method assumes that animal movements are identical over time and/or between areas being studied. In temperate environments, several methods have been used to observe tracks. Boyce (1989), for example, counted elk (Cervus elaphus) tracks left in snow to estimate their migration number into Jackson Hole Elk Refuge; Becker (1991) used an aircraft survey technique to count tracks left in fresh snow; Merill et al. (1994) used mule deer (Odoilecus hemionus) track counts for monitoring the effects of 
mining facilities on migration; Mooty et al. (1984) estimated white-tailed deer abundance on dirt roads; Van Dyke et al. (1986) did the same, but for the cougar; and Marten (1972) used tracks to estimate small mammal abundance. While these researchers point to certain limitations of their methods related to the characteristics of the species being measured and the particular environments where their research was carried out, all agree that using tracks is a suitable and effective method for measuring wildlife abundance. Furthermore, this method is considered reliable, cost effective and relatively easy to use (Reyna-Hurtado and Tanner 2007). It may also be the only feasible option for short-term species which investigate a large number of species (Thompson et al. 1998).

Though calibrating track counts to the actual number of a species population is rarely done because of the additional time and effort required, it has been successfully attempted by several researchers using Track Encounter Rate (TER), the number of tracks encountered over a specific distance or area $\left(\mathrm{n} / \mathrm{km}\right.$ or $\left.\mathrm{n} / \mathrm{km}^{2}\right)$. Fragoso (1991) found a correlation between tapir abundance and their tracks in Belize. Naranjo et al. (2004) found that TERs are positively correlated with population densities (animals $/ \mathrm{km}^{2}$ ) and with the frequency of animal observations for the 12 species they studied in the Lacandon forest of Mexico. Hill and Padwe (2000) designed an indirect observation/direct observation ratio for eight species of the Mbaracayu Reserve in Paraguay (which includes seven of the species studied here). Soil and weather conditions could play an important role in track visibility and the accuracy of TER estimates; however Weber (2000), found that these factors did not significantly affect track counts while studying three species of deer in the Calakmul forest in Mexico. 
In sum, tracking is probably the best method to use in short-term multi-species studies in tropical forest environments because it is cost effective, easy to use, and provides reliable estimates of relative abundance. This method was therefore adopted for this study. 


\section{Chapter 3:}

\section{Study Area and Research Methodology}

\subsection{Study Area}

The study took place in two sites within the Río Plátano Biosphere Reserve: around the village of Las Marías, which is in the cultural zone of the reserve, and at a site about 15 $\mathrm{km}$ to the southwest within the uninhabited, strictly protected nucleus zone (Figure 3.1 ). Although the results of this thesis concentrate on this indigenous settlement, they have application potential to other regions of Central and South America because of the similarities in physical, ecological and human attributes held by the local and regional settings. A brief description of the Moskitia is provided to offer an overview of the regional context.

\subsubsection{The Moskitia Region}

The Moskitia is a large and relatively isolated lowland region found in eastern Honduras and northeastern Nicaragua. The Moskitia includes some 600 kilometres of the Caribbean coast between Cape Camarón in Honduras and the Río San Juan in Nicaragua, and reaches inland to the base of the Central American highlands (Cochran 2005). Along the coast, the region is characterized by flat lowland plains and lagoons drained by several 
large, meandering rivers. The interior of the Moskitia is composed of hilly uplands and mountainous terrain farther inland. Pine savannas and broadleaf tropical forests cover most of these lands, with savannas located in the eastern part of the region.

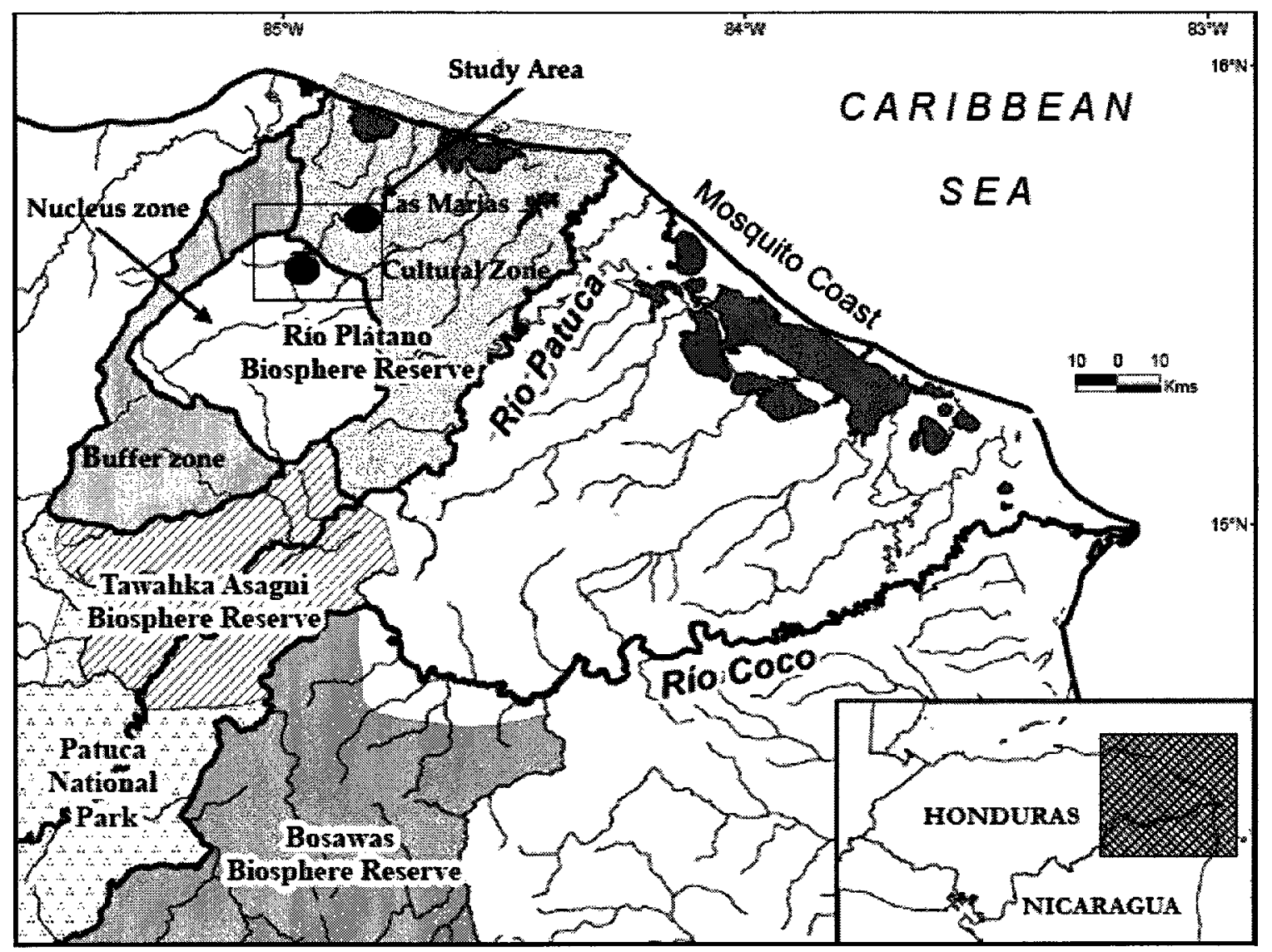

Figure 3.1: Location of the study area (adapted from Dunn 2004).

The study site is located within a region that has a rainy tropical climate and is dominated by two life zones as classified by Holdridge (1967): the humid tropical forest and the very humid subtropical forest. Average precipitation varies from 2,000 to more than 4,000 millimetres during the wettest months (UNEP/WCMC 1997), and daily temperature ranges from $25^{\circ} \mathrm{C}$ to $33^{\circ} \mathrm{C}$ (Cochran 2005:34). Both temperature and precipitation vary with the seasons, with the highest temperatures occurring from January to May, during the dry 
season (verano), and the highest precipitation from June to December, during the wet season (invierno).

The Moskitia is one of the principal reservoirs of biological diversity in Central America and includes coastal and lacustrine ecosystems, mangroves, coastal and pine savannas, and mature broadleaf tropical forests. Five ethnic groups inhabit this region: the Mestizos (also called Ladinos are the descendants of Spanish colonists - 52 percent), the Miskito (44 percent), the Garífuna (3 percent), the Pech (1 percent) (McSweeney 2004: 639, Herlihy 2001), and the Tawahka. In addition to agriculture and fishing, hunting is one of the main subsistence activities of the communities of the Moskitia, including those communities located with the Río Plátano Biosphere Reserve.

\subsubsection{The Río Plátano Biosphere Reserve}

The RPBR, together with the adjacent Patuca National Park, Tawahka Asagni Biosphere Reserve, and Nicaragua's Bosawás Biosphere Reserve, form the "heart of the Mesoamerican Biological Corridor" (World Bank 2005: 3), which is the largest track of moist tropical forest north of the Amazon (Padilla et al. 2003). Created in 1980 by UNESCO under the Man and the Biosphere Program, the Río Plátano Biosphere Reserve is the oldest biosphere reserve in Central America. It was expanded in 1997 to its current size of $8,300 \mathrm{~km}^{2}$, making it Central America's largest protected area. It is subdivided into three conservation zones: the nucleus zone, the cultural zone, and a buffer zone. The nucleus zone is the central area of the reserve, occupying some $2,100 \mathrm{~km}^{2}$ and composed almost entirely 
of primary tropical broadleaf forest. This zone is uninhabited, and resource extraction of any kind, including hunting, is strictly prohibited.

The cultural zone covers some $4,200 \mathrm{~km}^{2}$ and is composed of virgin and disturbed habitats. While the coast and the principal waterways are populated, this zone conserves large areas of relatively undisturbed natural ecosystems. Although four ethnic groups inhabit the zone, it is predominantly Miskito. The cultural zone has the dual purpose of providing the local population with the opportunity to use natural products to meet their community's needs and ensuring the long term protection and maintenance of biological diversity. The village of Las Marías is located within this zone.

The reserve is divided into two geomorphic zones: the mountains in the interior occupy approximately $75 \%$ of the area, and the coastal plains and lagoons of the north form the rest. With an elevation of 1,326 metres, Punta Piedra is the highest peak of the biosphere. In the center of the reserve is the Plátano River, which meanders some 45 kilometres through the lowlands, forming ox-bow lakes and swamps. From the coast to the village of Las Marías, the bank of the Plátano River is composed of secondary forests, traditional agricultural lands and small Miskito and Mestizos settlements, with some pockets of primary forest. South of Las Marías, upstream of the Plátano River, agricultural lands and secondary forests become scarce, giving way to primary forests as one gets closer to the nucleus zone. 


\subsubsection{Biodiversity of the reserve}

The Río Plátano Biosphere Reserve contains a valuable and highly diverse set of species and habitats (Vreugdnehill et al. 2002). About half of Honduras' ecosystems are represented, including 24 terrestrial and 11 aquatic ecosystems (Padilla et al. 2003). Its main ecosystems are estuarine and marine, mangrove swamps, coastal savanna, broadleaf gallery forest, humid subtropical forest, and very humid tropical forest, with the last ecosystem occupying about 80 percent of the total area (Herrera-MacBryde 1995, cited in UNEP-WCMC 1997). At least 2,000 species of vascular plants have been recorded in the biosphere, but since this region has not yet been thoroughly studied, this number could be considerably higher (Herrera-MacBryde 1995: cited in UNEP-WCMC 1997:2). In terms of fauna, 39 species of mammals, 377 species of birds, and 126 species of reptiles and amphibians have been recorded in the RPBR (Herrera-MacBryde 1995: cited in UNEPWCMC 1997:2). Table 3.1 describes the species at risk present in the RPBR. It is worth noting that the conservation status of species at the international, national or even regional level may not reflect the abundance of species within the reserve. This study provides more information on the abundance of some of the species considered at risk in the reserve. 
Table 3.1: Species at risk encountered in the RPBR.

\begin{tabular}{ll} 
Common name & Scientific name \\
\hline Mammals & Tapirus bairdii \\
Baird's tapir* & Mazama Americana \\
Red brocket deer* & Panthera onca \\
Jaguar* & Felis pardalis \\
Ocelot* & F. concolor \\
Puma* & F. wiedii \\
Margay* & F. yaguaroundi \\
Jaguarundi* & Myrmecophaga tridactyla \\
Giant anteater* & Lutra longicaudis \\
Central American otter & Trichechus manatus \\
Caribbean manatee & \\
\hline Birds & Harpia harpyia \\
Harpy eagle & Ara macao \\
Scarlet macaw & A. ambigua \\
Green macaw & A. militaris \\
Military macaw & Sarcoramphus papa \\
King vulture & Crax rubra \\
Great curassow* & Penelope purpurascens \\
Crested guan* &
\end{tabular}

Source: (UNEP-WCMC 2002)

*Species included in the research

\subsubsection{Las Marías}

Las Marías is a mixed Pech and Miskito village of about 500 people. It was chosen as a study site because it is located in a protected area and because the villagers have retained some traditional forms of resources management techniques, including hunting. Although some cultural differences may remain between the Pech and Miskito of Las Marías, they are almost imperceptible to an outsider. Las Marías is considered one of the last Pech bastions; however, the dominant culture here is in fact Miskito. Indeed, apart from the elders who 
still use it occasionally, the Pech language is practically not spoken in the village. All Pech, however, speak the Miskito language. Considering that in terms of resource management and economic activities, no obvious differences were noted between the two ethnic groups during this field research, both groups here are classified as indigenous "villagers" rather than attempting to distinguish them ethnically.

As in most of the Moskitia, Las Marías has remained isolated from the development visible in the rest of the country. There is no electricity apart from a few individually owned solar panels, and no sewage system. The main way to reach Las Marías is via the Plátano River, on which villagers travel by dugout canoes locally called pipante, or through a long and very challenging trail which leads to the coast. The difficulty in reaching the village of Las Marías has in no way barred its inhabitants from becoming a "purchase society" however (Helms, 1971). In fact, generating cash appears to be among the priorities of many villagers. People in Las Marías are poor and depend primarily on subsistence activities to meet their basic needs, but most families also engage in commercial pursuits, including ecotourism services, the sale of agricultural surpluses, and wage labour.

Swidden agriculture is the most important subsistence activity for most, if not all, the villagers. This activity provides food for the whole year and seeds for the following year. When or if there is a surplus, villagers make a trip to the coast to sell it. The villagers of Las Marías use their agricultural land on a rotational basis. When they acquire new land, the tallest trees are generally cut and used for building pipantes or as boards for construction. Smaller trees are used for firewood or removed by burning, depending on their needs and the distance from their settlements. The rest of the vegetation is then cut and left to dry for several months. Later, during the dry season, the slash is burned, and the 
land is prepared and sowed. Often, a few trees are left, providing a seed bank for natural regeneration. Agricultural fields are generally used for a year or two but may be used several years in a row if productivity is good. The land is then left to fallow for several years, often between five and ten, again depending on its fertility. The result of this shifting activity is a mosaic of landscapes around the village, with all pieces representing land at different stages, from an agricultural field to primary forest. The main crops produced here are yucca, beans, rice, and plantains. Chickens and eggs provide an occasional supplement of meat protein. Pigs and cows are also common in the village but are rarely consumed by the owners as they are generally raised for sale. Occasionally, a pig or cow is slaughtered and the meat is sold to the rest of the village. The price of domestic meat, however, remains higher than that of wild meat. Since not everyone in the village can afford to buy domestic meat, many villagers still rely on wild meat and fish to supplement their diet. However, not everyone hunts or fishes in the village, and those who do often sell their surplus to their neighbours to supplement their income. None of the villagers, however, specialize in hunting as a way to make money.

The two other principal economic activities of the villagers of Las Marías, apart from selling their products, are tourism and lobster fishing. All families in Las Marías benefit from tourism as most men (and at least one woman) work as guides. Although this activity is not steady and does not provide sufficient income to the villagers, it helps the villagers financially and appears to have given them a greater awareness of wildlife conservation. Several men of the village, including some known hunters, work on lobster fishing boats during the government regulated open season. Lobster fishing is an important source of income for many villages of La Moskitia because it can bring in a large amount of cash in a 
relatively short period of time. In a period of only a few weeks, divers can generate enough cash to sustain themselves and their families for a whole year. However, the risks associated with this work, which include death and permanent physical incapacities resulting from decompression syndrome, are very high.

\subsection{Data Collection and Analysis Methods Area}

\subsubsection{Introduction to the Community}

Preliminary contacts with MOPAWI (Moskitia Pawisa or Moskitia Development), the principal non-governmental organization working in the region, were made prior to my departure from Canada. Two weeks after my arrival in Honduras, and after I had obtained a research permit from the AFE-COHDEFOR, the Honduran ministry responsible for forestry, a representative of MOPAWI introduced me to the community of Las Marías through a general assembly during which I had the opportunity to present my research project. The MOPAWI representative also introduced me to potential research assistants and helped me find a place to stay for during my field research. Although there are four pensiones (small, modest lodgings) in Las Marías, I decided to lodge with a Pech family so as to better understand the daily life of the local inhabitants. In order to increase my involvement in the community I offered free English lessons on Sundays at the local school when I was present in the village. Both adults and children attended the classes. I also attended several community meetings. 


\subsubsection{Training of Local Research Assistants in Field Methods}

Over the summer, a total of eight research assistants were hired; three who worked consistently during that period had been recommended by MOPAWI staff, five worked intermittently and were hired when needed. All were selected for their ability to speak and write Spanish and for their knowledge of the local environment, especially the local fauna. The local research assistants were hired to clear and prepare the transect lines used for the study, to walk the transect lines and describe wildlife observations, and to present a map that delineates the principal hunting grounds used by the villagers of Las Marías.

All the local research assistants hired for this study were indigenous Pech and Miskito. Six had previous experience working as research assistants on other projects and were already experienced with some of the protocols required for this type of work. One, for example, had experience working on an avian study, three had worked on mammal research using transects, another had worked on a herpetofauna study, and one had experience with participatory mapping. All local assistants worked as local guides and had excellent knowledge of the local fauna. Their experience as hunters and thousands of hours of their own empirical observations in anthropogenic and undisturbed habitats during their varied subsistence activities had given them great skills in identifying wildlife and in recognizing different tracks. They were trained, however, in ecological data collection, and how to use a compass and a hip chain. The training varied between a few hours for some, to a week for others, depending on their involvement in the project and their previous knowledge and 
experience. Above all, I trained all the local research assistants to record data in a consistent manner and only within the specific parametres of this research. For example, their initial tendency during training was to look for wildlife tracks outside of the transect boundaries, so it was necessary to emphasize and reconfirm that tracks and visual observations of terrestrial mammals outside the two-metre wide transects should not be recorded. Observations of arboreal species could be recorded outside of the two-meter transects as unbounded transects were used for this class of species. All local research assistants worked under my direct supervision in the initial weeks of the field research. Never more than two transects were visited in one day. When only one transect was visited, I worked with one assistant, when two transects were visited in one day, then I worked with one assistant on one trail while two others assistants worked unsupervised. The team of unsupervised assistants always had at least one of the three principal research assistants whom I knew had good experience and rigor. The assistants were paid between 150 and 200 Lempiras (Honduran currency) per day (about \$8-12 CND) depending on experience, which is between fifty and one hundred percent more than the minimum wage for the hiring of a local guide for a single day excursion.

\subsection{Field Methods Applied}

\subsubsection{Transect Selection}


Transects were used (i) to compare the relative abundance of wildlife in an area that experiences hunting (Las Marías) and a non-hunted zone (Nucleus zone), and (ii) to measure changes in abundance of wildlife as a function of distance from the indigenous settlement of Las Marías. A total of eight transects were created. Four six-kilometre long transects were created around the village. The six-kilometre benchmark was chosen most of indigenous hunting is believed to be concentrated in a six-kilometre radius around settlements (e.g., Ventocilla 1992; Hill and Padwe 2000), including Las Marías, and because longer transects would have been too difficult to survey in a single day. Four threekilometre long transects were also created in the core area of the Río Plátano biosphere reserve, where harvest of natural resources is not permitted (Figure 3.2), some 15 kilometres away from the village of Las Marías. 


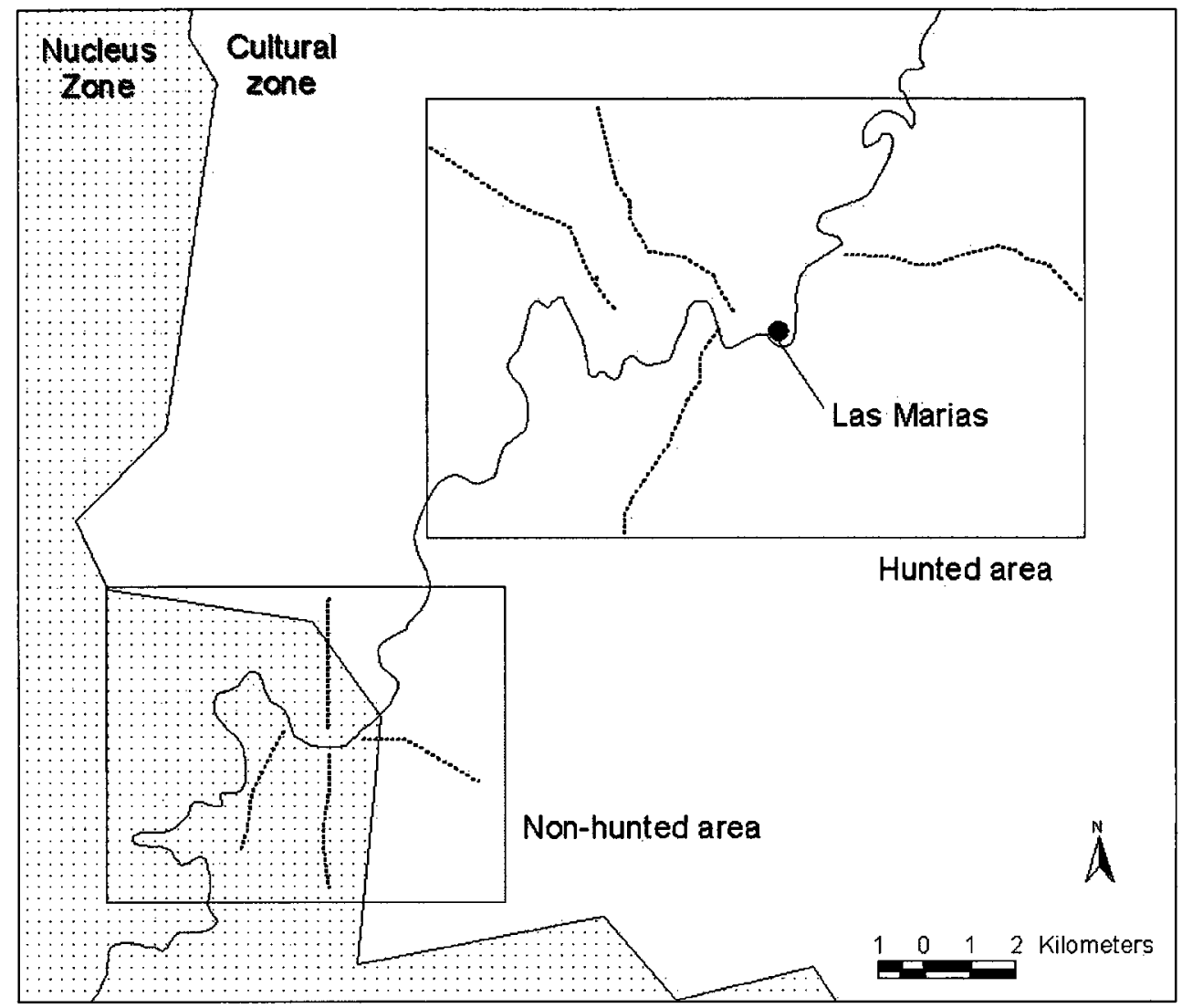

Figure 3.2: Transects location in the hunted area and the non-hunted or lightly hunted area (approximate locations).

*See figure 3.1 for location of the study area within Honduras.

$\dagger$ Boundaries between the cultural and nucleus zone are approximate

¥Although one transect is partially out of the nucleus zone, local informants indicated that hunting does not occur in this area.

The location of each transect was selected in collaboration with the local research assistants who had an excellent knowledge of the region and of where hunting occurs. An exercise delimiting the areas used by hunters reconfirmed that the transects were either entirely within, or outside of, the shared hunting zone ${ }^{\ddagger}$ (see Figure 3.2). Transects were selected to ensure that they would have similar topographical and other environmental conditions, and for their accessibility because the terrain in the region is very steep and dangerous to use on a regular basis. 
11 the trails had a width of two metres and were cleared with machetes. They were measured using a hip-chain (FIELD RANGER@) with a 6000-metre biodegradable thread, and chosen with the aid of a compass. Efforts were made to keep the transects as straight as possible, but difficult passages caused by large obstacles such as trees or rock outcrops and steep and slippery slopes/hills and cliffs required adjustments. Each transect was flagged every 100 metres with pink flagging tape, and the forest type of the surroundings at each of these 100metre segment marks was classified as either primary forest, secondary forest, agricultural land or bamboo-dominated environment. Once established, the ground along the transects was cleared of vegetation when necessary so as to not obstruct the researchers' ability to observe tracks. Once recorded, all animal marks observed on the transect lines were erased.

\subsubsection{Data collection}

Comparative analysis of wildlife abundance was done for the 21 species known to be present in the park and which can be easily identifiable either visually or through their tracks (Table 3.2). Wildlife was classified as game or non-game, based on interviews with the villagers of Las Marías. The margay (Leopardus wiedii) and jaguarundi (Herpailurus yaguarondi) were grouped into the combined category of "small felids" because of the difficulties in differentiating their tracks and because they are rarely encountered. 
Table 3.2: Game and non-game species included in this study

\begin{tabular}{|c|c|c|c|}
\hline & \multicolumn{2}{|c|}{ Common Name } & Scientific Name \\
\hline \multicolumn{4}{|l|}{ Game species } \\
\hline \multirow{5}{*}{ Ungulates } & \multicolumn{2}{|c|}{ Baird's tapir } & Tapirus bairdii \\
\hline & \multicolumn{2}{|c|}{ Collared peccary } & Tayassu tajacu \\
\hline & \multicolumn{2}{|c|}{ White-lipped peccary } & Tayassu pecari \\
\hline & \multicolumn{2}{|c|}{ White-tailed deer } & Odocoileus virginianus \\
\hline & \multicolumn{2}{|c|}{ Red brocket deer } & Mazama americana \\
\hline \multirow{4}{*}{$\begin{array}{l}\text { Medium-sized } \\
\text { game species }\end{array}$} & \multicolumn{2}{|c|}{ Nine-banded armadillo } & Dasypus novemcinctus \\
\hline & \multicolumn{2}{|c|}{ White-nosed coati } & Nasua narica \\
\hline & \multicolumn{2}{|l|}{ Paca } & Agouti paca \\
\hline & \multicolumn{2}{|c|}{ Agouti } & Dasyprocta punctata \\
\hline \multirow{2}{*}{ Cracids } & \multicolumn{2}{|c|}{ Great curassow } & Crax rubra \\
\hline & \multicolumn{2}{|c|}{ Crested guan } & Penelope purpurascens \\
\hline \multicolumn{4}{|l|}{ Non-game species } \\
\hline \multirow{3}{*}{ Primates } & \multicolumn{2}{|c|}{ Spider monkey } & Ateles geoffroyi \\
\hline & \multicolumn{2}{|c|}{ White-faced capuchin } & Cebus capucinus \\
\hline & \multicolumn{2}{|c|}{ Howler monkey } & Alouatta palliata \\
\hline \multirow{5}{*}{ Felids } & \multicolumn{2}{|l|}{ Jaguar } & Pantera onca \\
\hline & \multicolumn{2}{|l|}{ Puma } & Puma concolor \\
\hline & \multicolumn{2}{|c|}{ Ocelot } & Leopardus pardalis \\
\hline & \multirow{2}{*}{$\begin{array}{l}\text { Small } \\
\text { felids }\end{array}$} & Margay & Leopardus wiedii \\
\hline & & Jaguarundi & Herpailurus yaguarondi \\
\hline \multirow{2}{*}{ Anteaters } & \multicolumn{2}{|c|}{ Giant anteater } & Myrmecophaga tridactyla \\
\hline & \multicolumn{2}{|c|}{ Northern tamandua } & Tamandua mexicana \\
\hline
\end{tabular}

In both Las Marías and the nucleus zone, transect lines were walked six days a week between 8:00 a.m. and 2:00 p.m. by myself and one research assistant or by two trained local research assistants equipped with a compass, a pair of binoculars and a field notebook. Being the principal field observer, I contributed in about $80 \%$ of the observations in the hunted area, and $50 \%$ of the observations in non-hunted area. Transects were walked as 
quietly as possible, and slowly, at an approximate speed of 1.5 kilometres per hour. All direct and indirect observations of the 21 species made on the trails were recorded in the notebooks. Direct observations in this context refer to direct sightings of an animal, and indirect observations refer to signs, in particular, tracks, scat or burrows. The same trails were used on the way. The trails were visited on a rotational basis and were therefore left to "rest" for a minimum of two days before being revisited.

All direct observations were recorded including the name of the species, the number of individuals or the number of groups, and the time of the observation. The distance of the animal away from the centre of the trail was estimated visually because the rangefinders do not function well in dense forest environments. Only fresh indirect observations were recorded. All tracks or scats observed were erased or removed so as to not be recorded again. All burrows were marked with flagging tape and only new burrows were recorded. Tracks that followed the path were only recorded once. The general direction of the tracks was measured with a compass and recorded to help avoid recording the same individual more than once along the transect. Special attention was also given to the size of the tracks (adult or juvenile) so as to ensure again that the same individual was not recorded twice on the same transect. Tracks which were not recognizable were ignored.

When a group of animals was observed, but it was not possible to count the number of individuals or their separate tracks, Robinson and Redford's method (1991) to take an average group number for the species was used. White-lipped peccaries were counted as a group rather than individuals because this species forms very large herds, and estimating how many individuals form a herd from tracks is not possible. 
Each of the six kilometre long transects around Las Marías were visited between six and eight times. Observations were made along a total of 180 kilometres during 30 observation days. In the nucleus zone, all of the four transects measured three kilometres in length, and were visited between ten and twelve times. Observations of wildlife and wildlife tracks in the nucleus zone were made on a total distance of 132 kilometres over 44 observation days.

\subsubsection{Compiling the data and statistical analysis}

All data collected during the field period were entered into Microsoft Excel 2003. Quantitative data were compiled by transect (transects A1, A2, A3, A4 in the hunted zone, and transects B1, B2, B3, B4 in the non-hunted zone), and by study area (hunted versus non-hunted). All the statistical analysis was done using the statistical software package SPLUS ${ }^{\circledR}$ 8.0. In order to allow comparison between the hunted and non-hunted area, all observations made on transects were standardized to average observations per kilometer. Because very few visual observations of terrestrial mammals were made over the field season, sightings of terrestrial mammals observed on the transects were grouped with track observation for analysis purposes. Comparisons between the hunted and non-hunted areas were done for: (1) all species combined; (2) all game species; (3) all non-game species; and (4) all individual species. Parametric tests were chosen over non-parametric tests if the following assumptions were met: (1) the residuals were normally distributed; (2) the error variance was homogenous; and (3), the residuals were independent. In this study the third 
assumption is always assumed valid because the distance of 15 kilometres between the hunted and non-hunted areas was considered far enough to assume that no animals were counted in both areas. Indeed, even the species with the largest home range, the Baird's tapir, has an average home range of only 125 hectares (Foerster and Vaughan 2002). To verify if the data held the assumption required for parametric analysis the data were first visually examined, then a Kolmogorov-Smirnov Test of Composite Normality on the residuals was performed to check whether the data were normally distributed, and an Analysis of Variance (ANOVA) on the absolute value of the residuals was performed to see if the error variance was homogenous. When the data were normally distributed and the error of variance was homogenous, an ANOVA was performed using the data for each transect (A1, A2, A3, and A4 (hunted) versus B1, B2, B3, and B4 (non-hunted)). If the assumptions were not met, a non-parametric Kruskall-Wallis test was performed using the same data. For some species, too few observations were made to provide reliable comparison between sites. As a consequence, all data recorded in each transect were pooled by area $(\mathrm{A} 1+\mathrm{A} 2+\mathrm{A} 3+\mathrm{A} 4$ (pooled hunted) versus $\mathrm{B} 1+\mathrm{B} 2+\mathrm{B} 3+\mathrm{B} 4$ (pooled non-hunted)) so as to reduce the influence of zeroes in the distribution of data. Then, a KolmogorovSmirnov Test of Composite Normality on the residuals was performed to check whether the data were normally distributed, and a Levene's test was performed to see if the error variance was homogenous. If the assumptions required for parametric analysis were met, then a Welch Modified Two-Sample t-Test was performed; if the assumptions required for parametric testing were not met, then a non-parametric Wilcoxon rank-sum test was performed (see Figure 3.3). In order to compare the abundance of wildlife as a function of distance from the settlement, the transects made around the village were split into two- 
kilometre long segments. This length allowed me to collect enough data on each segment to perform statistical comparison.

The statistical methods used for this thesis was very effective for it allowed me, over a relatively short period of time, to clearly distinguish the abundance of twenty different game and non-game species in the hunted and non-hunted area and as a function of distance from the village. Furthermore, the cost of the study remained really low considering the amount of results obtained. 
in

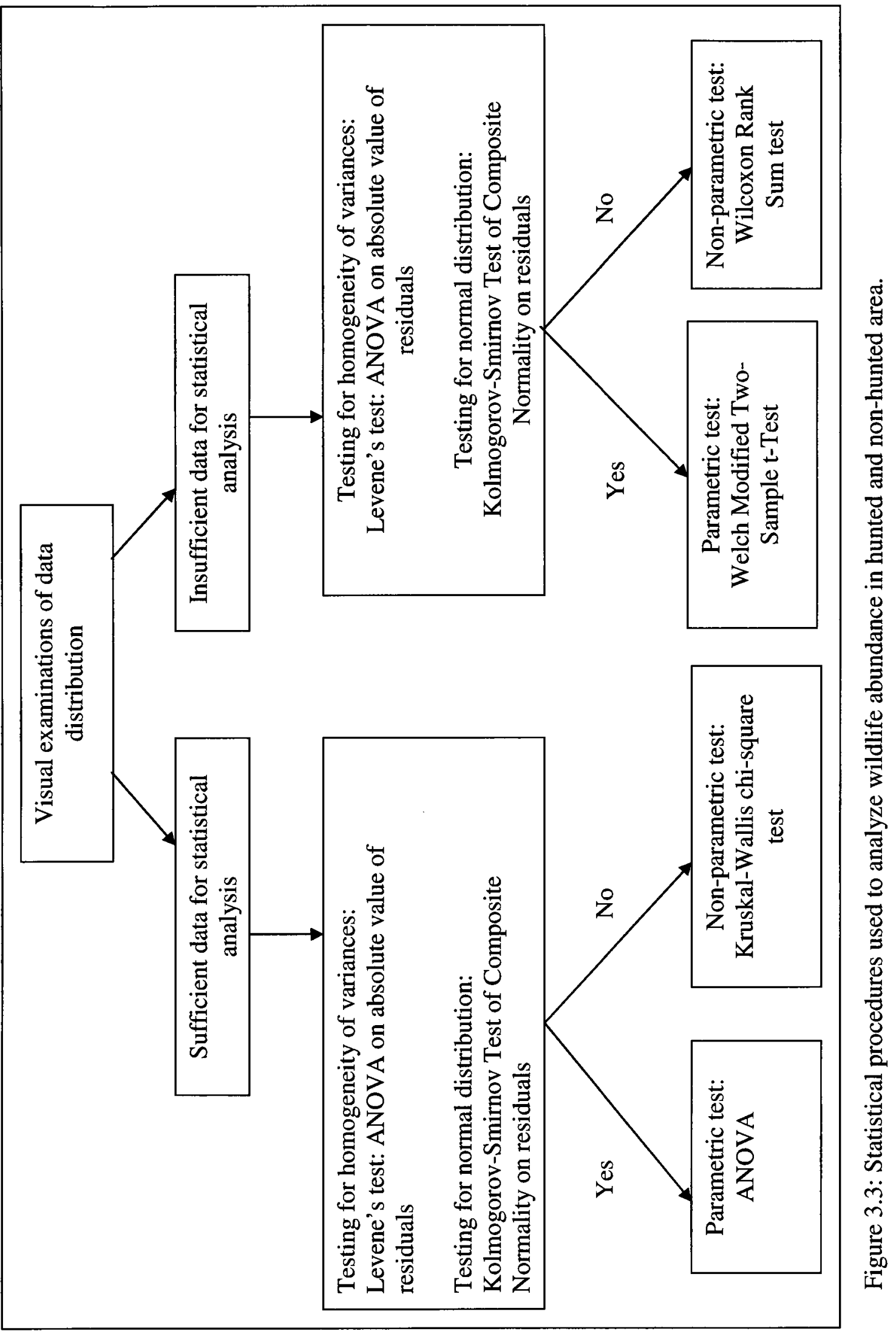




\subsubsection{Collecting Complementary Observations on Indigenous Hunting Activities}

Social science methods were used to collect complementary observations on hunting activity in the Las Marías region, to gain a basic understanding of how hunting is practiced and other information that might help interpret differences in species abundance between the two sites. The methods consisted of participatory mapping and informal conversations with hunters during the transect surveying and on other occasions while living in the village over the 12-week period of field research.

Participatory mapping is defined as a "methodology that recognizes the cognitive spatial and environmental knowledge of local peoples and transforms this into more conventional forms" (Herlihy and Knapp 2003:306). It assumes that "ordinary people are capable of critical reflection and analysis and that their knowledge is necessary" (ThomasSlayter 1995:11). Ultimately, participatory mapping can be considered a communication tool; it is used with, or by local people, to translate their local spatial knowledge into a medium, a map, easily read and understood by a wide range of people.

Participatory mapping is not new to the Moskitia. In fact, this region can be considered the cradle of participatory mapping in Central America. The first of such projects in the region, which started in 1992, consisted of mapping the indigenous lands of the Honduran Moskitia (Herlihy and Leake 1997). Herlihy later used the same participatory approach to define the management zone of the Río Plátano Biosphere Reserve where this study took place, in collaboration with MOPAWI, the Honduran State Forestry Agency (AFE/COHDEFOR) and the German Government Development Agency (GTZ, KfW), the management zone of the Río Plátano Biosphere Reserve, the study area of this current 
thesis. Interestingly enough, one local Miskito investigator who had worked a decade earlier with Herlihy on the delineation of the reserve proved to be an excellent contributor to this study because of his extensive knowledge of the area and great understanding of western cartography methods, suggesting that the knowledge acquired through participatory research remains in the communities for a long time.

This study took the participatory mapping approach used by Smith (2003) and Dunn (2004), both of whom have, with modest budgets, used participatory mapping to define indigenous hunting territories among the Buglé of western Panama and on the eastern limits of the Río Plátano Biosphere Reserve in the Honduran Moskita, respectively. Both researchers used local informants and a set of workshops to define indigenous territories and measure hunting yields. The map of hunting grounds provided here (Figure 4.1) is based on a similar (but more limited) methodology concentrating on the delineation of the outer limits of the hunting zone rather than presenting a geographic analysis of game extraction within the hunting zone.

In order to produce the delineation of the hunting grounds, a group of six local hunters were interviewed and were asked to name and orally describe the hunting regions around the village and in the reserve. All were or continue to be active hunters and have an excellent knowledge of the area as they were long term residents of the village between 30-55 years old. Once the names of all hunting areas were recorded, I asked the group to produce a map of the hunting zone including the named places. First, I provided them with a large blank sheet and asked them to draw the hunting territories and the areas they used for farming. Once this was done, I asked them to superimpose the sketch map of the hunting zone onto a 
1:50,000 scale topographic map. A map of the hunting grounds was later created by this researcher using ArcView GIS 3.2 (Figure 4.2).

In addition to the participatory mapping, hunting practices were also investigated by observing hunters returning to the village, and though numerous informal conversations during the course of the 12-week field research period. This allowed me to make numerous observations on the hunting habits of the Pech and Miskito and on such things as the types of technologies used, the use and distribution of game, and cultural preferences and proscriptions. 


\section{Chapter 4:}

$\underline{\text { Results }}$

\subsection{Hunting in Las Marías}

Hunting is not the primary form of acquiring food in Las Marías. Villagers are agriculturalists who derive most of their food from farming. Hunting intensity, therefore, varies in relation to other, more important activities, and decreases during harvest and sowing periods. It is important to underline, however, that hunting does not stop during these periods; it is simply more opportunistic. Two main strategies describe Pech and Miskito hunting in this region: they go on hunting expeditions which can last from one to several days, and secondly, they frequently harvest wildlife while undertaking other activities, such as harvesting palm leaves to build their roofs, looking for medicinal plants,

looking for trees to build pipantes (dugout canoes), or while working in their agricultural fields. Hunters almost always carry their rifles and machetes when working in their farms. If they see a game animal on the way to or in their field, they usually try to capture it, depending on the species. Sometimes, animals are also hunted because they are damaging the crops. In these cases, the farmer waits for the animal to come at night after attracting them with bait, and kills the animal if it arrives. Hunting is practiced less often during the rainy season because it is considered more difficult and less enjoyable at this time of the year. 
Only three villagers are known to hunt frequently, and they do this to capture wild meat for sale. The others hunt only occasionally. Most of the inhabitants of Las Marías do not eat meat every day, and the meat protein they consume comes primarily from eggs and chicken, followed by fish. Pork and beef are also occasionally eaten. Villagers, however, seem to prefer wild meat, especially white-lipped peccary, but also collared peccary, deer, and armadillo. Most villagers here say they do not eat monkeys, not even spider monkeys which are consumed widely in neotropical regions, but because of the mixed responses I received, I reserve some doubts on this subject.

Although no quantitative data on wildlife extraction were collected, hunting seems to be principally done with firearms ( 0.22 calibre rifles), followed by the machete, and most of the villagers seem to use dogs for hunting. At least two hunters use spears to kill large animals, including tapir. Hunting is principally done by men, but woman occasionally kill smaller animals such as armadillos, with machetes. The use of firearms, however, is restricted to men. Occasionally, women accompany men on distant hunting trips to take care of the camp and cook the game captured. Multi-day hunting expeditions are infrequent and are usually done by younger people in large part as an enjoyable activity.

\subsection{Delineation of the Principal Hunting Grounds}

The hunting zone around Las Marías delimited using participatory mapping methods measures approximately $107 \mathrm{~km}^{2}$ clustered around the village and includes both agricultural and forest areas. The size of their hunting zone is within the range of other Central 
American groups. Dunn (2004: 137), for example, estimated the principal hunting lands of two Miskito villages in the Rio Patuca region at $240 \mathrm{~km}^{2}$, but this difference is to be expected as the combined population of the two villages (population $=947$ ) is about twice that of Las Marías. Smith (2008: 925) estimated the shared hunting territory of five Buglé and Ngöbe settlements in Panama at $131 \mathrm{~km}^{2}$ for a combined population of 725 . 


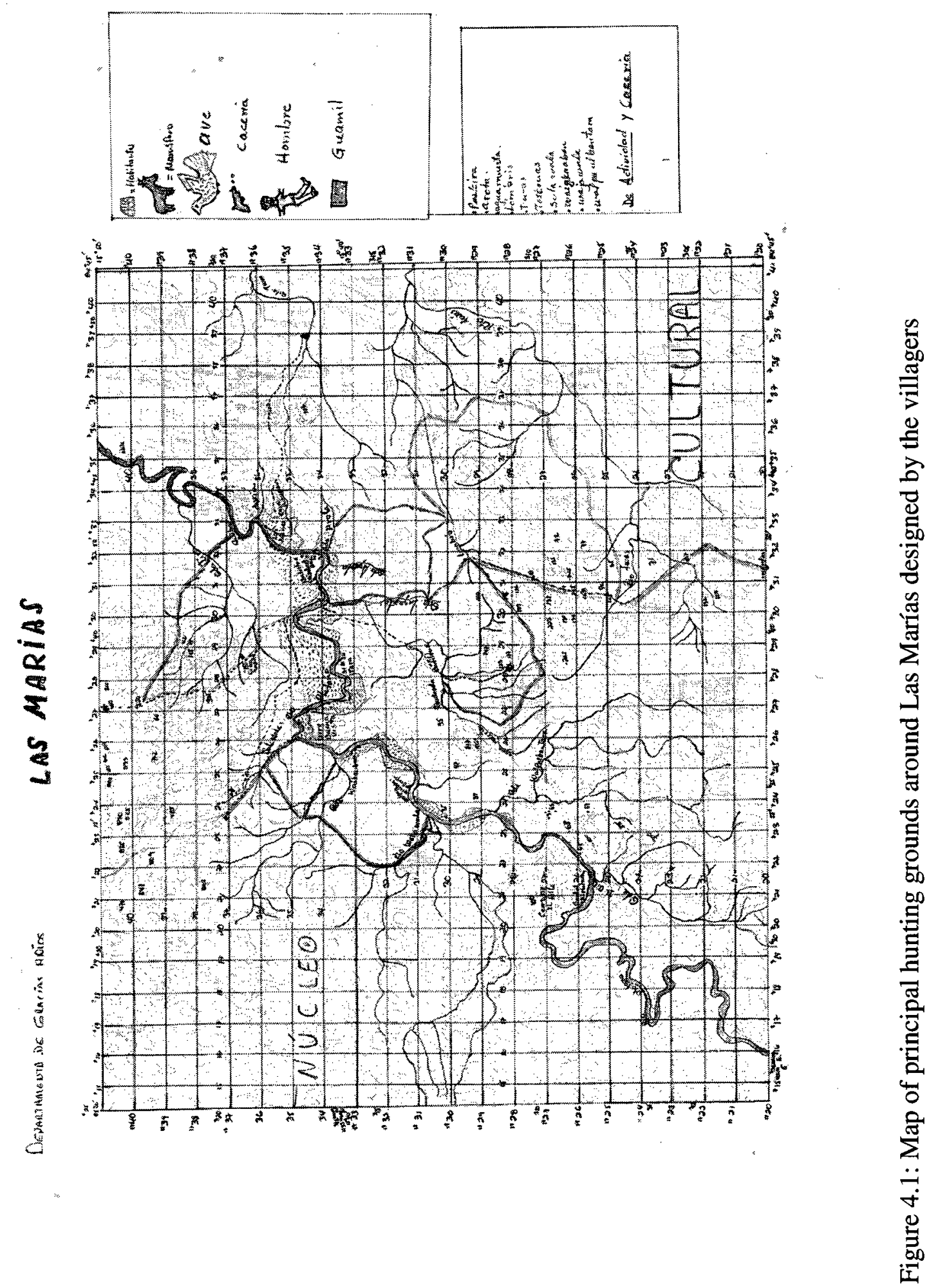




\section{Principal Hunting Grounds around Las Marías, Río Plátano Biosphere Reserve, Honduras.}

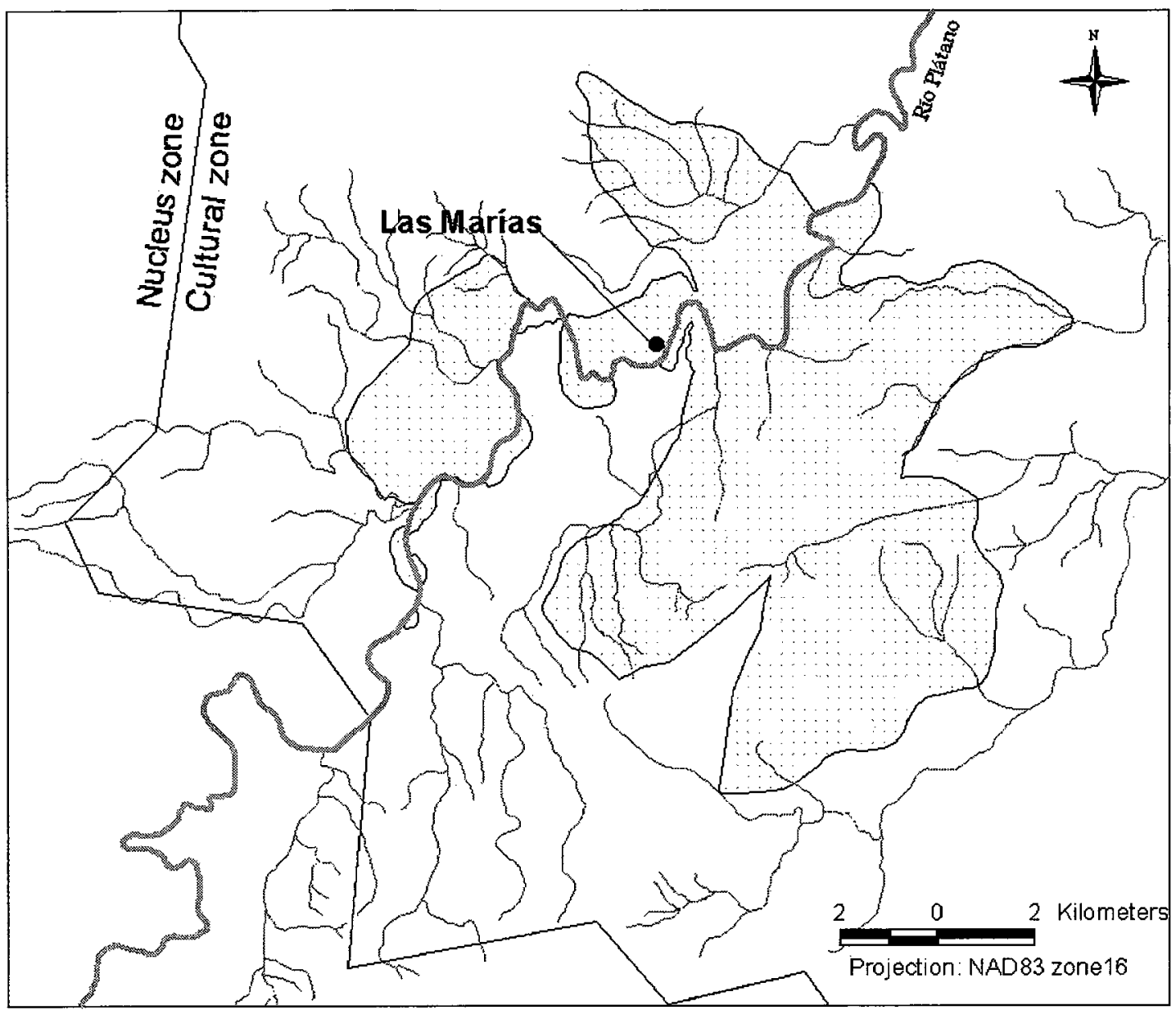

Figure 4.2: Principal hunting grounds around Las Marías, 2006 (approximate delineation).

Contrary to what could be expected, the hunting grounds are perpendicular to rather than running alongside the Plátano River, and include areas as far as 12 kilometres from the river. The Plátano River being the principal axis of transportation in the area, I expected that the villagers hunted principally along the river, but instead, hunters reach the principal hunting grounds on foot rather than using their canoes, and hunt principally inland rather than along the Plátano River. Interestingly, one of the area close to the village, to the south 
is not hunted, even though it is along the Plátano River and is very close to the village, showing that the shape of a hunting area is not necessary linked to distance from the village.

Hunting is a dynamic activity and the boundaries used to this effect will necessarily change with time, wildlife density, and the needs and wants of the villagers, among other factors. As a consequence, the boundaries presented here represent only the most commonly used areas and represent the size of the hunting zone at the time of field research. Apart from documenting the size and shape of the hunting zone, a primary outcome of the delimitation is confirmation that hunting is practiced exclusively within the cultural zone of the reserve, and not in the nucleus zone - something that was also supported by my other observations. When conducting the transects, for example, we never encountered human tracks crossing our trails in the non-hunted zone.

\subsection{Comparative Analysis of the Hunted and Non-hunted Region}

In total, 36 kilometres of repeat transects were used, with 24 kilometres of transects in the hunted area, and 12 kilometres in the non-hunted area. The land surveyed included primary forest, secondary forest, bamboo dominated environments, and agricultural fields. Data were collected between May and August, a season characterized by frequent rain, including heavy showers, but with dry spells lasting up to a week. Table 4.1 describes the percentage of habitat type found along the transect lines of the hunted and non-hunted areas. 
Table 4.1: Percentage of land type occupancy along the transects in the hunted and nonhunted area.

\begin{tabular}{lcc}
\hline Habitat type & \multicolumn{2}{c}{ Percentage of habitat along transects } \\
Hunted area & Non-hunted area \\
\hline Agricultural land* & 7 & 0 \\
Bamboo dominated & 0 & 7 \\
Primary forest & 84 & 93 \\
Secondary forest & 9 & 0 \\
\hline *Agricultural land also includes younger fallow lands locally called "guamiles."
\end{tabular}

Over the study period, a total of 1,760 direct and indirect wildlife observations were made over 312 kilometres, giving an overall average encounter rate of 5.64 observations per kilometre surveyed (Table 4.2).

In the non-hunted area, a total of 901 observations were made, giving an average of 6.83 observations per kilometre, ranging from the observation of giant anteaters tracks three times over the 132 kilometres visited (giving less than 0.1 observations per kilometre) to just over 200 indirect observations of nine-banded armadillos ( 1.53 observations per kilometre). In the hunted area, a total of 859 observations were made over the 180 kilometres surveyed, giving an average of 4.77 observations per kilometre, or about 42 percent less than in the non-hunted area. The observations in this zone range from no observations for the spider and howler monkeys to 1.53 observations per kilometre for the collared peccary. 
Table 4.2: Total observations and observations per kilometre of each game and non-game species in the non-hunted and hunted areas.

\begin{tabular}{|c|c|c|c|c|}
\hline \multirow{2}{*}{$\begin{array}{l}\text { Species } \\
\text { Game Species }\end{array}$} & $\begin{array}{l}\text { Non-I } \\
\text { \# of ol } \\
\text { rove }\end{array}$ & bs/kr & \multicolumn{2}{|c|}{$\begin{array}{l}\text { \# of obs obs/Km } \\
\text { (over } 180 \mathrm{~km})\end{array}$} \\
\hline & $\sqrt{2-2}$ & 5 & $2 x=$ & \\
\hline Tapir & 92 & 0.7 & 18 & 0.1 \\
\hline Collared peccary & 76 & 0.58 & 293 & 1.63 \\
\hline White-Lipped peccary (groups) & 12 & 0.09 & 2 & 0.01 \\
\hline White-tailed deer & 60 & 0.45 & 26 & 0.14 \\
\hline Red brocket deer & 22 & 0.17 & 7 & 0.04 \\
\hline Armadillo & 202 & 1.53 & 159 & 0.88 \\
\hline Coati & 20 & 0.15 & 150 & 0.83 \\
\hline Paca & 54 & 0.41 & 12 & 0.07 \\
\hline Agouti & 93 & 0.7 & 84 & 0.47 \\
\hline Great curassow & 31 & 0.23 & 9 & 0.05 \\
\hline Crested guan & 44 & 0.33 & 35 & 0.19 \\
\hline Total game & 706 & 5.35 & 795 & 4.42 \\
\hline Non-Game Species & 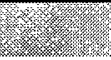 & ate & 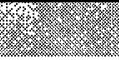 & (3) \\
\hline Spider monkey & 79 & 0.6 & 0 & 0 \\
\hline White-faced capuchin & 11 & 0.08 & 29 & 0.15 \\
\hline Howler monkey & 40 & 0.3 & 0 & 0 \\
\hline Jaguar & 16 & 0.12 & 10 & 0.05 \\
\hline Puma & 23 & 0.17 & 6 & 0.03 \\
\hline Ocelot & 5 & 0.04 & 1 & 0.01 \\
\hline Leopardus spp. & 13 & 0.1 & 11 & 0.06 \\
\hline Giant anteater & 5 & 0.04 & 3 & 0.02 \\
\hline Northern tamandua & 3 & 0.02 & 4 & 0.02 \\
\hline Total non-game & 195 & 1.48 & 64 & 0.34 \\
\hline Total for each area & 901 & 6.83 & 859 & 4.77 \\
\hline
\end{tabular}

The number of observations per kilometre was higher in the non-hunted zone for sixteen out of the twenty species investigated $(80 \%)$. The northern tamandua was found at similar abundance $(0.2 \mathrm{obs} / \mathrm{km})$ in both areas, and the collared peccary, coati and whitefaced capuchin were more numerous in the hunted area than in the non-hunted area. In a 
few cases, however, the total number of observations is not sufficient to determine whether there any significant differences between the two sites.

A non-parametric Kruskal-Wallis test was performed to see if there is a significant difference in the total number of observations between the hunted and the non-hunted research sites (Kruskal-Wallis chi-square $=9.395, \mathrm{df}=1, \mathrm{p}$-value $=0.002)$. This test confirmed that the overall abundance of the target species in the non-hunted area is significantly higher than in the hunted area (Figure 4.3).

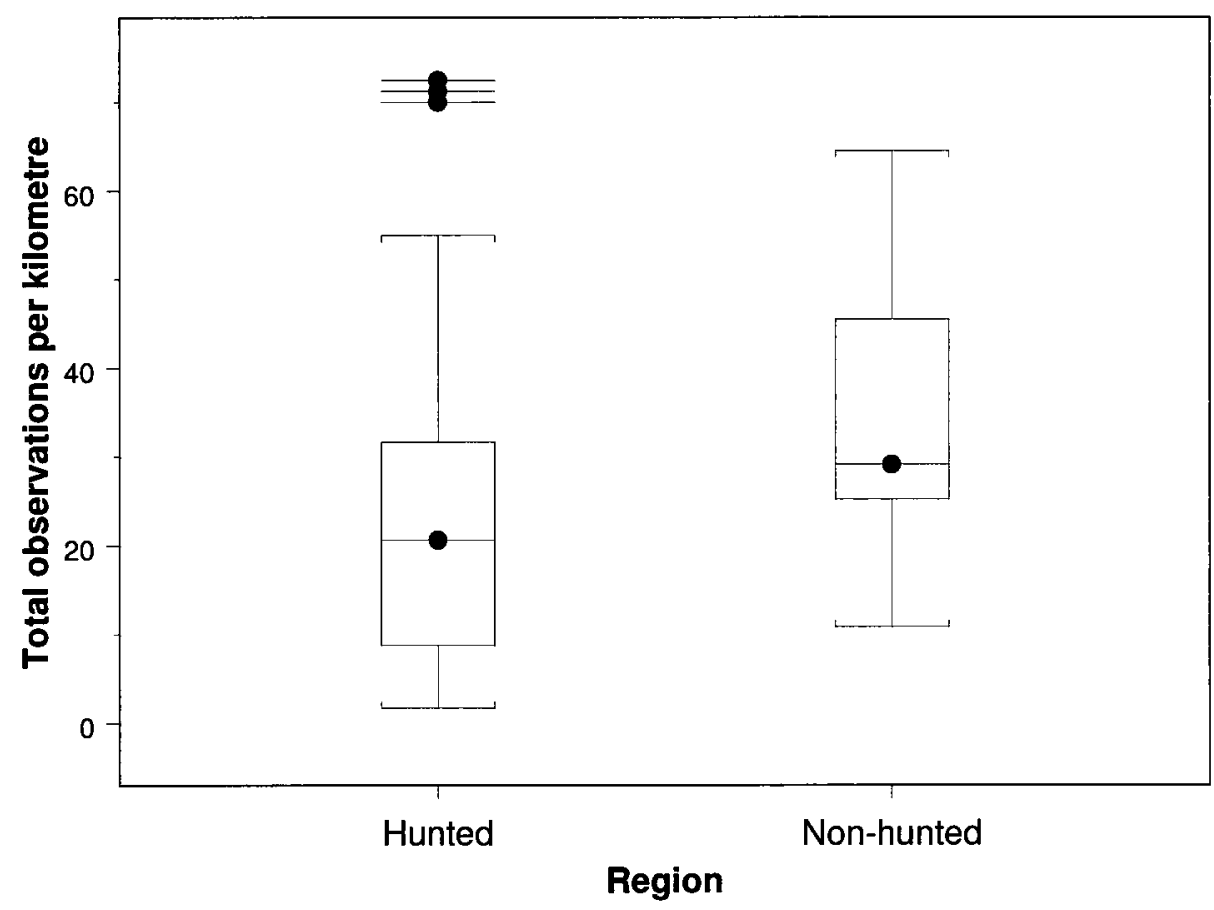

Figure 4.3: Box plot for the total number of wildlife observations per kilometre in the hunted area (Las Marías) and the non-hunted area (nucleus zone).

[Bottom and top of box represent 25 th and 75 th percentiles, middle line is the median, bottom and top whiskers represent lowest and highest values that are not outliers, and $\rightarrow-$ represent outliers] 
4.3.1. Comparing the Abundance of Game and Non-game species in the Hunted and Non-hunted Region

In addition to the overall comparison between wildlife abundance at the two sites, species were grouped into two categories depending on whether or not they are game animals hunted in the region, based on the assumption that hunting will reduce the abundance of games species, and not the other group.

\section{Abundance of Game Species}

In total, 1,501 observations of game species were recorded over the field season, giving an average of 4.81 observations per kilometre. In the nucleus zone, a total of 706 observations were made over the 132 kilometres surveyed, giving an average of 5.35 observations per kilometre. The number of observations in this area ranges from 12 observations $(0.09 \mathrm{obs} / \mathrm{km})$ for the white-lipped peccary to 202 observations $(1.53 \mathrm{obs} / \mathrm{km})$ for the nine-banded armadillo (Figure 4.4). 


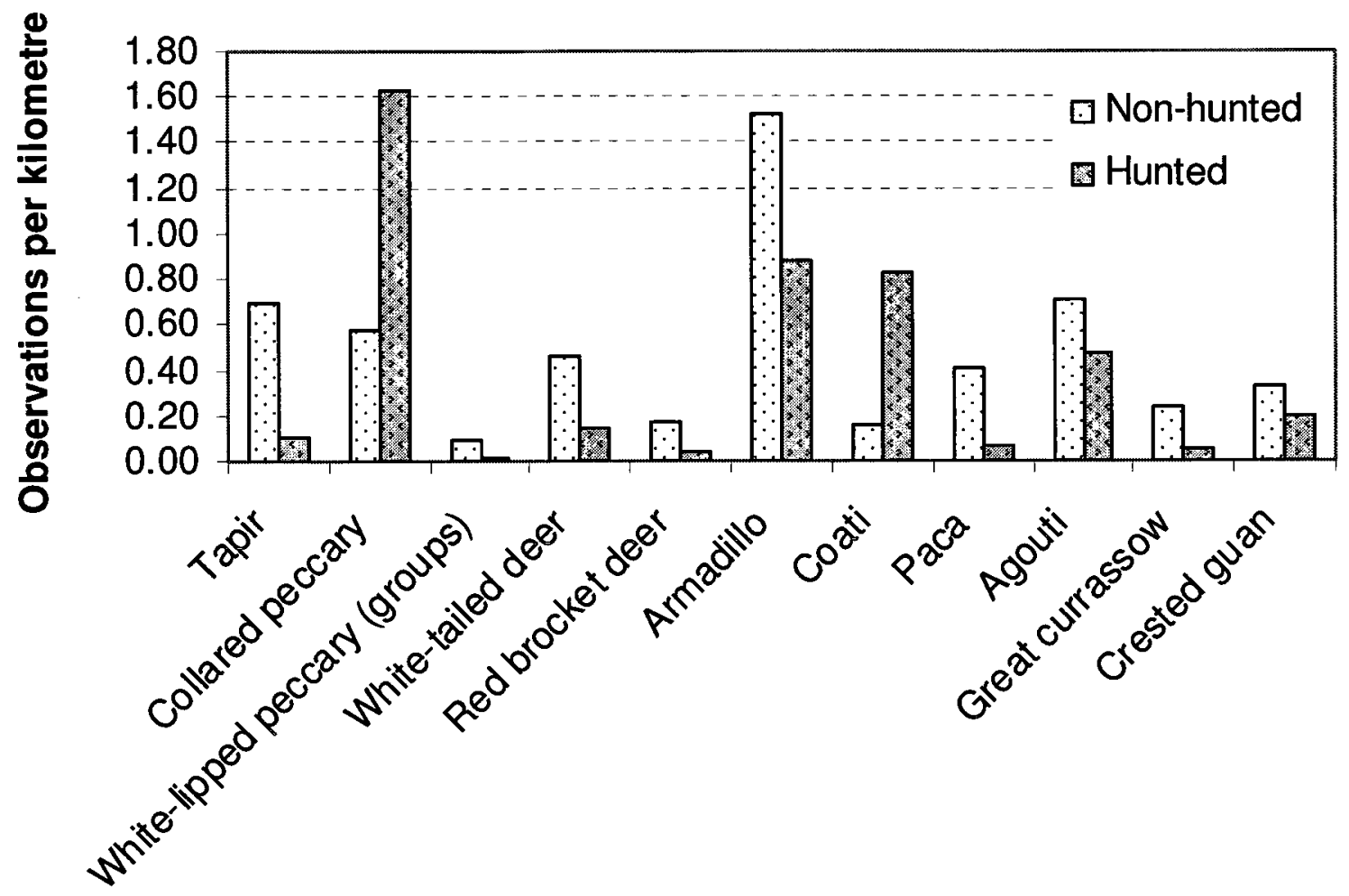

Game species

Figure 4.4: Number of observations per kilometre for each game species in the hunted and non-hunted areas. 
The number of observations for different game species in the hunted area ranged from two observations of tracks made by white-lipped peccary groups $(0.01 \mathrm{obs} / \mathrm{km})$ to 293 observations of collared peccaries $(1.63 \mathrm{obs} / \mathrm{km})$. In total, 795 observations of game species were made over the 180 kilometres surveyed, giving an average of 4.4 observations per kilometre, or about $17 \%$ less than in the non-hunted area. Most games species were more abundant in the non-hunted area according to the transect observations, but two, the whitenosed coati and the collared peccary, were observed more frequently in the hunted area.

A non-parametric KW statistical test was performed to test whether a difference in the number of observations per kilometre of game species existed in the two areas (Figure 4.5).

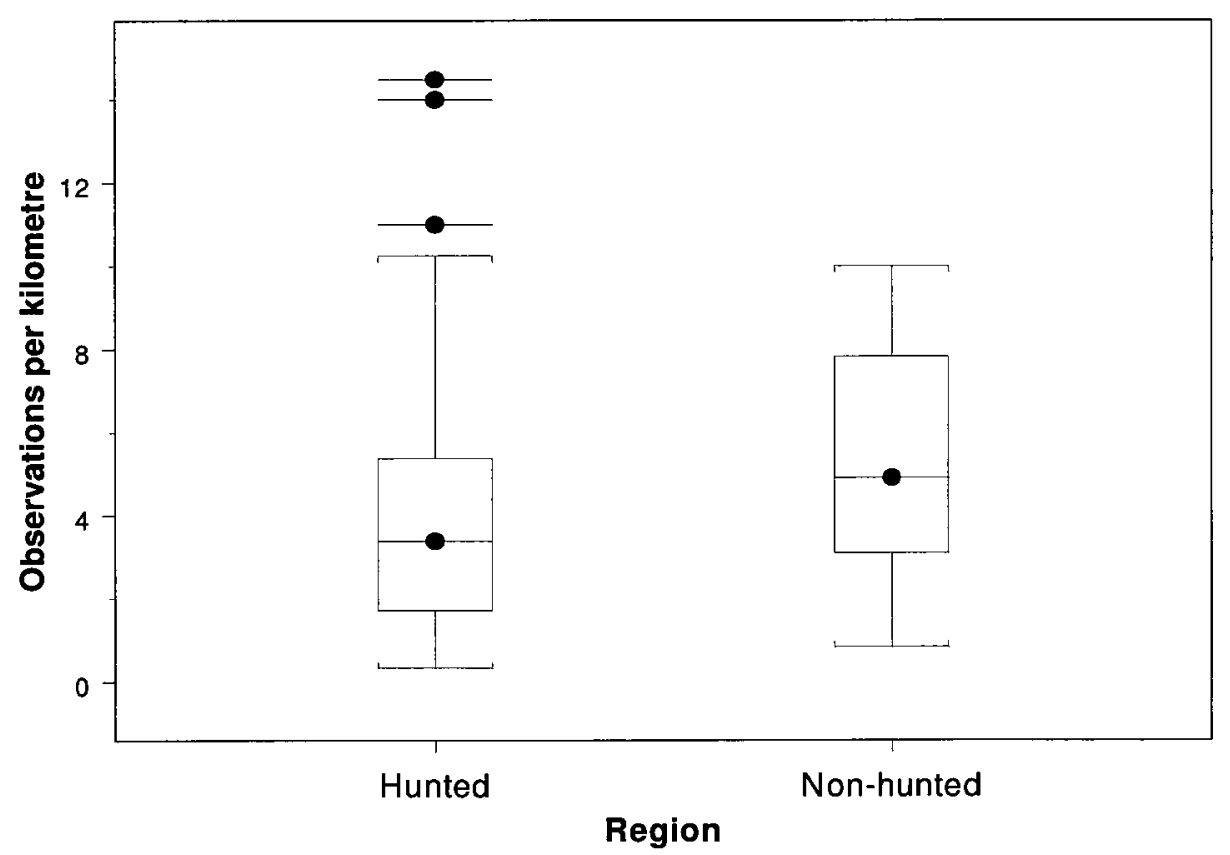

Figure 4.5: Box plot for the observations per kilometre of game species in the hunted area (Las Marías) and the non-hunted area (nucleus zone).

Bottom and top of box represent $25^{\text {th }}$ and $75^{\text {th }}$ percentiles, middle line is the median, bottom and top whiskers represent lowest and highest values that are not outliers, and $\rightarrow$ represent outliers] 
The results indicate a significant difference between the two areas (Kruskal-Wallis chisquare $=4.7563, \mathrm{df}=1, \mathrm{p}$-value $=0.0292$ ), which suggests that game animals are indeed more abundant in the non-hunted zone than in the hunted area.

Abundance of Non-game Species

The number of observations per kilometre of each non-game species in the hunted and non-hunted area is presented in figure 4.6.

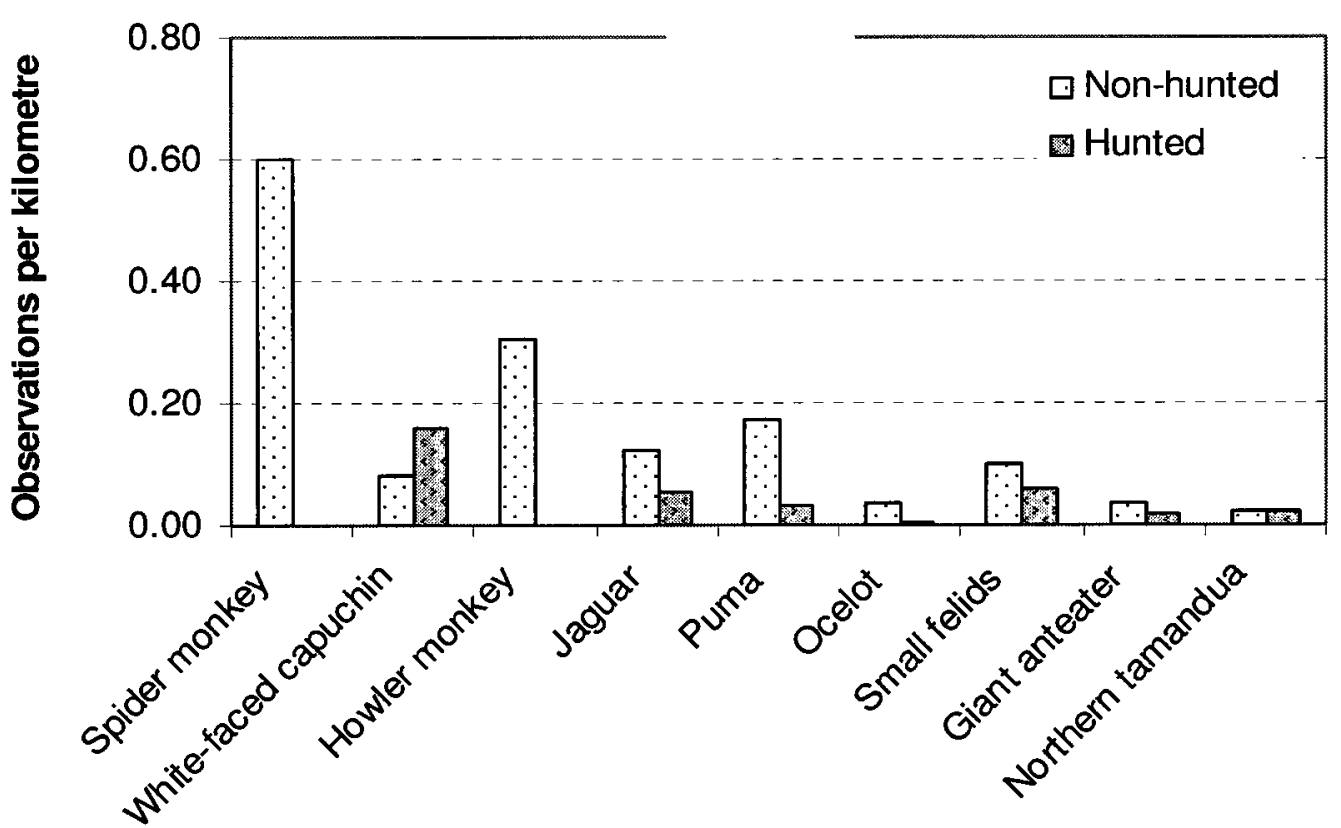

Non-game species

Figure 4.6: Number of observations per kilometre for each non-game species in the hunted and non-hunted areas.

In total, 259 observations of non-game species were made at the two sites during field research, giving an average of 0.83 observations per kilometer. In the non-hunted area, 195 
observations were recorded $(1.48 \mathrm{obs} / \mathrm{km})$, and in the hunted area the total of observations was $64(0.36 \mathrm{obs} / \mathrm{km})$ (Figure 4.7). Observations per kilometre of non-game species were therefore 2.3 greater in the non-hunted area.

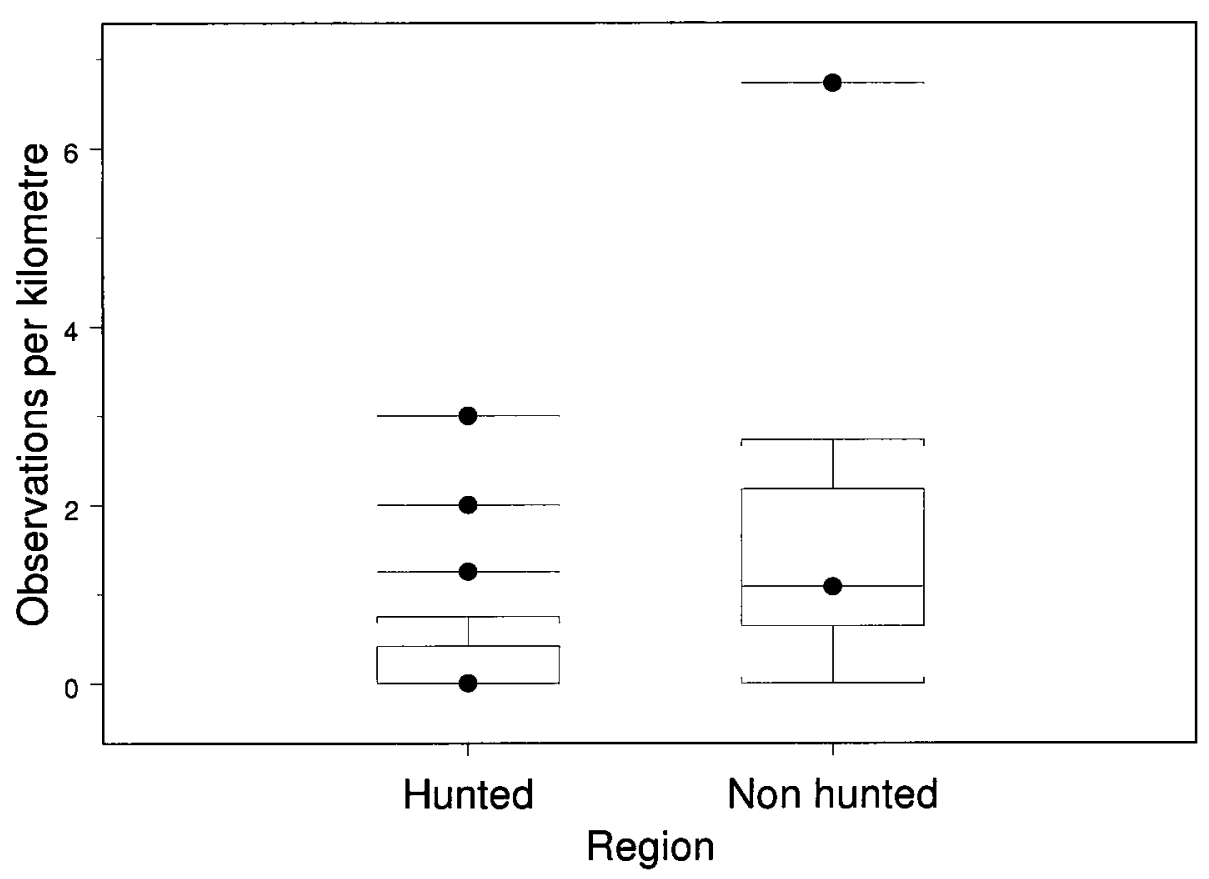

Figure 4.7: Boxplot for the observations per kilometre of non-game species in the hunted and non-hunted area.

[Bottom and top of box represent $25^{\text {th }}$ and $75^{\text {th }}$ percentiles, middle line is the median, bottom and top whiskers represent lowest and highest values that are not outliers, and $\rightarrow-$ represent outliers]

After verification of the assumptions required for parametric analysis were made (Kolmogorov-Smirnov Test of Composite: $\mathrm{ks}=0.2325$, $\mathrm{p}$-value $=0$; Levene's test: $\mathrm{df}=1$; $\mathrm{F}=5.301, \operatorname{pr}(\mathrm{F})=0.0243)$, a non-parametric Kruskal-Wallis rank sum test was performed (Kruskal-Wallis chi-square $=25.434, \mathrm{df}=1, \mathrm{p}$-value $=0$ ); contrarily to what was expected, it was concluded that the number of observations of non-game species was significantly greater in the non-hunted area. While the above findings give a general idea on the overall 
differences and the relative abundance of different categories of wildlife in the hunted and non-hunted areas, further examination is required to understand faunal differences at the species level. For this reason, all game species were also analyzed individually.

\subsubsection{Comparative Abundance of Individual Species}

\subsubsection{Ungulates}

Five ungulates were included in this study: the Baird's tapir, collared peccary, whitelipped peccary, white-tailed deer and red brocket deer (Figure 4.8). A total of 608 observations of these ungulates were made over the field season, giving an average of 1.95 observations per kilometre: 262 in the non-hunted area $(1.98 \mathrm{obs} / \mathrm{km})$ and 346 in the hunted area $(1.92 \mathrm{obs} / \mathrm{km})$, representing a difference of only $3 \%$ in terms of observations per kilometre. However, these aggregated results are strongly influenced by the high abundance of collared peccary in the hunted region, which was about three times higher than in the nonhunted area (Figure 4.8). 


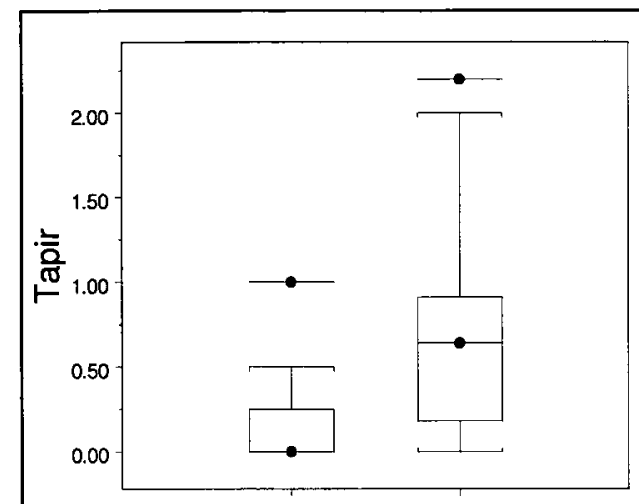

a) Hunted Non-hunted

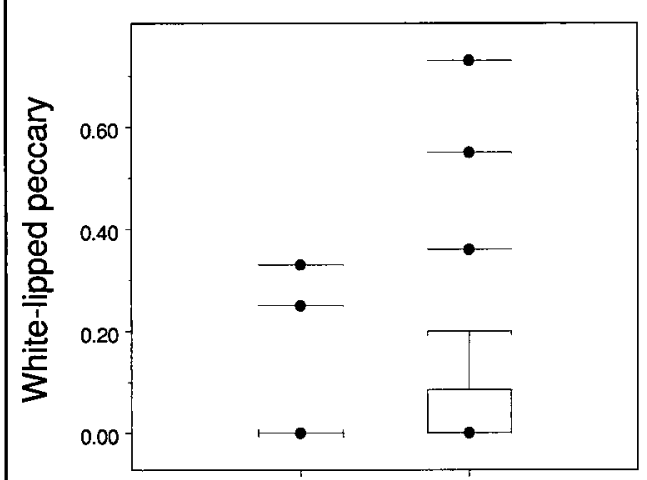

c) Hunted Non-hunted

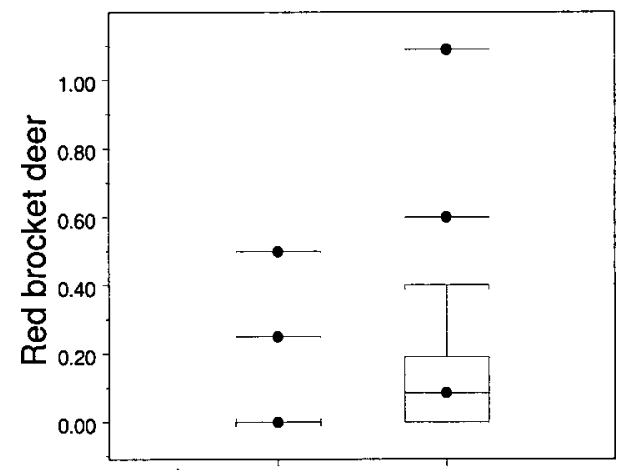

e) Hunted Non-hunted

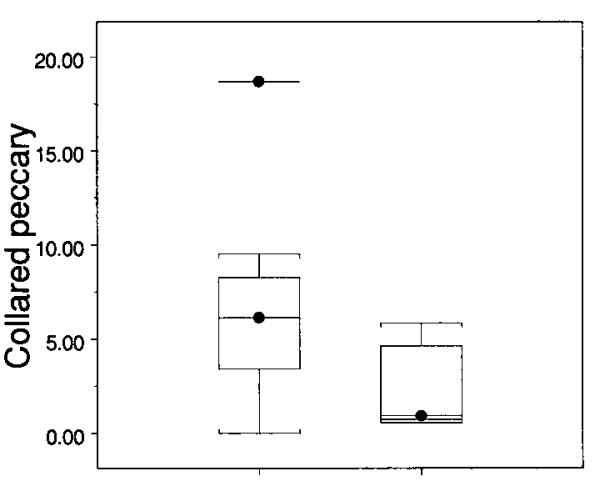

b)

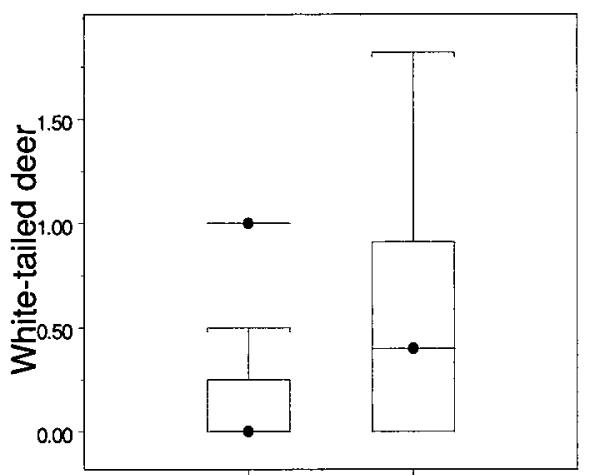

d) Hunted Non-hunted
[Bottom and top of box represent $25^{\text {th }}$ and $75^{\text {th }}$ percentiles, middle line is the median, bottom and top whiskers represent lowest and highest values that are not outliers, and $\rightarrow-$ represent outliers]

Figure 4.8: Box plots for the observations per kilometre of each of the five ungulates studied in the hunted and non-hunted area: a) tapir, b) collared peccary, c) white-lipped peccary, d) white-tailed deer, and e) red brocket deer.

Statistical analysis was performed on each of these five species to determine whether a difference in abundance existed between the hunted and non-hunted area (Table 4.3). 
Table 4.3: Statistical tests comparing the abundance of ungulate species in the hunted and non-hunted area

\begin{tabular}{lllllll}
\hline \multicolumn{5}{c}{ Statistical significance (95\% CI) } & Zone of greater relati \\
Species & Statistical test & df. & p-value & Significant & abundance \\
\hline \hline & $\mathrm{KW}=26.895$ & 1 & $\mathrm{p} \leq 0.01$ & Yes & $>$ in non-hunted area \\
$\begin{array}{l}\text { Tapir } \\
\text { Collared peccary }\end{array}$ & $\mathrm{t}-\mathrm{test} ; \mathrm{t}=2.4148$ & 16 & $\mathrm{p} \leq 0.03$ & Yes & $>$ in hunted area \\
$\begin{array}{l}\text { White-lipped pecca } \\
\text { (groups) }\end{array}$ & $\mathrm{KW}=6.9021$ & 1 & $\mathrm{p} \leq 0.01$ & Yes & $>$ in non-hunted area \\
$\begin{array}{l}\text { White-tailed deer } \\
\text { Red brocket deer }\end{array}$ & $\mathrm{KW}=9.6961$ & $\mathrm{KW}=10.5835$ & 1 & $\mathrm{p} \leq 0.01$ & Yes & $>$ in non-hunted area \\
\hline
\end{tabular}

Tracks of Baird's tapir were encountered 110 times over the field season, giving an overall average of 0.8 observations per kilometre. A female with one young were also spotted crossing the Plátano River in the nucleus zone. The differences in the number of observations between the two research sites were quite marked. In the non-hunted region of the nucleus zone, 92 track observations were recorded over the 132 kilometres surveyed, giving an average of 0.70 observations per kilometre. In the hunted area, 18 observations were made over the 180 kilometres surveyed, giving an average of 0.10 observations per kilometre, which is seven times lower than in the non-hunted area. Statistical analysis (Table 4.3) revealed that the abundance of Baird's tapir was significantly higher in the nucleus zone than around the village of Las Marías.

During the field research period, a total of 369 direct and indirect observations of collared peccary were made, giving an average of 1.2 observations per kilometre (Figure 4.8). In the nucleus zone, a total of 76 observations were made over the 132 kilometres surveyed, giving an average of 0.6 observations per kilometre. Around the village of Las Marías, 293 observations were made, translating into an average of 1.6 observations per 
kilometre. However, no significant differences in the number of observations were noted between the non-hunted and the hunted regions according to the Kruskal-Wallis chi-square test. Considering that the number of observations was much higher in the hunted area (1.6 $\mathrm{obs} / \mathrm{km})$ than in the non-hunted area $(0.6 \mathrm{obs} / \mathrm{km})$, this result was very surprising. Further analysis was therefore done on the pooled data. All transects in the hunted zone were pooled together and the same was done in the non-hunted area. Since the data for the collared peccary satisfy the assumptions required for parametric analysis (KS test of composite normality: $\mathrm{ks}=0.1408, \mathrm{p}$-value $=0.5$; and ANOVA on absolute value of residuals: $\mathrm{df}=1$, F-value $=0.7711, p(F)=0.3929)$ a student $t$-test was possible. Observations of collared peccary were found to be significantly greater in the hunted area (Table 4.3).

White-lipped peccaries usually form large herds of 50-200 individuals (Painter et al. 1995; Carrillo et al. 2002). Because this species was only observed through tracks, the number of individuals in the herds encountered is unknown. Estimating the exact number of individual white-lipped peccaries in a herd from tracks may not be possible; however, according to villagers who have visited the nucleus zone in recent years and to the number of tracks left behind, herds of this animal in the nucleus zone are believed to be around 200 individuals. In the hunted area, however, herd size appeared much smaller; the local assistant and I estimated the herds encountered around in the hunted area to be between 50 and 70 individuals.

During the field period, the tracks of fourteen groups of white-lipped peccary were observed, giving an average of 0.04 observations per kilometre over the two studied areas. In the non-hunted area, twelve observations were made, giving an average of 0.09 observations per kilometre. In the hunted area, only two observations were made. 
Statistical analysis indicates a significant difference between the number of observations in the non-hunted region and the hunted region (Table 4.3). Assigning an average number of 100 individuals to each herd observed gives 1200 white-lipped peccaries in the nucleus zone (low estimate) compared to 200 individuals in the hunted area (high estimate). These results suggest that white-lipped peccary are relatively more numerous in the nucleus zone than around the village of Las Marías.

Observations of the white-tailed deer were recorded much more frequently in the nonhunted site -0.5 observations per kilometer, as opposed to 0.1 observations per kilometer around the village. This species was found to be significantly more abundant in the nonhunted area (Table 4.3).

In total, 29 observations of red brocket deer were made over the two studied regions, giving an average of 0.09 observations per kilometre. Only a mother and fawn were directly observed, all other observations were based on tracks. In the non-hunted area, 0.17 observations per kilometre were recorded ( 22 observations over $132 \mathrm{~km}$ ), and in the hunted area, 0.04 observations were recorded ( 7 observations for $180 \mathrm{~km}$ ). Statistical analysis revealed that red brocket deer was significantly more abundant in the non-hunted area (Table 4.3), but because of the relatively few observations recorded over the study period, inference on these results should be made with caution.

\subsubsection{Medium-Sized Game Species}


This category includes the nine-banded armadillo, white-nosed coati, paca and agouti. These terrestrial mammal species are important prey species throughout the humid neotropics. Combined, a total of 774 observations of medium-sized game species were made $(2.48 \mathrm{obs} / \mathrm{km})$ over the field season: 369 in the non-hunted area $(2.80 \mathrm{obs} / \mathrm{km})$ and 405 in the hunted area $(2.25 \mathrm{obs} / \mathrm{km})$. Box plots representing the relative abundance for each of the four species of medium-sized game species is presented below (Figure 4.9).

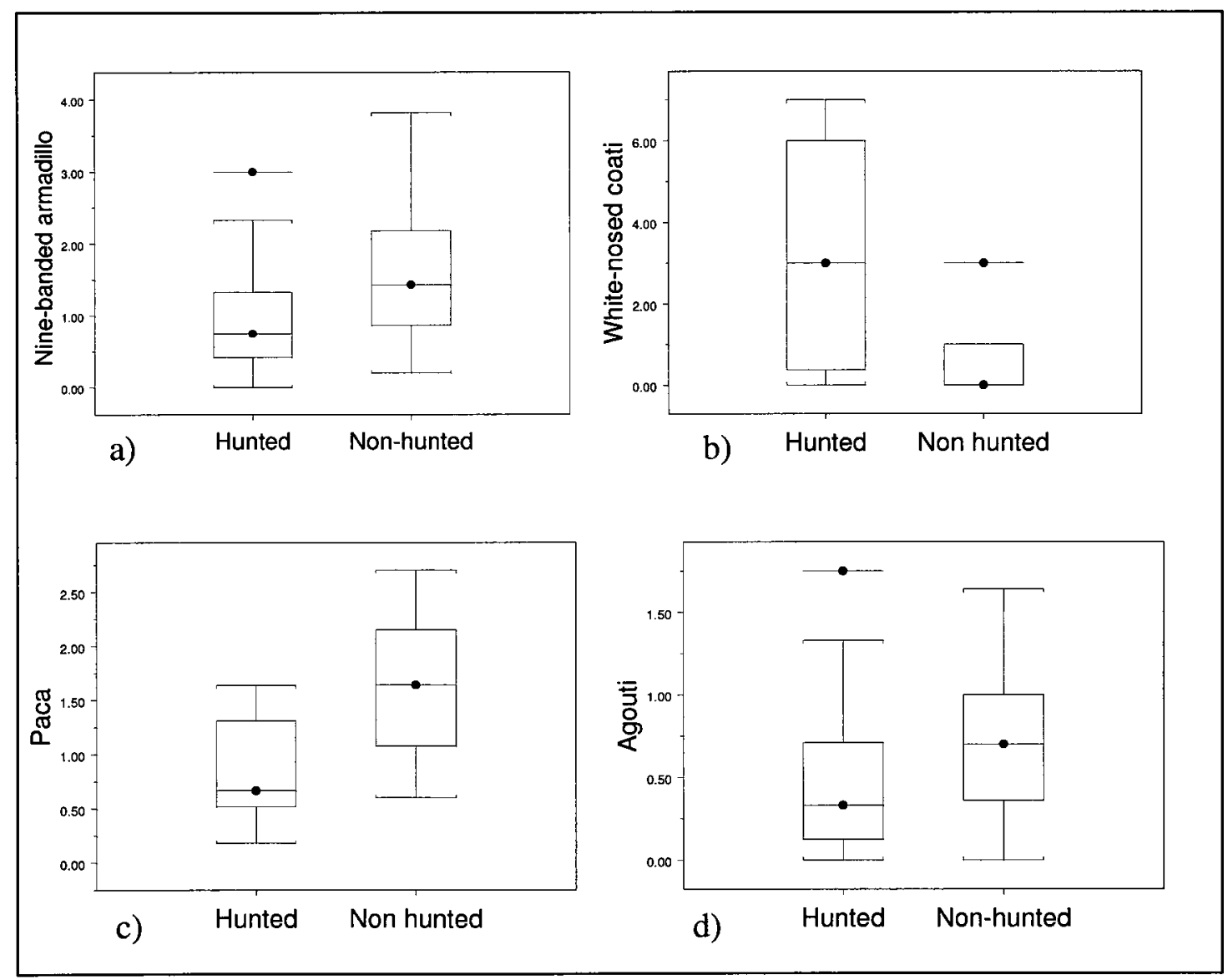

Figure 4.9: Box plots for the number of observation per kilometre for each of the four medium-sized game species studied at the two research sites: a) nine-banded armadillo, b) white-nosed coati, c) paca, d) agouti.

[Bottom and top of box represent $25^{\text {th }}$ and $75^{\text {th }}$ percentiles, middle line is the median, bottom and top whiskers represent lowest and highest values that are not outliers, and $\rightarrow-$ represent outliers] 
Statistical analysis of differences in abundance between the two sites was performed for each species (Table 4.4). The results obtained indicate that three of the four species were more abundant in the non-hunted area. The white-nosed coati was more abundant in the hunted area.

Table 4.4: Statistical tests comparing the abundance of medium-sized species in the hunted and non-hunted area

\begin{tabular}{llllll}
\hline Species & $\begin{array}{c}\text { Statistical significance (95\% CI) } \\
\text { Statistical test }\end{array}$ & p-value & Yes/No & $\begin{array}{c}\text { Zone of greater relativ } \\
\text { abundance }\end{array}$ \\
\hline \hline & & & & & \\
Armadillo & ANOVA; $\mathrm{F}=10.8611$ & 1 & $\operatorname{Pr}(\mathrm{F})<0.01$ & Yes & $>$ in Non-hunted area \\
Coati & $\mathrm{t}$-test; $\mathrm{t}=2.8264$ & $16 \mathrm{p}=0.01$ & Yes & $>$ in hunted area \\
Paca & KW $=20.4076$ & 1 & $\mathrm{p}<0.01$ & Yes & $>$ in Non-hunted area \\
Agouti & ANOVA; $\mathrm{F}=6.0018$ & 1 & $\operatorname{Pr}(\mathrm{F})=0.02$ & Yes & $>$ in Non-hunted area \\
\hline
\end{tabular}

Although nine-banded armadillos are relatively difficult to encounter during the day, they are very active at night and leave numerous visible tracks that are easily observable. During the field period, a total of 361 observations were made over the 312 kilometres surveyed, giving an average of 1.16 observations per kilometer, the most of any of the species examined. In the non-hunted area, a total of 202 observations were recorded, translating into an average of 1.53 observations per kilometre. In the hunted area, 159 observations of this species were made, translating into 0.88 observations per kilometre.

Once transformed $(\mathrm{LOG}+1)$, the data followed the assumptions required for parametric analysis (Kolmogorov-Smirnov Test of Composite Normality: ks $=0.0767, \mathrm{p}$ value $=0.5 ;$ Levene's test: $\mathrm{df}=1, \mathrm{~F}=0.01077, \operatorname{Pr}(\mathrm{F})=0.9176)$. The ANOVA performed $(\mathrm{df}=1, \mathrm{~F}=10.8611, \operatorname{Pr}(\mathrm{F})=0.0015)$ confirmed a significant statistical difference in the number of nine-banded armadillos in the hunted and non-hunted areas. We can conclude 
with a very high degree of confidence that nine-banded armadillos are relatively more abundant in the non-hunted area.

During the study period, white-nosed coatis were mostly observed in groups of nine to sixteen individuals, but were also occasionally found in smaller groups. Since it was not always possible to see all individuals in a group, an average group number of twelve was attributed to those groups we could not precisely count. In total, we observed 170 coatis over the study period, giving an average of 0.54 observations per kilometre. Observations per kilometer of the animal were much less numerous in the non-hunted area, where only 20 were observed, translating into an average of 0.15 observations per kilometre. In the hunted area, 150 observations of white-nosed coati were made, giving an average of 0.83 observations per kilometre.

Observations made in the four transects of the hunting zone were pooled together, and the same was done for the non-hunted area. Once pooled, the data held the assumptions required for parametric analysis (Kolmogorov-Smirnov Test of Composite Normality: $\mathrm{ks}=$ $0.1618, \mathrm{p}$-value $=0.5 ;$ Levene's test: $\mathrm{df}=1, \mathrm{~F}=3.5622, \mathrm{p}(\mathrm{F})=0.0774)$, and the Welch Modified Two-Sample t-Test performed (Table 4.4) indicated that coatis were more abundant in the non-hunted area.

In total, 66 observations of paca were made over the study period, giving an average of 0.21 observations per kilometre. In the non-hunted area, this animal was observed 54 times $(0.41 \mathrm{obs} / \mathrm{km})$, and in the hunted area, it was observed 12 times, giving an average of 0.07 observations per kilometre. Abundance of paca was significantly higher at the site where hunting is not allowed (Table 4.4). 
In total, 177 observations of agouti were made over the field season $(0.57 \mathrm{obs} / \mathrm{km}): 93$ in the non-hunted area $(0.70 \mathrm{obs} / \mathrm{km})$, and 84 in the hunted area $(0.47 \mathrm{obs} / \mathrm{km})$. When logtransformed $(\log +1)$ the data held the assumptions for parametric analysis (KolmogorovSmirnov Test of Composite Normality: $k s=0.0954$, p-value $=0.5$; Levene's test: $\mathrm{df}=1, \mathrm{~F}$ $=0.8756, \operatorname{Pr}(F)=0.3526)$. The null hypothesis of no difference in the number of observations of this animal between the two sites was tested using an ANOVA. The results of this test indicate a significant difference between the number of observations in the hunted and non-hunted areas (Table 4.4) indicating a greater abundance of agoutis in the non-hunted area.

\subsubsection{Birds}

The two bird species included in this study - the great curassow and crested guan - are the two most highly prized birds in the region according to local, and were observed more frequently at the site within the nucleus of the reserve (Figure 4.10). A total of 119 birds were seen over the field season, giving a total average of 0.38 per kilometre: 75 were observed in the non-hunted area $(0.57 \mathrm{obs} / \mathrm{km})$ compared to 44 in the hunted area $(0.24$ obs $/ \mathrm{km}$ ), representing a decrease of $41 \%$. 


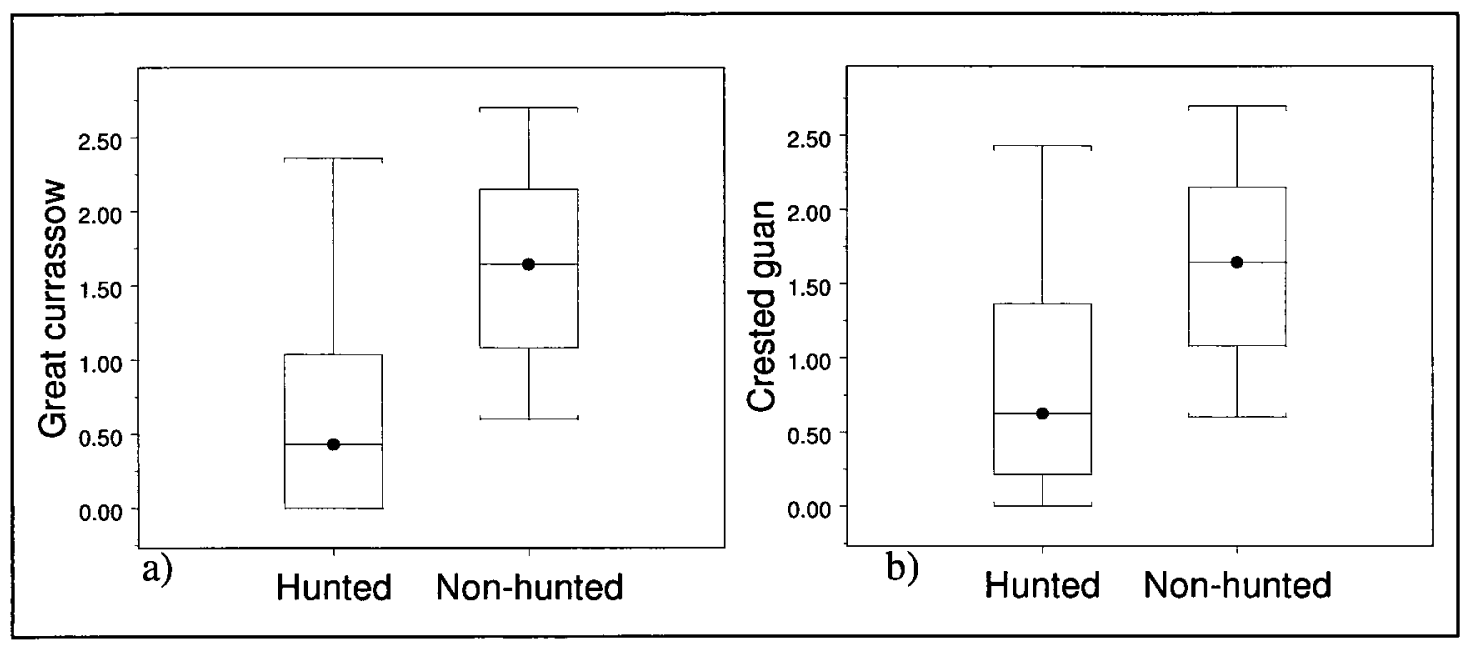

Figure 4.10: Box plots for the number of observations per kilometre of a) great curassow, and b) crested guan.

[Bottom and top of box represent 25th and 75th percentiles, middle line is the median, bottom and top whiskers represent lowest and highest values that are not outliers, and $\rightarrow$ represent outliers]

Statistical analysis for the two species (Table 4.5 ) indicates that the great curassow is significantly more abundant in the non-hunted area, but that the abundance of crested guan was not significantly different between the two sites.

Table 4.5: Statistical tests comparing the abundance of birds in the hunted and non-hunted area

Statistical significance $(95 \% \mathrm{CI})$ Zone of greater relative abundance

\begin{tabular}{llllll} 
Species & Statistical test & df. & p-value & Yes/No & \\
\hline Great curassow & $\mathrm{t}$-test; $\mathrm{t}=\mathrm{t}=-2.6197$ & 10 & $\mathrm{p}=0.03$ & Yes & > in non-hunted area \\
Crested guan & $\mathrm{t}$-test; $\mathrm{t}=-1.963$ & 10 & $\mathrm{p}=0.08$ & No & no difference \\
\hline
\end{tabular}

All observations of great curassow were direct sightings. In total, 40 great curassows were observed over the field period, giving a total average of 0.13 observations per kilometre. In the nucleus zone, 31 great curassow were observed $(0.23 \mathrm{obs} / \mathrm{km})$, compared to 9 in the hunted area $(0.05 \mathrm{obs} / \mathrm{km})$, or about four times fewer. 
Since relatively few observations of this species were made over the field period, it was deemed better to pool all data within each region together so as to reduce the influence of zeroes on the analysis. The normality of residuals and homogeneity of variances were first tested (Kolmogorov-Smirnov Test of Composite Normality: $k s=0.2007$, p-value $=$ 0.0534; Levene's test: $\mathrm{df}=14, \mathrm{t}=-0.206$, $\mathrm{p}$-value $=0.8397$ ). Then a Welch Modified TwoSample t-Test was done; the abundance of great curassow was found to be significantly higher in the non-hunted zone than around the village (Table 4.5).

As with the great curassow, only direct visual observations of the mainly arboreal crested guan were made. In total, 79 animals were seen over the field period $(0.25 \mathrm{obs} / \mathrm{km})$. In the non-hunted area, the bird was observed 44 times $(0.33 \mathrm{obs} / \mathrm{km})$, and in the hunted area this animal was seen 35 times $(0.20 \mathrm{obs} / \mathrm{km})$.

Here again, the data were pooled by region (hunted versus non-hunted). When tested, the data showed a normal distribution of residuals and homogeneity of variances (Kolmogorov-Smirnov Test of Composite Normality ks $=0.1911, \mathrm{p}$-value $=0.0813$; Levene's test: $\mathrm{df}=14, \mathrm{t}=0.1047$, $\mathrm{p}$-value $=0.918$ ), and therefore held the assumptions required for parametric analysis. No significant difference in the abundance of crested guan between the two studied areas was found (Table 4.5).

\subsubsection{Primates}

Three primate species were included in this study: the Central American spider monkey, the white-faced capuchin, and the mantled howler monkey. Although these species are frequently consumed in other parts of the neotropics, villagers of Las Marías state they 
no longer consume nor hunt monkeys. They were therefore included in the non-game category. In total, 159 monkeys were observed over the field season $(0.51 \mathrm{obs} / \mathrm{km}): 130$ in the non-hunted area $(0.98 \mathrm{obs} / \mathrm{km})$ and 29 in the hunted area $(0.16)$, representing a six-fold difference. The monkeys studied here are arboreal species; all observations made here were therefore visual. The spider and howler monkey were observed more frequently in the nonhunted area, but surprisingly, the white-faced capuchin was observed more frequently in the hunted area (Figure 4.11; Table 4.6).

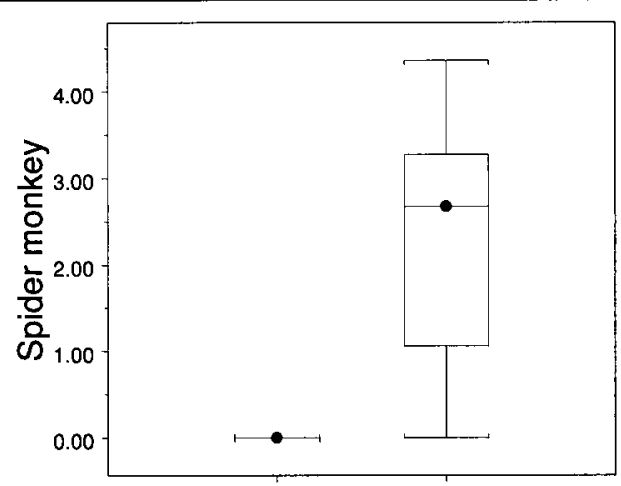

a) Hunted Non hunted

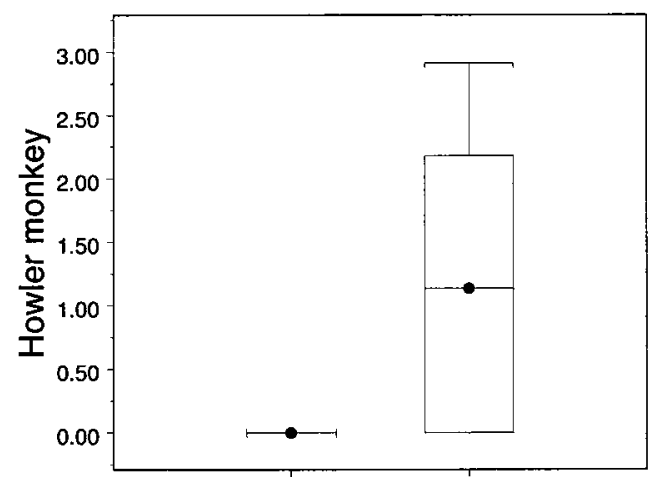

c) Hunted Non-hunted

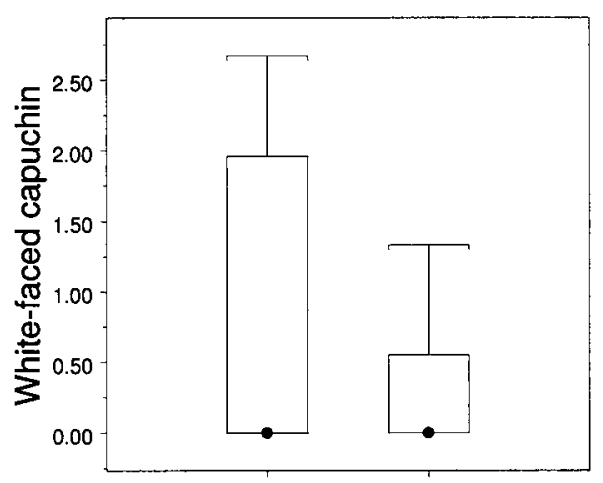

b) Hunted Non-hunted

[Bottom and top of box represent 25th and 75th percentiles, middle line is the median, bottom and top whiskers represent lowest and highest values that are not outliers, and represent outliers]

Figure 4.11: Box plots for the number of observation per kilometre of primates: a) Central American spider monkey, b) white-faced capuchin, and c) mantled howler monkey. 
Table 4.6: Statistical tests comparing the abundance of primates in the hunted and nonhunted area

\begin{tabular}{|c|c|c|c|c|c|}
\hline \multirow[b]{2}{*}{ Species } & \multicolumn{4}{|c|}{ Statistical Significance (95\% CI) } & \multirow{2}{*}{$\begin{array}{c}\text { Zone of greater relativ } \\
\text { abundance } \\
\end{array}$} \\
\hline & Statistical Test & df. & p-value & Yes/No & \\
\hline Spider monkey & $K W=17.6733$ & 1 & $\mathrm{p}<0.01$ & Yes & $>$ in non-hunted area \\
\hline White & WRST: $Z=0.279$ & $\mathrm{n} / \mathrm{a}$ & $\mathrm{p}=0.78$ & No & no difference \\
\hline Howler monkey & WRST: $Z=-3.022$ & $\mathrm{n} / \mathrm{a}$ & $\mathrm{p}<0.01$ & Yes & $>$ in non-hunted area \\
\hline
\end{tabular}

No spider monkeys were observed around the village and the villagers attest to not having seen this animal for a long time in the vicinity of the village. In the nucleus zone, 79 individuals were observed, giving an average of 0.60 observations per kilometre. This animal was sometimes seen alone, but generally in groups of up to 12 individuals. When in groups, the animal often exhibited curious or aggressive behaviour in response to our presence, including throwing branches at us.

After verification of the assumptions required for parametric analysis (KolmogorovSmirnov Test of Composite: $\mathrm{ks}=0.33$, p-value $=0$; Levene's test: $\mathrm{df}=1, \mathrm{~F}=93.633, \mathrm{p}(\mathrm{F})$ $<0.001$ ), a KW test was performed (Table 4.6). The abundance of spider monkeys was found to be significantly higher in the nucleus zone than in the hunted area.

In total, 40 white-faced capuchin were encountered over 312 kilometres of transects surveyed, giving a total average of 0.13 observations per kilometre. This monkey was encountered at both research sites: 11 sightings were made in the non-hunted zone $(0.08$ $\mathrm{obs} / \mathrm{km})$, and 29 around the village $(0.16 \mathrm{obs} / \mathrm{km})$. As with the other two primate species studied, white-faced capuchin monkeys often approached the researchers when in proximity, showing some form of curious or aggressive behaviour. It appears as though the dominant males were attracting attention while allowing the females and young to move away. This 
behaviour in some cases alerted us to the presence of the group which might have otherwise been missed, demonstrating that the various characteristics of different species affect their 'detectability' in faunal surveys. Because observations were relatively few, the data were pooled by region for the statistical analysis. Since the data were not normally distributed (Kolmogorov-Smirnov Test of Composite: $\mathrm{ks}=0.2887$, p-value $=0.0003$; Levene's test: $\mathrm{df}$ $=16, \mathrm{t}=3.14, \mathrm{p}$-value $=0.0065$ ), a Wilcoxon Rank Sum test was performed; the abundance of white-faced capuchin in the non-hunted zone was not significantly different than in the hunted zone (Table 4.6).

No howler monkeys were recorded in the hunted zone while collecting data; however, this animal was seen and heard occasionally during the study period, not surprising given that the loud calls it makes can be heard at significant distances. In the non-hunted zone, this animal was heard almost daily, especially early in the morning and just before rain started. In total, we made 40 observations of this monkey in the nucleus zone, giving an average of 0.30 observations per kilometre. For statistical analysis, the observations recorded for this species were first pooled by region (all transects in hunted zoned pooled together and all transects in non-hunted zone pooled together). Since the distribution of data did not hold the assumptions of normality required (Kolmogorov-Smirnov Test of Composite: $\mathrm{ks}=0.3616$, $\mathrm{p}$-value $=0$; Levene's test: $\mathrm{df}=5, \mathrm{t}=-3.45$, $\mathrm{p}$-value $=0.0183$ ), a Wilcoxon Rank Sum test was used (Table 4.6); howler monkeys were significantly more abundant in the nucleus zone than around the village of Las Marías. 


\subsubsection{Felids}

Five felid species are included in this study: the jaguar, puma, and ocelot were examined as individual species, while the margay and jaguarundi were grouped together into the "smaller felid" category because of their similarities and difficulty in distinguishing their tracks. In total, 85 felids observations were made over the field season, representing an average of 0.27 observations per kilometre. In the non-hunted area, 57 observations were recorded $(0.43 \mathrm{obs} / \mathrm{km})$ compared to $28(0.16 \mathrm{obs} / \mathrm{km})$ in the hunted area, some 2.7 times lower than in the non-hunted area. 


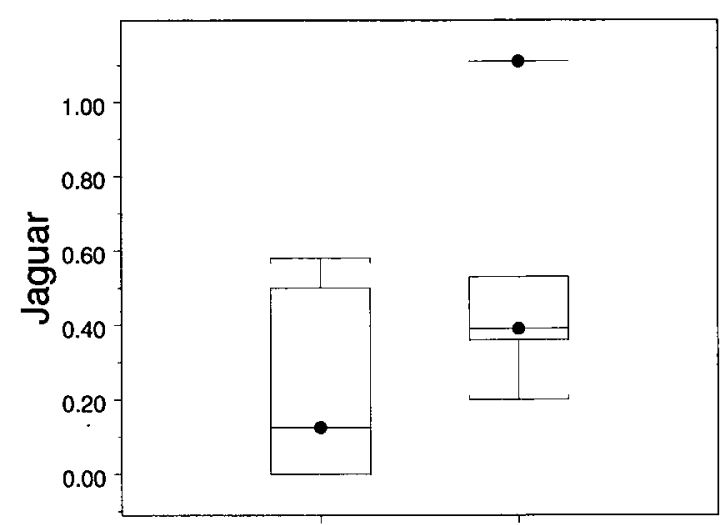

a) Hunted Non-hunted

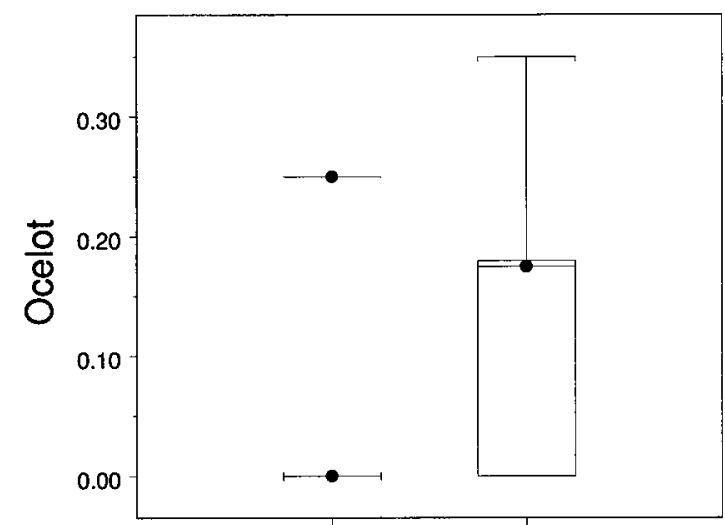

c) Hunted Non-hunted

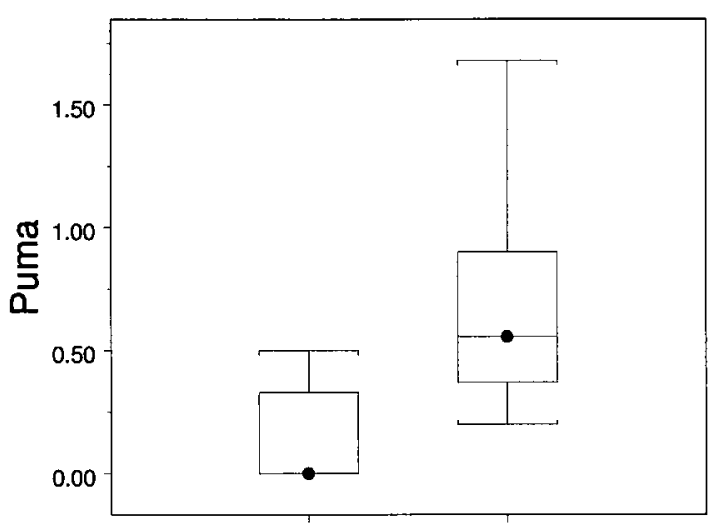

b) Hunted Non-hunted

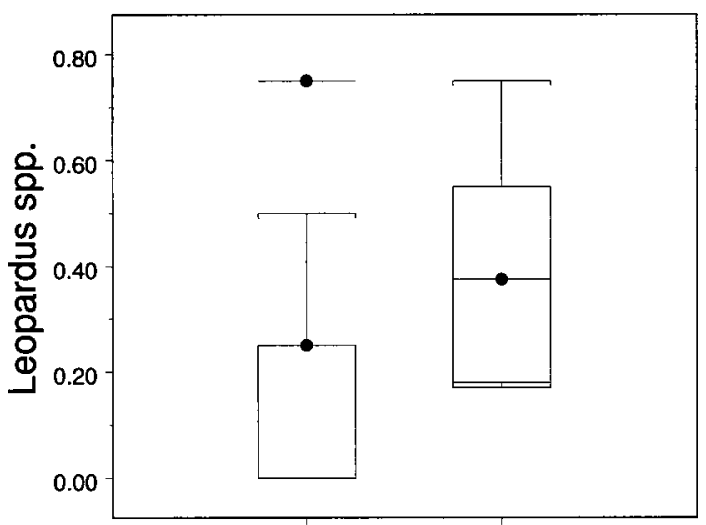

d) Hunted Non-hunted

Figure 4.12: Box plots of the relative abundance of felids (obs/km) in the hunted and nonhunted zone: a) jaguar, b) puma, c) ocelot, and d) small felids.

[Bottom and top of box represent $25^{\text {th }}$ and $75^{\text {th }}$ percentiles, middle line is the median, bottom and top whiskers represent lowest and highest values that are not outliers, and $\rightarrow-$ represent outliers]

Comparing box plots for the abundance of felids in the two areas (Figure 4.12), we can observe that all species were more numerous in the non-hunted area. Statistical analysis performed on these taxa, however, suggests that pumas and ocelots were more abundant in the non-hunted area, but that the abundance of jaguars and the smaller felids is not significantly different between the two research sites (Table 4.7). 
Table 4.7: Statistical tests comparing the abundance of felids in the hunted and non-hunted area

\begin{tabular}{llllll}
\hline & \multicolumn{2}{c}{ Statistical Significance $(95 \%$ CI $)$} & & Zone of greater relative \\
Species & Statistical Test & df. & p-value & Yes/No & abundance \\
\hline & & & & & \\
Jaguar & $\mathrm{t}$-test $\mathrm{t}=-1.9045$ & & $\mathrm{p} \leq=0.09$ & No & no difference \\
Puma & $\mathrm{t}$-test $\mathrm{t}=-2.5329$ & & $\mathrm{p} \leq<0.05$ & Yes & $>$ in Non-hunted area \\
Ocelot & WRST: $\mathrm{Z}=-2.3133$ & $\mathrm{n} / \mathrm{a}$ & $\mathrm{p} \leq=0.02$ & Yes & $>$ in Non-hunted area \\
Smaller felids & WRST: $\mathrm{Z}=-1.3435$ & $\mathrm{n} / \mathrm{a}$ & $\mathrm{p} \leq=0.18$ & No & no difference \\
\hline
\end{tabular}

In total, 26 jaguar tracks were observed over the field season, giving a mean average of 0.08 observations per kilometre. In the hunted zone, 10 tracks were recorded $(0.06 \mathrm{obs} / \mathrm{km})$, but none were within two kilometres of the village. In the nucleus zone, 16 tracks of jaguar $(0.12 \mathrm{obs} / \mathrm{km})$ were recorded during the observation period, and we heard one animal fleeing from a tree about 10 metres away. Tracks were also occasionally observed on top of our own tracks on the way home, suggesting that our presence combined with the curiosity of these individuals affected the results for this species.

Because jaguar observations were relatively few over the field period, it was deemed more suitable to pool the data by region to proceed with the statistical analysis. Since the data held the assumptions required for parametric analysis (Kolmogorov-Smirnov Test of Composite: $\mathrm{ks}=0.1997, \mathrm{p}$-value $=0.056 ;$ Levene's test: $\mathrm{df}=6 ; \mathrm{t}=-0.0061, \mathrm{p}$-value $=$ 0.9954), a Welch Modified Two-Sample t-test was performed (Table 4.7), and it was concluded that the abundance of jaguar in the non-hunted zone was not significantly different than in the hunted area.

During the field study a total of 29 puma tracks were observed, giving a total average of 0.09 observations per kilometre. In the non-hunted zone, the animal was recorded 23 times, giving an average of 0.17 observations per kilometre. In the hunted zone, puma tracks were recorded six times, giving an average of 0.03 observations per kilometre. Since 
observations were relatively few, they were pooled by region for analysis purposes. Given that the data held the assumptions required for parametric analysis (Kolmogorov-Smirnov Test of Composite: $\mathrm{ks}=0.2437, \mathrm{p}$-value $=0.0059 ;$ Levene's test: $\mathrm{df}=6 ; \mathrm{t}=-1.6558, \mathrm{p}$ value $=0.1565)$, a Welch Modified Two-Sample t-test was performed (Table 4.7): it was concluded that the relative abundance of puma in the non-hunted zone was significantly higher Only six observations of ocelot $(0.02 \mathrm{obs} / \mathrm{km})$ were recorded during field research, with five in the nucleus zone $(0.04 \mathrm{obs} / \mathrm{km})$, and one in the hunted zone $(<0.01 \mathrm{obs} / \mathrm{km})$. After pooling the data and verification of the distribution of residuals and variances (Kolmogorov-Smirnov Test of Composite: $\mathrm{ks}=0.3116$, p-value $=0.0001$; Levene's test: $\mathrm{df}$ $=8 ; \mathrm{t}=-1.6565, \mathrm{p}$-value $=0.1355)$, a Wilcoxon rank-sum test was performed (Table 4.7); it was concluded that the relative abundance of ocelots in the hunted zone was significantly lower than in the non-hunted zone. However, since very few observations of this species were made, the results of this analysis should be approached with caution.

This category includes the margay and jaguarundi. These two species were grouped together because their tracks can be difficult to differentiate, especially for the young animals, and because local investigators group all these felids under the local term "tigrillo", making differentiation between them difficult. Over the field period, a total of 24 smaller felid tracks were seen in the two studied regions, giving a total average of 0.08 observations per kilometre. In the hunted area, 11 tracks were recorded $(0.06 \mathrm{obs} / \mathrm{km})$, and $13(0.10$ $\mathrm{obs} / \mathrm{km})$ in the non-hunted region.

Data for this group of species were pooled per region, and the assumptions required for parametric analysis were verified (Kolmogorov-Smirnov Test of Composite: $k s=0.2396$, $\mathrm{p}$-value $=0.0075 ;$ Levene's test: $\mathrm{df}=12 ; \mathrm{t}=-0.2005$, $\mathrm{p}$-value $=0.8443$ ). A non-parametric 
Wilcoxon rank-sum test was performed (table 4.7), and the number of observations of this group of species in the non-hunted zone was not found to be significantly different from that in the hunted area.

\subsubsection{Anteaters}

Two species of anteaters were included in this study: the northern tamandua, which is the common anteater, and the much rarer giant anteater. Only 15 anteater observations were made over the field period, representing an average of 0.06 observations per kilometre. In the non-hunted area, 8 observations $(0.06 \mathrm{obs} / \mathrm{km})$ were made, and 7 in the hunted area $(0.04$ obs $/ \mathrm{km}$ ). Box plots of the number of observations per kilometre made for each anteater species is presented below (Figure 4.13) with the results of the statistical analysis (Table 4.8). 

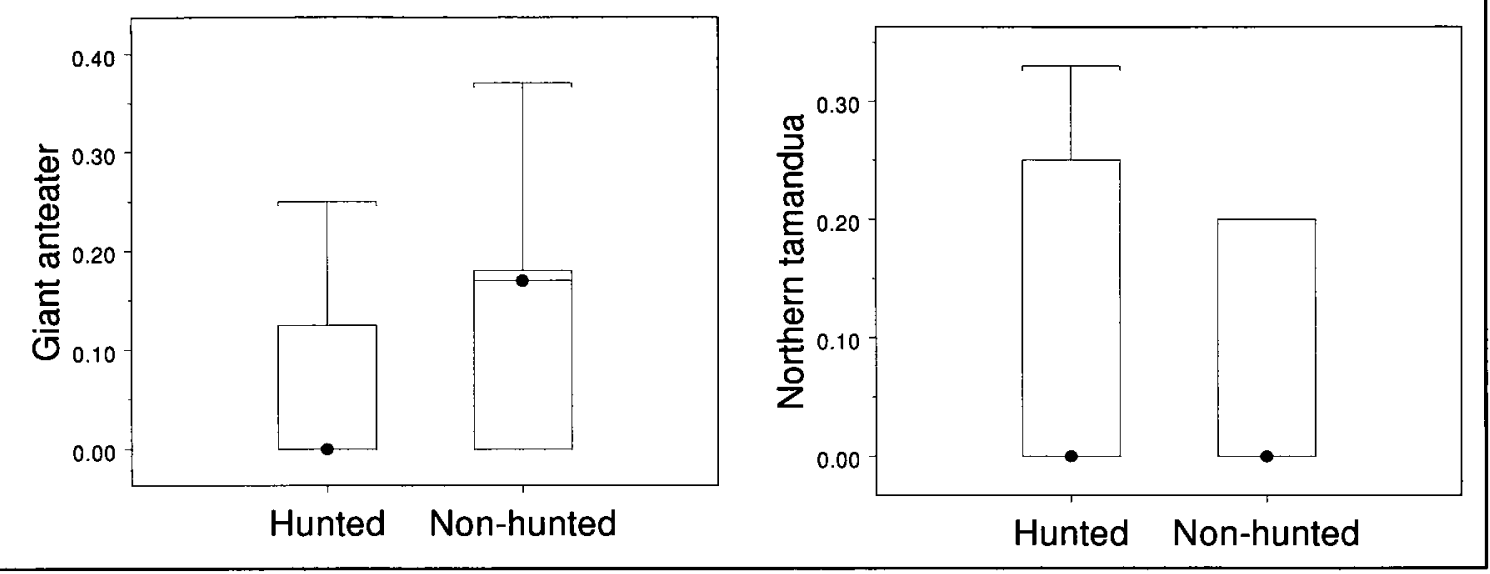

Figure 4.13: Box plots of the relative abundance of anteaters (obs/ $/ \mathrm{km})$ in the hunted and non-hunted zones.

Bottom and top of box represent $25^{\text {th }}$ and $75^{\text {th }}$ percentiles, middle line is the median, bottom and top whiskers represent lowest and highest values that are not outliers, and - represent outliers]

Table 4.8: Statistical tests comparing the abundance of anteaters in the hunted and nonhunted area

\begin{tabular}{llllll}
\hline & \multicolumn{4}{c}{ Statistical Significance (95\% CI) } & \multicolumn{2}{c}{ Zone of greater } \\
Species & statistical test & df. & p-value & Yes/No & relative abundance \\
\hline \hline & & & & & \\
Giant anteater & WRST: $Z=-1.2292$ & $\mathrm{n} / \mathrm{a}$ & $\mathrm{p}=0.22$ & No & No difference \\
Northern tamandua & WRST: $\mathrm{Z}=0.3913$ & $\mathrm{n} / \mathrm{a}$ & $\mathrm{p}=0.70$ & No & No difference \\
\hline
\end{tabular}

During the field period, a total of eight giant anteater observations $(0.03$ observations per kilometre) were recorded, including one visual observation. In the non-hunted zone, five observations were made $(0.04 \mathrm{obs} / \mathrm{km})$, and in the hunted zone, three observations of this animal were made $(0.02 \mathrm{obs} / \mathrm{km})$. Because of the relatively few observations made of this species during the field research, data were pooled by region for the statistical analysis. Since the assumptions required for parametric testing were not met (Kolmogorov-Smirnov Test of Composite: $\mathrm{ks}=0.3133$, p-value $=0.0001$; Levene's test: $\mathrm{df}=7 ; \mathrm{t}=-0.1336, \mathrm{p}$ value $=0.8974)$, a non-parametric Wilcoxon rank-sum test was performed (Table 4.8). This 
test led to conclude that the relative abundance of giant anteaters in the two studied zones was not significantly different.

No tracks of northern tamandua were observed during the field season. All observations of this species, hence, result from direct encounters. In total, seven individuals $(0.02 \mathrm{obs} / \mathrm{km})$ were encountered over the field period, three in the non-hunted zone $(0.02$ $\mathrm{obs} / \mathrm{km})$, and four in the hunted area $(0.02 \mathrm{obs} / \mathrm{km})$. For statistical purposes, the data were pooled per region and the assumption of normality and homogeneity of variances were verified (Kolmogorov-Smirnov Test of Composite: $\mathrm{ks}=0.3637$, p-value $=0$; Levene's test: $\mathrm{df}=7 ; \mathrm{t}=1.9183, \mathrm{p}$-value $=0.0748)$. Following, a non-parametric Wilcoxon rank-sum test was performed (Table 4.8), and the result led to the conclusion that no significant different difference existed in abundance of northern tamandua between the two studied sites (hunted and non-hunted).

\subsection{Wildlife Abundance as a Function of Distance Away from the Village}

In order to better understand the spatial pattern of the impacts of subsistence hunting around Pech and Miskito settlements, direct and indirect observations of 2wildlife were analysed as a function of their distance from the village of Las Marías. The four sixkilometre long transects used around the village were split into three segments of two kilometres, ranging from the nearest to the farthest away from the village $(0-2 \mathrm{~km}, 2-4 \mathrm{~km}$, and 4-6 km from Las Marías). Seven percent of the transect length surveyed crossed agricultural lands because these surround the village and represent important anthropogenic 
habitats that likely influence wildlife abundance, particularly closer to the village. Primary forest dominates the landscape within the $2-4 \mathrm{~km}$ and $4-6 \mathrm{~km}$ segments of the transects.

Overall, 859 wildlife observations were made around Las Marías: 210 observations were made within the first two kilometres of the transects ( $24 \%$ of total observations), 318 (37\%) between 2-4 kilometres of Las Marías, and 331 (39\%) in the farthest 4-6 kilometre segments (Figure 4.14). Because human modification of ecosystems and human activity are greater near the village, it was expected that there would be fewer observations in the first two-kilometre segments. However, when tested statistically, the difference in the number of observations between the different segments was not statistically significant (Kruskal-Wallis chi-square $=4.1241, \mathrm{df}=2, \mathrm{p}$-value $=0.1272$ ). When analyzed individually, two species were absent from the area, 10 species were less numerous in the segment closest to the village than in the other segments, two species were less numerous in segment $1(0-2 \mathrm{~km}$ from village) than segment 3 (4-6 km from village), two species had similar densities in the three segments, and four species were more abundant in the segments closer to the village (Table 4.9). 


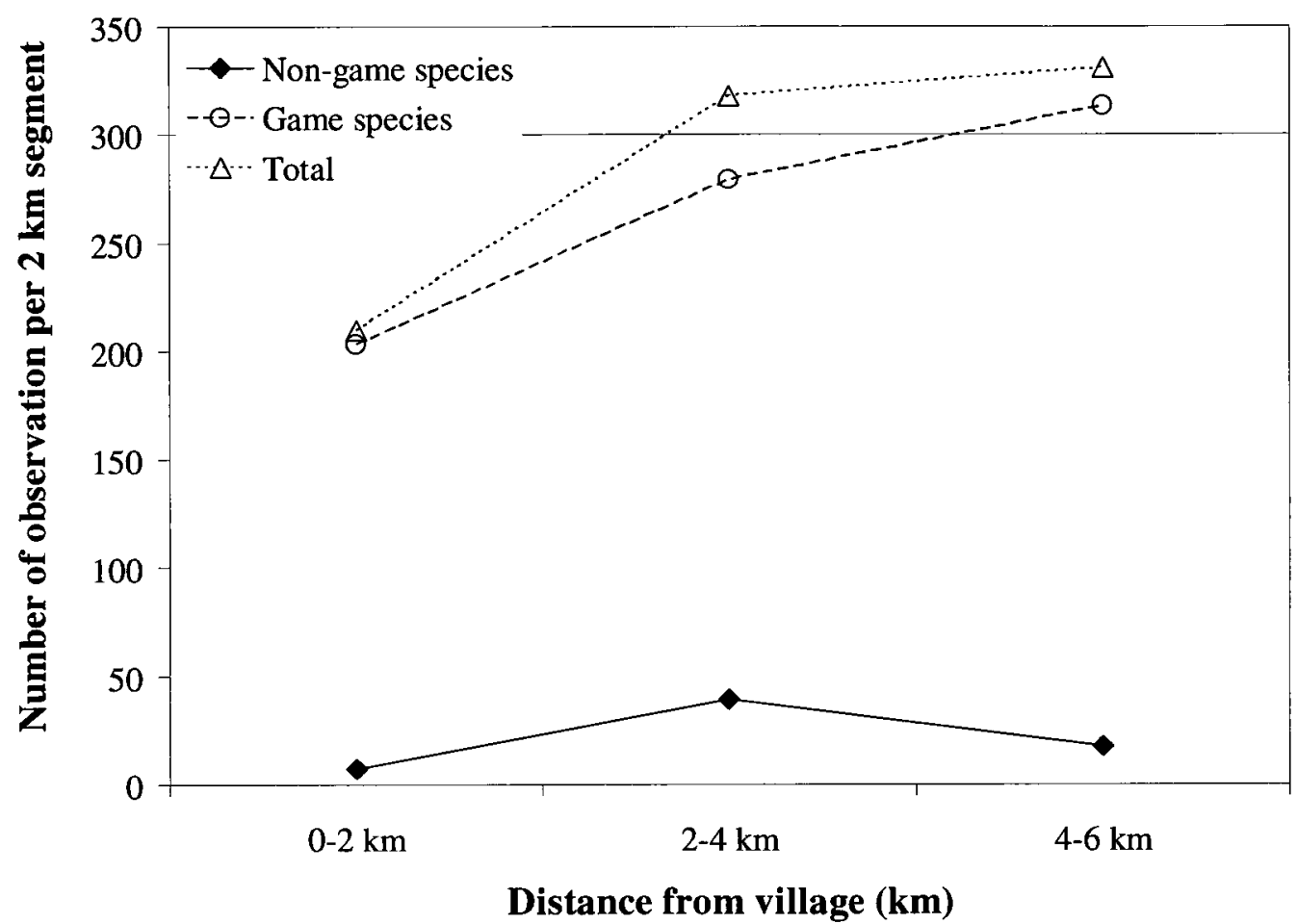

Figure 4.14: Number of observations for game species, non-game species and total species for each segment of land surveyed $(0-2 \mathrm{~km}, 2-4 \mathrm{~km}$, and 4-6 km from Las Marías). 


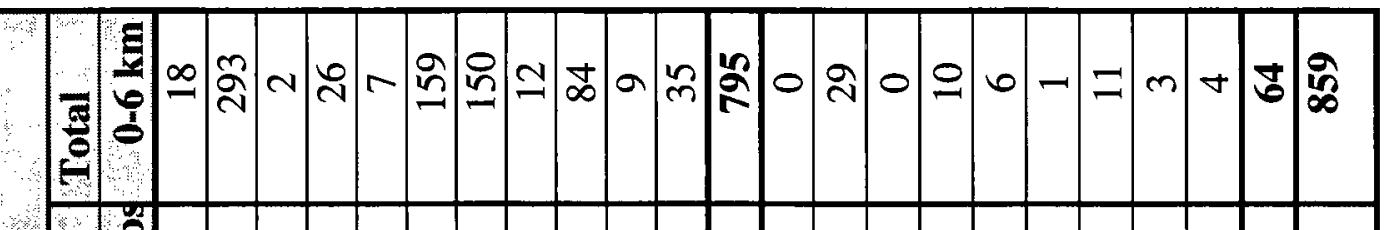

鱼

它

路

边

동

๑ึ

릉 है

है

产

需

沗

00

웡

刃ํ

훔 흔

蛋

完

\%

$\exists$

0

$\stackrel{0}{\circ}$

:

吾

7

을

흐

옹

沓

눈

京

믐

ठㅇํㅇ

4

त

ह

要

․․

$\ddot{\sigma}$

$\forall \&$

음

तै

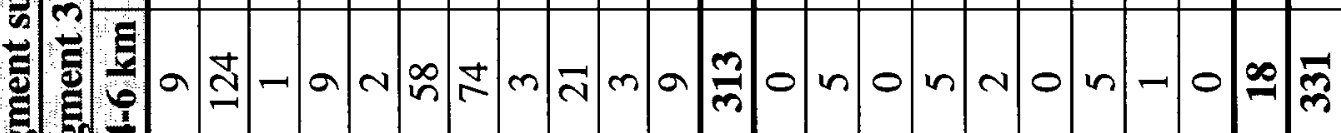

:

:

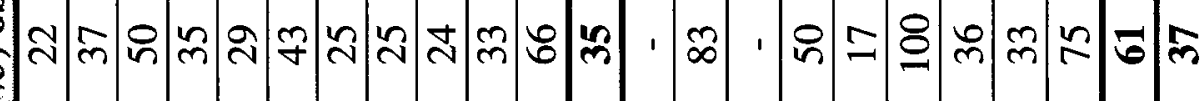

-

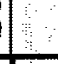


A total of 795 observations of game species were made around Las Marías; 203 observations (representing 26\% of total observations for game species) in the first two kilometres, $279(35 \%)$ in the $2-4 \mathrm{~km}$ segments, and 313 (39\%) in the farthest $4-6 \mathrm{~km}$ segment (Table 4.9; Figure 4.15). Since the number of observations of game species strongly influences the total number of observations (game species represent $93 \%$ of total observations), the results of the analysis for game species were very similar to those for the total observations. As for the total observations of wildlife, the number of observations of game species between the different segments was not significantly different (Kruskal-Wallis chi-square $=2.3962, \mathrm{df}=2, \mathrm{p}$-value $=0.3018$ ).

Observations of non-game species were much less numerous than those of game species, and represented only 7 percent of the total observations. In total, 64 observations of non-game species were made; 7 in the first 2-kilometre segment (representing $11 \%$ of the total observations of non-game species), 39 observations (61\%) in the 2-4 kilometre segment, and 18 observations (28\%) in the 4-6 kilometre segment (Table 4.9). The number of observations of non-game species between segments was found to be significantly different (Kruskal-Wallis chi-square $=6.1943, \mathrm{df}=2, \mathrm{p}$-value $=0.0452$, , suggesting that non-game species are less numerous at closer distances to the village. 

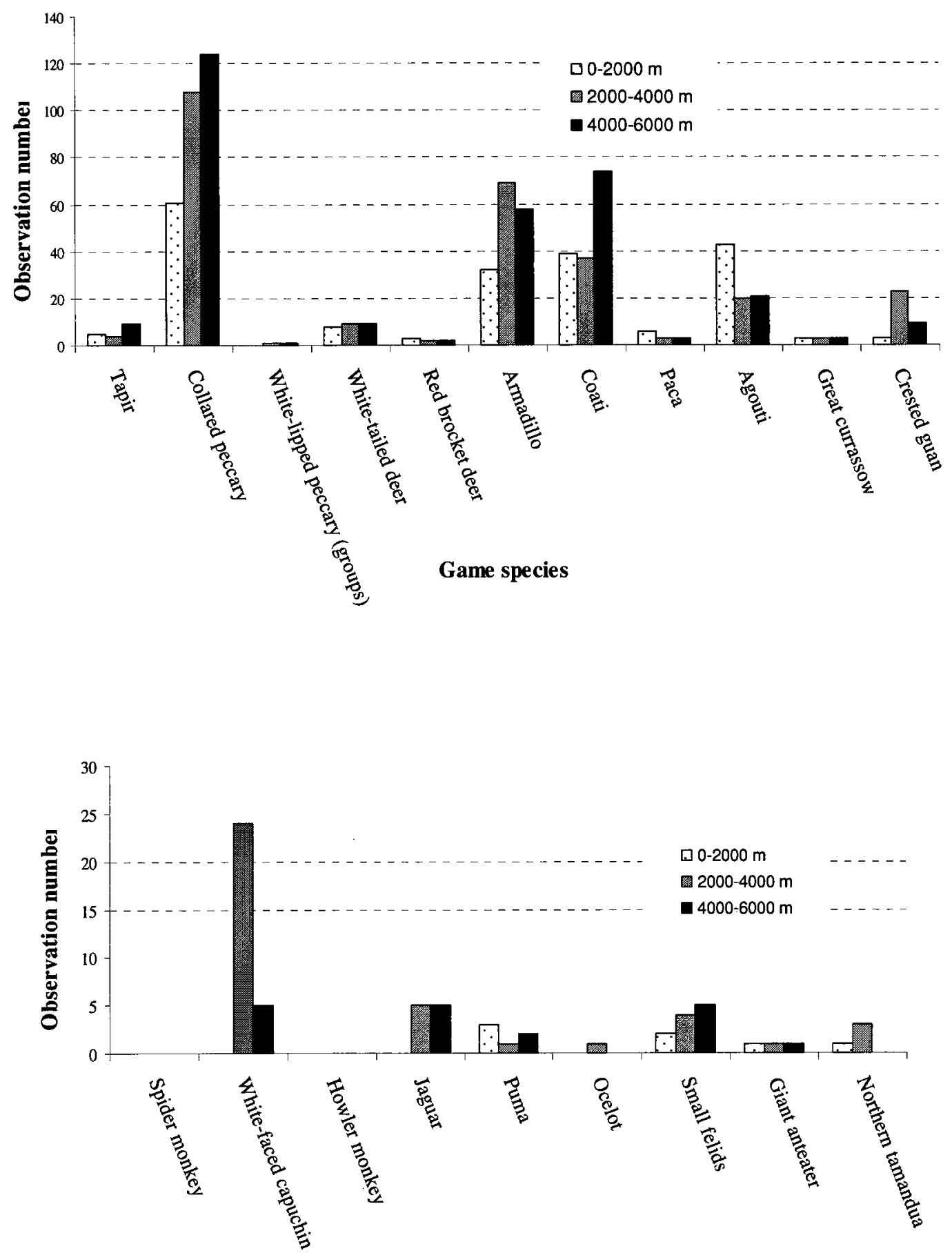

Non-Game species

Figure 4.15: Observations of game (top) and non-game species (bottom) as a function of distance $(0-2 \mathrm{~km}, 2-4 \mathrm{~km}$, and 4-6 km) from the village of Las Marías. 


\section{Chapter 5:}

\section{Discussion}

Biosphere reserves, national parks and other protected areas in Latin America are frequently established to simultaneously conserve biodiversity and allow for the use of natural resources for those inhabiting them. Whether both goals are attained in such areas remains in question, and the answer often depends on finding a balance between the regulation of resource use and the needs of the local populations.

The broad purpose of this research is to further the understanding of the role of protected areas in conserving wild resources, and to investigate whether the dual mandate of protecting fauna and preserving the cultural diversity of local inhabitants is reached in the cultural zone of the RPBR. It is understood that the results of this investigation should be approached with some caution as several assumptions are made. To start, differences in habitats affect the distribution of wildlife species. Approximately seven percent of the transect lines around Las Marías crossed agricultural and fallow lands, but no land was classified as such in the non-hunted area. Conversely, about seven percent of the transects surveyed in the non-hunted area crossed bamboo dominated ecosystems, though none were categorized as such in the hunted area. Bamboo dominated ecosystems resemble guamiles (fallow lands) that are in their first stages of recolonisation, before they become secondary and then primary forests. Moreover, only mature secondary forest with distinct canopy layers was recorded as such, and secondary forests, while different, have many of the attributes of primary forests, apart from absence of larger dominant trees. Because 
variations exist naturally between ecosystems and because no major differences were noted between the hunted and the non-hunted areas, I considered the two sites to be sufficiently similar to allow comparison between the two sites.

In this study it is assumed that the activity of hunting is the primary factor affecting wildlife in the hunted and the non-hunted sites. However, the mere presence of humans could potentially be a factor affecting wildlife abundance. Monitoring the effects of hunting can be difficult because this activity leaves almost no visible trace (Redford 1992). One technique adopted by several researchers was to collect skulls and genital parts of game hunted in order to calculate the number, species, sex and age group of the animals hunted by local hunters (e.g., Bodmer and Puertas 2000; Jorgenson 2000; Leeuwemberg and Robinson 2000). This technique is optimal because it allows for a clear picture of the local fauna to be extracted over a defined period of time. When coupled with a survey of the wildlife population on hunting grounds, it allows for an estimation of whether the rates of extraction are sustainable. However, this approach is only feasible for longer term studies. Furthermore, such work relies on the participation of local people, which can be difficult to count on in a village like Las Marías, where hunters tend to be as private as possible about their hunting activities. An interesting technique adopted by Dunn (2004) and Smith (2005) was to investigate the harvest rate through interviews with local people. This technique has the advantage of being inexpensive and can be done on a short term; however, it also depends on the honest participation of the local population for success. Such studies, however, do not measure the relative abundance of wildlife but rather game extraction.

For this research, tracks were used for comparing the relative abundance of several species. It is assumed that similar species leave the same number of easily visible tracks in 
the two areas and that the numbers of tracks encountered reflect the actual densities in each area.

The relative abundance of wildlife was significantly higher in the non-hunted area than in the hunted area. This result was expected as the removal of animals by indigenous hunters will undoubtedly reduce their abundance, at least temporarily. However, in a sustainable system, the removal of wildlife should only marginally reduce their populations, but stay within the range of natural oscillations; we would expect sufficient time in between each kill to replenish local populations. If wildlife extraction is not a factor differentiating the hunted from the non-hunted area and if wildlife abundance was not affected by habitat and human presence, then we would expect both sites to have relatively similar wildlife abundance. Since hunting affects whole faunal communities, we could also expect differences to a lesser degree between the two sites for non-game species due to the impact of hunting on predator-prey relationships and competition between species.

This study found a difference of about 42 percent between the two sites for the observations of all species combined, with 6.8 and 4.8 observations per kilometre for the non-hunted area and hunted areas, respectively. In addition, 12 out of 20 species studied $(60 \%)$ were found to be less abundant in the hunted area, while only two species $(10 \%)$ were found to be more abundant in the hunted zone, and no difference in the relative abundance was found for the other six $(30 \%)$ species. Such results indicate that wildlife is below expected abundance around the village of Las Marías, and that the variations between areas are caused by factors other than natural variations in populations. As expected, this trend was even more pronounced for game species; out of the 11 game species studied, eight (73\%) were less abundant in the hunted area, one (18\%) had similar abundance, and only the 
white-nosed coati and collared peccary were more numerous in the hunted area. Non-game species followed a different trend as no difference in abundance was found for five out of nine species $(56 \%)$. The remaining four $(44 \%)$ species, however, were also more abundant in the non-hunted area within the nucleus zone of the protected area.

When compared in relation to distance away from the village, the abundance of wildlife increased positively with distance, with $3.5,5.3$, and 5.5 observations per kilometre for the 0-2, 2-4, and 4-6 kilometres segments, respectively. This result was expected because of the greater hunting pressure and human presence at closer proximity to the village. However, even in the farthest 4-6 kilometre segment, where human activity apart from hunting is negligible, observations per kilometre were approximately $24 \%$ below those in the non-hunted area (5.5 compared to $6.8 \mathrm{obs} / \mathrm{km}$ ). These results provide convincing support for the argument that hunting has a significant impact on game populations, and that the impact is greatest closer to human settlements. Developing conservation priorities and effective measures, however, requires both an understanding of the overall status of the species, as well as the practices and perspectives of local communities who rely on game to meet their basic needs. What follows is a discussion of conservation management issues for the species examined in this research that combines both the quantitative results and qualitative observations made during field research. It represents an attempt to move beyond the differences in abundance measured in this study toward wildlife management strategies for Río Plátano Biosphere Reserve that respond to the game depletion that were documented. 
5.1 Relative Abundance of Wildlife in Hunted and non-hunted Sites

\subsubsection{Ungulates}

\section{Baird's tapir}

Loss and fragmentation of habitat and hunting pressure throughout most of its range have caused the population of Baird's tapir to decline by half over the last three decades (Castellanos et al. 2008). Listed as endangered by the IUCN Red List (2009), its current distribution is restricted mostly to protected and/or remote areas (Naranjo 2009). In Las Marías as elsewhere in the cultural and buffer zone of the RPBR, the tapir remains a prey of choice because the quality of its meat and its large size are appreciated. Although no statistics exist on the harvest rate of this species in the RPBR, local hunters attest that this animal is occasionally hunted by locals using firearms, or in the case of at least two hunters in Las Marías, with spears. In part due to its heavy weight, hunters tend to pursue this animal in groups, near river transportation gateways, or in proximity of the village. A villager, however, admitted that if a tapir were killed during a hunting trip, hunters may carry what they can and leave the rest to waste. Others, however, prefer not killing the animal rather than leaving it to waste. Tapirs are occasionally killed in farming areas where they eat crops.

Hunting significantly affects Baird's tapir populations: in areas where it is protected the species is common, and in hunted areas the animal is practically absent (Castellanos et al. 2008). Populations of this species in the RPBR followed this trend as the number of 
observations per kilometres in the hunted area $(0.1 \mathrm{obs} / \mathrm{km})$ was seven times smaller than that in the non-hunted area $(0.7 \mathrm{obs} / \mathrm{km})$. Our results in the nucleus zone are comparable to those found in other protected areas of Central America. Lira- Torres et al. (2004), for example, estimated the track encounter rate of this species to be at $0.67 \mathrm{obs} / \mathrm{km}$ in the nucleus zone of the Triunfo Biosphere Reserve in Mexico, and Naranjo (1995) estimated it at $0.60 \mathrm{obs} / \mathrm{km}$ in Corcovado National Park in Costa Rica. Closer to the village, in the $0-2$ and the 2-4 kilometre segments away from the village of Las Marías, the number of observations is even lower, with 0.08 and 0.07 observations per kilometre, respectively. The significant difference in the relative abundance of Baird's tapir between the non-hunted area and the hunted area suggests that this species is overhunted around Las Marías, although a study on the removal rate of this species should be done to confirm this suspicion. The fact that secondary forests were more prominent around the village than in the non-hunted area does not undermine this argument, as in fact tapirs are frequently associated with secondary forests (Fragoso 1991; Naranjo 1995; Foerster and Vaughan 2002) and regenerating riparian forests (Williams 1984).

This study suggests that the cultural zone of the RPBR does not adequately protect the endangered Baird's tapir. If the population estimate of less than 500 given to the population of Baird's tapir in Honduras (Tapir Specialist Group 2009) is correct, then this species is at great risk of extirpation in the country. Lack of enforcement and information on protected species may hinder the protection of this animal; inhabitants of Las Marías, for example, did not seem to be aware of the existing laws protecting this species. The hunting of this species in the cultural zone of the biosphere may contribute to the overall decline of this population because this area may act as a sink rather than a corridor to other areas where this animal is 
protected. Enforcement of hunting regulations and education of local population on this particular species is needed to protect the remaining populations of this species in the country. The nucleus zone, however, appears to have kept all the attributes required to preserve this species.

Peccaries

Collared peccaries range from the south of the United States to the north of Argentina, as well as on the Caribbean island of Trinidad and Tobago (Sowls 1997; Beck et al. 2008). This species is considered a habitat generalist and can be encountered from semidry environments to primary rainforest (Williams 1984; Painter et al. 1995; Peres 1996; Sowls 1997; Keuroghlian et al. 2004; Reyna-Hurtado and Tanner 2005; Beck et al. 2008). It is considered common and widespread where not hunted (Reid 1997). The collared peccary is under no conservation risks; however, over-hunting and destruction of its natural habitats have led to extirpation of some collared peccary populations over large parts of its former range (Bodmer and Sowls 1993). This does not appear to be the case in the RPBR.

The white-lipped peccary occupies approximately the same distribution as collared peccary but is patchily distributed throughout Mexico and Central America (Reid 1997) and is classified as Near Threatened by the IUCN Red List (Ibid). Hunting pressure and habitat fragmentation are considered its principal conservation threats (Cullen et al. 2000). Whitelipped peccary herds require large tracks of continuous habitat for survival (Painter et al. 1995; Keuroghlian et al 2004; Reyna-Hurtado et al 2008). (Carrillo et al. 2002), however, 
found that the home range sizes of these animals was of $100 \mathrm{~km}^{2}$ for a herd of 130 animals, and $22 \mathrm{~km}^{2}$ for a herd of 53 in the Corcovado National Park in Costa Rica, a much smaller area than generally believed.

Peccaries are almost consistently amongst the most important game species of neotropical subsistence hunters (Ayres et al. 1991; Redford and Robinson 1991; Vickers 1991; Kaplan and Kopischke 1992; Mena et al. 2000), and are among the most favoured prey species in Las Marías. Villagers tend to favor white-lipped peccary, however, for its meat's flavour. They attest that this animal has become rare around the village and finding it requires increasingly longer treks. Collared peccaries, on the other hand, seem to persist in the hunted area and are occasionally encountered in agricultural fields, where they are hunted opportunistically, or are pursued because they damage local crops. While no data on hunting harvest rates was taken during field work, discussions with villagers indicate that the collared peccary is the most hunted of the large mammals in this area, followed by white-tailed deer.

Although one would expect a large, primary game species to be depleted or at low density in a heavily hunted area, collared peccaries were in fact significantly more abundant in the hunted area $(1.6 \mathrm{obs} / \mathrm{km})$, than in the non-hunted area $(0.6 \mathrm{obs} / \mathrm{km})$. On the other hand, the abundance of white-lipped peccaries was as expected: significantly lower in the hunted area, where only two groups were observed (giving an average $0.01 \mathrm{obs} / \mathrm{km}$ ), than in the non-hunted area, where 12 groups were observed (average of $0.09 \mathrm{obs} / \mathrm{km}$ ). Although it is difficult to estimate group size in function of tracks, the physical evidence suggests that groups of this animal in the hunted area are smaller than in the non-hunted zone, something that several local hunters also told me. The closest tracks of white-lipped peccaries 
encountered were at some four kilometres from the village's boundaries. Tracks of collared peccary, on the other hand, were encountered in agricultural fields in the village, and $21 \%$ (61/293) of all tracks encountered in the hunted area were within the first two-kilometre transect segments. The quantative data analyzed here do not provide any conclusive evidence as to why this particular species is more abundant in the zone where hunting occurs. One possible factor could be the fact that shifting cultivators plant manioc, maize and other crops that are attractive to collared peccaries (especially during seasons when foods in mature forest are scarce) and may even enhance reproductive fitness - as has been suggested elsewhere (Smith, 2005). In addition, the potential reproductive rates of collared peccaries are very high relative to other species their size, with production rates per square kilometre per year estimated at 12.03, allowing for higher harvest rates (Robinson and Redford 1991). Collared peccaries also form smaller herds and are consequently able to survive in smaller areas, including in disturbed forest fragments (Cullen et al. 2000; Keuroghlian et al. 2004).

The results of this investigation coincide with other studies of peccaries. Cullen et al. (2000), for example, found that hunting did not affect collared peccary populations in the forests of southeastern Brazil, but did contribute to the extirpation of white-lipped peccaries. In the Beni Biosphere Reserve in Bolivia, Painter et al. (1995) found that collared peccaries were relatively more abundant in areas with greater human population density, and whitelipped peccaries were more abundant in protected areas. They suggest that the collared peccary benefits from the decreased population of the white-lipped peccary, a direct competitor for palm nuts. Competition is another plausible factor explaining the lower abundance of collared peccaries in the nucleus zone. White-lipped peccaries being more 
numerous and aggressive than collared peccaries, it is possible that the large herds push the latter into other areas. When white-lipped peccaries are removed through hunting, collared peccaries may occupy the available niche.

White-lipped peccaries are a highly mobile species, which means that interpretation of transect results over a short period must be cautions. However, villagers of Las Marías support the conclusion that the white-lipped peccary has been depleted, given that they have not been seen for a long time around the village, and affirm that they are much more abundant in the nucleus zone. Some people argued that non-indigenous mestizos from the coast used to come to the village to commercially hunt the species, using large dogs, which has a lasting impact. Some local hunters also admitted to having, at times, killed more animals than they needed during hunting trips. Since this species lives in large herds, they are easily followed and many animals can be killed during a single hunting expedition.

The cultural zone of the RPBR, therefore does not appear to fulfill its role of protecting the vulnerable white-lipped peccary but provides good habitat for collared peccary. Both species provide villagers with important sources of meat protein. Further studies should be done to investigate whether the hunt of white-lipped peccaries should be restricted in this zone. However, hunting efforts could focus on collared peccaries, which appear able to sustain current harvest levels in this area. 
Cervids

Both the white-tailed and red brocket deer are among the preferred principal game species in Las Marías. While no harvest data were collected during field period, local hunters attest to hunting these two species when the opportunity arises; a preference, however, is given to white-tailed deer because of the larger return brought by its larger size. In fact, this species may be the most commonly harvested large species in Las Marías, in part because it damages agricultural fields and is encountered relatively frequently in these areas.

Both species are considered fairly common and widespread throughout their ranges (Reid 1997). White-tailed deer range from southern Canada to northern Brazil and are under no particular conservation threat (Gallina and Lopez Arevalo 2008) although overharvesting has been observed in many areas (Vaughan and Rodriguez 1991; DelfinAlfonso et al. 2009; Sanchez Rojas et al. 2009). Red Brocket deer range from southern Mexico to northern Argentina. Studies on hunting in the Neotropics report that red brocket deer are generally hunted within sustainable limits (Hill and Padwe 2000; Leuwemberg and Robinson 2000; Mena et al. 2000; Hurtado-Gonzales and Bodmer 2004; Reyna-Hurtado and Tanner 2007), but can be overexploited (Julia and Richard 1999; Leni 1999). Both species respond well to disturbed areas (Freese and Saavedra 1991; Vaughan and Rodriguez 1991, for white-tailed deer; Hurtado-Gonzales and Bodmer 2004; Reyna-Hurtado and Tanner 2007 , for red brocket deer).

Considering that a greater amount of early regeneration of vegetation considered good habitat for cervids is found around Las Marías, we could expect the population of both 
species to be higher around the village than in the nucleus. This study found that both species were in fact relatively less abundant around the village than in the non-hunted zone. With $0.17 \mathrm{obs} / \mathrm{km}$ recorded in the non-hunted area, the relative abundance of red brocket deer was about four times greater than in the hunted area, where $0.04 \mathrm{obs} / \mathrm{km}$ were recorded. White-tailed deer were about five times more abundant in the non-hunted area than in the hunted zone, with 0.5 and $0.1 \mathrm{obs} / \mathrm{km}$, respectively. These results coincide with those of Weber (2000), who found the abundance of these two species significantly lower in sites with high hunting pressure than at sites with low or no hunting pressure in southeastern Mexico. The results of this study indicate that hunting significantly reduces the abundance of both the white-tailed deer and the red-brocket deer around the village. Whether the harvest of these species is sustainable is difficult to assess without proper knowledge of what is actually harvested and the age class composition of the live population. It is possible that the survival of the two species depend on metapopulation dynamics and the migration of individuals from the nucleus zone. Considering that white-tailed deer are under no conservation threat, and taking into account the benefits brought to the community of Las Marias, the current extraction levels of this species certainly have little effect on their global populations, especially since white-tailed deer are known to repopulate areas rapidly when habitat conditions are favourable (Vaughan and Rodriguez 1991). Red brocket deer, however, are more frequently associated with primary forests and their conservation status is not well-known (Bello et al. 2008). Considering that such forests have been greatly reduced in Honduras, current hunting levels may not be sustainable; this is especially true if the local variety Mazama americana temama is in fact a separate species from the red brocket deer of 
South America. We suggest that that this species should be studied outside the RPBR to better understand its conservation status.

\subsubsection{Medium-sized Game Species}

The agouti, the nine-banded armadillo, the paca and the white-nosed coati are among the most important mammals to subsistence hunters in the neotropics (Redford and Robinson 1991) but because of their wide distribution and relatively stable and large populations, they are classified as "Least Concern" by the IUCN Red List of Threatened Species (2009). Although hunters generally prefer larger ungulates, the harvest of mediumprey species such as those presented here is often larger in terms of the number of individuals harvested (e.g., Escamilla et al. 2000; Dunn 2004; Smith 2005). Indeed, the species are generally more abundant than the larger species and are therefore more easily encountered. Besides, these species are associated with swidden gardens and regenerating stands (Linares 1976; Irvine 1987), and are therefore frequently hunted in such areas (Smith 2005; Dunn 2004). Pacas, armadillos and agoutis can be easily killed with a simple machete once they are flushed out of their burrows. Coatis, on the other hand, are more mobile and escape rapidly in trees when threatened; they are therefore more difficult to hunt without a firearm. Villagers indicated that coatis are generally not preferred by hunters, and this, together with its ability to make use of disturbed forest fragments, may help explain its significantly higher abundance in the hunted area. Indeed, the coati was about four times more abundant in the hunted area. Interestingly, the results of this study coincide with those 
of Novack (2003), who also found coatis to be significantly more abundant in the hunted area than in the non-hunted area of the Maya Biosphere Reserve in Guatemala. Studies which compare the relative abundance of wildlife in hunted and non-hunted sites, however, more frequently find the coatis to be more numerous in the non-hunted zones (e.g., Glanz 1991; Carrillo et al. 2000; Escamilla et al. 2000; Hill and Padwe 2000). The relatively high presence of coatis in the hunted area could be explained by the lower abundance of puma in the hunted area. However, Novack (2003) found that coatis are much more preyed on by jaguars than by pumas, which appear to prefer deer, agoutis and pacas.

The abundance of coatis in the more distant 4-6 kilometre segments around the village was about twice that found at closer distance to the village. According to the optimal foraging theory (MacArthur and Pianka 1966), hunters may harvest less preferred preys such as the coati at closer distances to the village because both the probability of encountering another prey and the cost of returning to the village are low. At greater distances, however, hunters are generally active hunters in search of specific prey; they might therefore ignore the less preferred preys and concentrate their energy on finding preferred ones (Robinson and Bennet 2000). Although the reasons for the higher abundance of coatis in the hunted area are not entirely unclear, the results of this study indicate that the coati is not threatened by current hunting rates.

Because the paca, the agouti and the nine-banded armadillo are strongly associated with swidden agriculture (Linares 1976; Irvine 1987; Smith 2005), one might expect the abundance of these species to be relatively higher near the village if hunting rates were modest. They were, however, significantly less abundant in the non-hunted area. In fact, the relative abundance of armadillos was 1.7 times greater in the non-hunted zone, that of 
paca was 4.0 times greater, and that of agouti was 1.4 times greater. These results suggest that these three species are frequently harvested around the village. Interestingly, the abundance of both paca and agouti in the first 2-kilometre segment around the village was twice that found in the subsequent segments, even though this zone is subjected to greater overall hunting pressure. This finding supports evidence that they may be able to sustain high harvest levels in areas where shifting cultivation is practiced. At greater distances from the village, they do not benefit from human-modified habitats but are still subjected to hunting, and may also experience higher predation by jaguars, pumas and ocelots, their principal predators. The coati, armadillo, paca and agouti are under no conservation threats and appear to withstand hunting pressure relatively well; current hunting levels in Las Marías may therefore not affect the long-term survival of these species in this region

\subsubsection{Birds}

The two birds studied here are both cracids, a family of relatively large birds found in Latin American tropical forests and which are the most hunted birds by neotropical hunters. They play an important ecological role as seed dispersers, and are sometimes used as indicators of habitat quality and whether or not an area has experienced overhunting (Brooks 2006).

The great curassow is found from central Mexico to western Ecuador (Peterson and Chalif 1973), but its distribution is restrained to fragments of undisturbed humid evergreen forest (BirdLife International 2008a). High hunting pressure and habitat loss have caused the 
population of this bird species to be in constant decline; it has been locally extirpated from many areas and is becoming uncommon to rare throughout much of its range (lbid). For these reasons, it is classified as near threatened by the IUCN Red List (2009) and is included in the Appendix III of CITES.

Crested guans range from Mexico to Ecuador and Venezuela; however, $P$. purpurascens purpurascens, the subspecies found in Honduras, is not found south of Nicaragua (Blake 1977). Like for C. rubra, P. purpurascens is believed to require undisturbed forest habitats for survival (Brooks 2006). However, it is not currently under any conservation threat (BirdLife International 2008 ) and is classified as "Least Vulnerable" by the IUCN Red List (2009), indicating that it may be less vulnerable to habitat changes and hunting pressure than the great curassow.

Observations made in this study reflect the global abundance of the two species; great curassows $(n=79)$ were encountered twice as frequently as the crested guan $(n=40)$ over the field period, but the difference in observation numbers was much more pronounced for curassows. Are great curassows selectively hunted over crested guans? The result of this study would certainly support this hypothesis. Whereas no difference between sites was found for crested guans, great curassows were significantly more abundant in the nonhunted zone. Furthermore, crested guans were about $40 \%$ more abundant than curassow in the non-hunted area ( $n=31$ for great curassow and $n=44$ for crested guan), but some $400 \%$ more in the hunted area $(n=9$ for great curassow and $n=35$ for crested guan). This difference may be caused by these birds' behavioral responses to hunting; guans may be more difficult to encounter and hunt than curassows, or they may respond better to hunting pressure. Further investigation could be done on this subject. 
Because cracids generally have a low reproductive rate (2 eggs per year), long maturation period ( 3 years) and require relatively large breeding territories, they do not withstand hunting pressure very well (Cracid Specialist Group 2009). As the occasional feathers found in the houses of local inhabitants can attest, villagers of Las Marías hunt both species, but the harvest rate of both species is unknown. The results of this study, however, suggest that hunting has reduced the population of great curassow around the village; hunting regulations on this species could be advisable. Crested guans, on the other hand, appear to be harvested at a sustainable level. However, in the first two-kilometre segment around the village, the abundance of guans was very low $(\mathrm{n}=3 ; 0.05 \mathrm{obs} / \mathrm{km})$, suggesting it is heavily hunted near the village or affected by other human activities. In fact, the number of observations in this segment was the same as for the curassows, but at greater distance the guan abundance triples $(n=9 ; 0.15 \mathrm{obs} / \mathrm{km})$ whereas that of curassows remains the same. Curassows are larger than guans and provide a better return for the hunter, they are therefore pursued everywhere. Guans, on the other hand, may be considered a good prey near the village, but may not be pursued at greater distances.

\subsubsection{Primates}

Large primates are among the most important game animals in Latin America (Redford and Robinson 1991). According to annecdotal interviews with villagers, however, monkeys are not eaten in Las Marías; they were therefore not classified as game species in this study. Some villagers indicated that the resemblance of these animals to humans make 
them unappealing for human consumption, a sentiment shared by other Miskito groups (Helms 1971). Not long ago, however, spider monkeys were still consumed by villagers. Why the consumption of this animal became taboo remains in question. Some interesting beliefs also exist with regards to the black mantled howler monkey, which they often nickname "tio" (ie: "uncle"); it is believed that if an expectant father or mother looks at this monkey in the eyes, the baby will be born with a monkey face. Because monkeys are not hunted in the vicinity of the village, one would expect their abundance to be similar at both the hunted and non-hunted research sites. While this was true for the white-faced capuchin, the abundance of spider monkeys and howler monkeys was significantly higher in the nonhunted area.

The Central American spider monkey (Ateles geoffroyi) ranges from Mexico to Colombia, but the subspecies found in Honduras, A. geoffroyi vellerosus, is only found from Mexico to the Honduran Moskitia region (Cuarón et $\mathrm{al}^{\mathrm{a}}$. 2008); this subspecies is therefore at its southernmost range in the RPBR. Constant decline in its population, caused principally by habitat loss (ibid), has resulted in this subspecies being classified as critically endangered by the IUCN Red List (2009). In fact, the spider monkey is considered as the primate the most at risk of extinction in Mesoamerica (Garber et al. 2006); yet, it remains hunted in various parts of Honduras. Dunn (2004) reveals that the spider monkey is, along with the white-lipped peccary, the preferred meat for the Miskito of the upper Río Patuca. He adds that over a year, an impressive 71 spider monkeys were killed by 30 hunters in the communities of Kuhrpa and Tukrun. During field season in Las Marías, no spider monkeys were ever spotted in the vicinity of the village, and locals explained that this species had not been around the village for some time. Why then, have spider monkeys disappeared from 
around Las Marías? Spider monkeys have large home-range requirements, strongly associated with fruit availability (Chapman 1989), and because of their low natural population density and reproductive rates, they are considered highly vulnerable to habitat fragmentation (Ramos-Fernandez et al. 2003). While transects around Las Marías included secondary forests, especially within the first two kilometres around the village, $84 \%$ of the surveyed land around the village was primary forest. Forest habitat around the village may be naturally less suited for spider monkeys than the non-hunted area, with, for example, a lower abundance of particularly important fruiting tree species. Another possible explanation is that previous hunting has caused local extirpation of this monkey, and that its population has still not recovered. Currently, too little is known to understand the difference in abundance observed between the two sites, but the difference was striking as spider monkeys were the most abundant monkeys observed in the non-hunted area $(n=79 ; 0.6$ $\mathrm{obs} / \mathrm{km}$ ), but were completely absent from the hunted area. If hunting was the cause of local extirpation of this species, this study suggests that populations of this species do not rebound quickly. Sorensen and Fedigan (2000) support this hypothesis as they argue that spider monkeys may take up to 25 years to re-colonize areas subjected to overharvesting.

Contrarily to spider monkeys, the population of mantled howler monkeys as a whole is not under any conservation threat. This species is classified as Least Concern by the IUCN Red List (2009). Unlike spider monkeys, which are frugivores, howler monkeys have a much larger dietary breadth, which includes a high component of leaves, a resource much more available than mature fruits. In fact, their dietary diversity is often linked to their ability to adapt to a much wider range of environments than other primates, and include primary rainforest, dry deciduous forests, riparian and coastal habitats, regenerating 
rainforests (Fedigan et al. 1998), cloud forests (Wolfheim, 1983), shaded coffee plantations (Mccann et al. 2003), and even highly fragmented areas (Méndez-Carvajal 2005). Why then, if howler monkeys are not hunted and are able to adapt to a wide variety of habitats, were they markedly less abundant in the hunted area? This species was not encountered during observation hours in the hunted area, but 40 howler monkeys $(0.30 \mathrm{obs} / \mathrm{km})$ were seen in the non-hunted area during field period. This is not to say that $A$. paliatta were not present around the village; they were in fact seen and heard several times during the field season, but always outside observation hours.

While howler monkeys are consumed by many indigenous groups in Latin America, they are not consumed by the Miskitos of Nicaragua (Ojasti 1996) and the Miskitos in the Río Patuca region find them "inedible" (Dunn 2004). Villagers in Las Marías seemed to share this opinion. The difference in abundance observed for the mantled howler monkey, therefore, cannot be explained by harvesting of the species, but is rather likely related to differences in habitat not observed by this researcher. Howler monkeys are often associated with riparian areas (Stoner 1996; Fedigan et al. 1998). Since most agricultural land around the village is also along the Plátano River, it is possible that howler monkeys were pushed into suboptimal habitats, away from the river.

Although Cebus capucinus tends to prefer mature forest (Van-Hulle and Vaughan 2009), it adapts to a variety of habitats and is frequently found in agricultural landscapes (Schutt and Vaughan 1995; Williams and Vaughan 2001; Causado et al. 2008). Partly because of this, the white-faced capuchin is widespread throughout its range from Honduras to Ecuador, and is classified as Least Concern by the IUCN Red List (2009). It is occasionally killed by farmers to prevent damage to fruit crops (Reid 1997) and is even 
considered the "most destructive species" by the Guaymi of Costa Rica (Gonzales-Kirshner and Sainz de la Maza 1998:15). Although sometimes hunted for food, including by some Miskito hunters (Dunn 2004), it is not considered edible in Las Marías, where capuchins are not hunted, but some are occasionally kept as pets. A pet trade certainly exists in the country as this animal is very frequently seen in cages in touristic areas, including hotels and restaurants. However, no extraction of this species was recorded from Las Marías during the field season. The results of this study coincide with what was expected for non-game species that is somewhat tolerant of human habitat modification: the abundance of white-faced capuchin in the hunted area was not significantly different than in the non-hunted area.

In summary, we can conclude that the cultural zone of the RPBR is effective at protecting white-faced capuchins, and may help in protecting howler monkeys. Spider monkeys, however, seem to have disappeared from this area and appear restricted to the nucleus region of the biosphere, where they are abundant.

\subsubsection{Felids}

While the spotted cats may have been hunted for their fur in the Las Marías region before the Convention on International Trade in Endangered Species (CITES) imposed an international ban on these products in 1975 , they are sometimes killed when they are felt to threaten to villagers or their livestock. Although the existence of illegal poaching is a possibility, it has not been observed during the field period, and villagers do not believe such activity occurs around the village. Because felids are generally wary of humans, we 
expected these animals to be somewhat less abundant around the village than in the hunted area. While the abundance of jaguar (Panthera onca) and smaller felids (Leopardus spp.) such as the margay and jaguarundi were similar at both sites, the puma (Felix conconlor) and the ocelot (Leopardus pardalis) were more abundant at the non-hunted site.

The jaguar is the largest felid in the RPBR and the top predator in the region. Habitat destruction, fragmentation and persecution, especially by cattle ranchers, are the principal threats to this species (Silveira 2004). Although still found from Mexico to northern Argentina, the jaguar is restricted to about half of its original range (Sanderson et al. 2002) and is classified as Near Threatened by the IUCN Red List (2009). According to villagers, this species has not been spotted around the village for a long time and the majority of younger people have never seen one. As a result, this species was expected to be significantly less abundant in the hunted area, especially since subsistence hunters and large felids tend to compete for the same prey species (Jorgenson and Redford 1993). Although more observations of this species were made in the non-hunted area $(0.12 \mathrm{obs} / \mathrm{km})$ than in the hunted area $(0.6 \mathrm{obs} / \mathrm{km})$, the difference was not deemed statistically significant, suggesting that the jaguars have not been reduced in the vicinity of the village due to human activity. However, and concordant with the villagers' observations, no jaguar tracks were seen in the first two-kilometre segments around the village. This species may therefore selectively choose habitats away from human settlements, but is able to sustain viable populations in fairly close proximity, as long as it is not subjected to hunting pressure, habitat destruction, or a significant decrease of its food source. The high abundance of collared peccaries in the hunted area may be a factor affecting the presence of jaguars in this area. 
Pumas are much more adaptable than jaguars and have as a result a much larger distribution, ranging from the Yukon in Canada to southern Chile (Novack 2003; Caso et

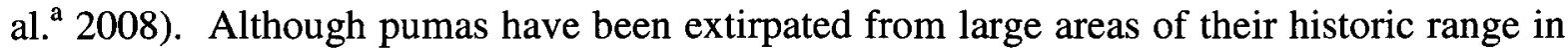
North America (Nowell and Jackson 1996), they are under no conservation threats and are classified as Least Concern by the IUCN Red List (2009). In the hunted area around Las Marías, few observations of pumas were made $(n=6)$, but half were within the first twokilometre segments around the village, suggesting this species may be less wary of human presence than the jaguar. Pumas may also be more attracted to livestock than jaguars: during the field period a villager lost a pig to a puma and was considering pursuing and killing this animal. Not only was the villager upset about the loss of his pig, but he was also very concerned for the safety of his young children. Although some pumas were found at relatively close range to the village, the abundance of this species in the hunted area $(0.03 \mathrm{obs} / \mathrm{km})$ was still about six times lower than those recorded in the non-hunted area $(\mathrm{n}=23 ; 0.17 \mathrm{obs} / \mathrm{km})$. Higher prey densities, lack of conflict with villagers, or simply better habitats are all factors that could explain its presence here.

Ocelots range from the southern United States to northern Argentina and can be found in evergreen and deciduous forests, second growth and agricultural land with ample cover (Reid 1997). This species is classified as Least Concern by IUCN Red List (2009). Although ocelots (Leopardus pardalis) tend to be the most abundant felids throughout their

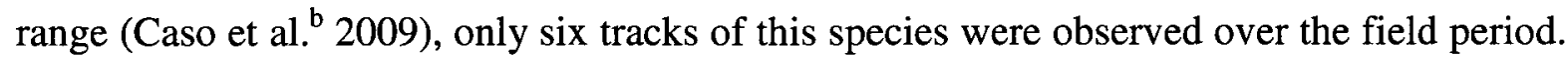
This species is considered difficult to study because of its secretive, solitary and nocturnal habits (Haines et al. 2006). Ocelots also tend to avoid new and established trails (Dillon and Kelly 2007), making track-based study for this species even more challenging, especially 
since the relatively small size of the animal makes its tracks less visible than other larger species. Apart from potential illegal trade of its fur, which does not appear to occur in Las Marías, villagers have no reason to kill this animal because it is not consumed and is not a threat to the villagers' livestock. The abundance of ocelots, however, was nonetheless significantly lower in the hunted area. While five tracks were encountered in the non-hunted area $(0.04 \mathrm{obs} / \mathrm{km})$, only one was encountered in the hunted area $(0.01 \mathrm{obs} / \mathrm{km})$. The difference in abundance could be explained by a depletion of some of its important prey species in the hunted area, such as agoutis (Aliaga-Rossel et al. 2006; Moreno et al. 2006); however, ocelots principally feed on smaller preys of less than 100 grams (Ludlow and Sunquist 1987; Abreu et al. 2008), which are not harvested by local hunters. The presence of dogs in the village is not likely an important factor as this would reduce the population of ocelots only at close proximity to the village and not in the whole hunted area. However, because of the rarity of tracks encountered in this study and the low power of analysis associated with such results, greater caution should be taken in interpreting these data. An intensive camera trapping study (e.g., Dillon and Kelly 2007) would provide better results on the abundance and distribution of this secretive animal.

The margay (Leopardus wiedii) and jaguarundi (Herpailurus yaguaoundi) were combined under the category "small felids" because of the resemblance of their tracks and the relatively low track encounter rate observed. However, the conservation issues for the two species are different as the margay is classified as Near Threatened and the jaguarundi as Least Concern by the IUCN Red List (2009). Neither species is pursued by hunters; hence, a similar abundance in the two areas was expected. Both cats prey predominantly on small animals not hunted by people. The mass of prey species for the jaguarundi averages 
380 grams (Caso et al. ${ }^{\mathrm{c}}$ 2008); it is less than 200 grams for the margay (Payan et al. 2008). The abundance of small felids in the hunted area was not significantly different than in the non-hunted area, indicating that subsistence hunting does not negatively affect the abundance of the smaller felids. However, the mere presence of humans and dogs, along with the ecosystem alterations caused by anthropogenic activities, may reduce the abundance of the smaller felids; in the farthest segments, observations of small felids $(n=5)$ were twice as great as in the first two-kilometre segments $(n=2)$ around the village.

\subsubsection{Anteaters}

Anteaters are not consumed by the Miskito and Pech of Las Marías. Since these animals feed almost exclusively on ants and termites, they are not affected by prey depletion from subsistence hunters. As a consequence, I expected both species to be similarly abundant in the hunted and non-hunted regions. However, great differences exist on the abundance, distribution and conservation status of these two species in Central America.

The northern tamandua (Tamandua mexicana) ranges from Mexico to Peru (Meritt et al. 2008), and can be found in mature and secondary rainforests, savannahs, and mangroves (Reid 1997). It is considered common throughout its range and classified as Least Concern by the IUCN Red List (2009). This species appears to have similar abundance in both areas $(0.02 \mathrm{obs} / \mathrm{km})$. We can therefore assume that hunting around the village has no negative effect on this species, and that the cultural zone of the biosphere reserve helps protect this species. 
The giant anteater (Myrmecophaga tridactyla) has a much larger distribution, from northern Central America to Argentina. While it is classified as Near Threatened throughout its range (IUCN Red List 2009), the giant anteater is very rare in Central America and is considered the most endangered mammal of this region (Reid 1997). It is extinct in Guatemala (Porini et al. 2008) and is believed to be extirpated throughout most of their Central American range (McCain 2001). Interestingly, the first live capture recorded in Honduras was captured around Las Marías in 1996, by a Miskito who wanted to sell it to the Asian market, but who released later because of the difficulties he encountered in feeding it (ibid). During the field period, one direct observation was made, and seven tracks were encountered; the relative abundance of giant anteaters in the non-hunted area was not significantly different than in the hunted area. The cultural zone of the biosphere, then, appears to help in protecting this rare species.

\subsection{Wildlife distribution in relation to distance from settlement}

As expected, and as witnessed in other studies (Alvard 1994; Alvard et al. 1997; Hill and Padwe 2000), wildlife observations were fewest within the first two kilometres around the village. While the total observations of game and non-game species numbered 210 in the first two-kilometre segments around the village, 318 observations were made in the $2-4$ $\mathrm{km}$ segments, and 331 in the $4-6 \mathrm{~km}$ segments, representing an increase of $51 \%$ and $58 \%$, respectively. Clearly, wildlife abundance around Las Marías is lower than at farther distances. Animal abundance, however, is not only determined by hunting. It is also be 
affected by habitat structure, soil fertility, and floristic composition (Haugaasen and Peres 2005), forest connectivity (ibid), and trail density (Goulart et al. 2009), all of which can be altered by indigenous land use. It is therefore difficult to ascertain whether or not the lower abundance of wildlife observed around the village is solely caused by hunting activities even though the majority of the transects length ( 84 percent) passed through primary forest, and even within the first 2-kilometer segments, less than $20 \%$ passed through gardens and fallows.

The distribution of game species as a group followed the same overall trend in large part because the total number of observation for game species $(n=795)$ was about twelve times that of non-game species $(n=64)$, and therefore strongly influenced the results for all species combined. The abundance of game species was lower around the village than at distances farther away. In the first two kilometres a total of 203 observations were made, while 279 were made in the $2-4 \mathrm{~km}$ segment, and 313 in the 4-6 km segment, representing an increase of $37 \%$ and $54 \%$ respectively. This trend was expected because the area around the village is considered to experience the greatest hunting pressure, especially when including opportunistic hunting, and the practice of awaiting game where they have been foraging in agricultural areas. Also, even when they visit the more distant hunting grounds, they usually need to pass through the closer areas on their way there and back, increasing their probability of encountering prey at closer distances. It is important to note, however, that, because of their prohibitive cost, not all villagers own a firearm but all villagers carry their machete and many bring their dogs on their way to work. The use of machetes as a tool for hunting, though, is more effective for small and medium-sized burrowing animals such as armadillos, pacas and agoutis. 
The principal agricultural areas around the village were not included in the transects but are an important source of game for the villagers of Las Marías and other indigenous groups. Smith (2005), for example, found that $47 \%$ of the game captured by the Bugle of Panama was captured in agricultural areas. Although garden game species such as the paca, agouti or armadillo frequently use agricultural fields as habitats, larger species feed in the fields use the neighboring forests as cover the rest of the time. The forested zone at close proximity to the village, may then act as a source for the heavily hunted agricultural lands. While this study did not systematically investigate these possibilities, the results highlight the importance of examining the spatial patterns of wildlife abundance, habitat modification, and hunting to develop more effective conservation management strategies for rain forest regions.

While game abundance was markedly lower near the village, the difference between the 2-4 km and 4-6 km segments was very narrow, with observations in the farthest segments being only four percent more abundant. A possible explanation for this observation is that at close range from the community, villagers hunt frequently but opportunistically while focusing on other activities. At farther distance, they go on specific day hunting expeditions which include the two farther zones presented here.

Only 64 observations of the nine non-game species were made in the three segments around the village. As a consequence, analyzing trends of abundance in relation to distance from the village is difficult. Further research is required to determine whether there are significant differences in the abundance of non-game species due to the indirect impacts of hunting or greater levels of habitat modification caused by shifting cultivation and other activities. 
All results were analyzed by segments to better envision the composition of species as a function of distance from the village (Table 4.9). The species that were more abundant in the closest segment around the village, were the agouti $(51 \%, n=43)$, the paca $(50 \%, n=6)$, the puma $(50 \%, \mathrm{n}=3)$, and the red brocket deer $(43 \%, \mathrm{n}=3)$. The relatively high presence of agouti, paca and red brocket deer in relation to the other segments was expected as these species are frequently associated with anthropogenic habitats (Linares 1976; Irvine 1987; Medelín and Equihua 1998; Naughton-Treves et al. 2003; Smith 2005; Dunn 2004). Smith (2003), for example, shows that these species are among the principal vertebrate crop pest for the Buglé farmers in western Panama and argues that agricultural areas created by shifting agriculture provide "highly suitable habitat" for many species (ibid: 521). However, in this study both the paca and the agouti were significantly less abundant in the hunted zone than in the non-hunted zone, suggesting that any benefits brought by enhanced habitat may be offset by hunting.

Because pumas are negatively affected by human density (Laundré et al. 2009) and habitat degradation (Paviolo et al. 2009), the abundance of this species in the hunted area was expected to be lowest near the village. However, three out of six puma tracks observed in the hunted area were recorded in the segment closest to the village. While too few numbers were observed for meaningful conclusions, the presence of pumas in close proximity to the village could be related to their frequent use of forest edges (Holmes and Laundré 2006), forest trails (Emmons et al. 1989) and even dirt roads (Goulart et al. 2009), possibly because it facilitates their capturing and killing of prey (Currier 1983; Emmons et al. 1989). The presence of pumas close to the village could also be related to the relatively 
high abundance of one of its principal prey species, the agouti (Novack 2003), or the presence of livestock that wander freely in and around the village.

Species that were significantly more abundant in the $2-4 \mathrm{~km}$ segment (Table 4.9 ) were the white-faced capuchin $(83 \% ; \mathrm{n}=24)$, the crested guan $(66 \% ; \mathrm{n}=23)$, and the armadillo $(43 \% ; n=69)$. All of these species encountered here are medium-sized animals generally associated with forested environments. The armadillo, however, is frequently associated with agricultural areas. Dunn (2004), for example found that more than seventy five percent of armadillos killed by the Miskito of the Río Patuca were encountered in agricultural areas. This species is also the second most important prey encountered in agricultural areas of the Buglé of Panama, after the paca (Smith 2003). The relatively low abundance of armadillos in the area close to the village $(n=32)$ in comparison to the farther segments $(n=69$ and $n=$ 58 for the 2-4 and 4-6 km segments, respectively) could therefore be caused by higher hunting pressure rather than by the species preference for forested habitats. The Pech and Miskito of Las Marías consider the armadillo to be an excellent food item and will almost always try to capture it when they have the opportunity.

The abundance of crested guan in the 2-4 km segment was about eight times greater than in the 0-2 km segment, and three times greater than in the 4-6 km segment. While the lower abundance of this species in the vicinity of the village can be explained by greater hunting pressure, its lower abundance is the farthest segment is surprising. The difference could be caused by differences in important habitat features such as differences in the availability of nesting sites or feeding trees. In the case of the white-faced capuchin, because it is not hunted around Las Marías, we can assume that the rarity of this monkey around the village is caused by habitat preferences. These monkeys, however, occasionally 
approach the village; a group was seen by this researcher outside observation hours near a banana plantation near the village, and villagers attest that this species occasionally damage their crop. White-faced capuchins may be killed occasionally by villagers who want to protect their crop. The greater abundance of white-faced capuchins in the $2-4 \mathrm{~km}$ segment as opposed to the $4-6 \mathrm{~km}$ segment could be due to habitat preferences.

The species most abundant in the farthest segment, were the tapir $(50 \%, \mathrm{n}=9)$, the coati $(49 \%, \mathrm{n}=74)$, the small felids $(45 \%, \mathrm{n}=5)$, and the collared peccary $(42 \%, \mathrm{n}=124)$. The white-lipped peccary, white-tailed deer and jaguar were found at the same abundance in the $2-4 \mathrm{~km}$ segment, and the giant anteater $(33 \%, \mathrm{n}=1)$ and great curassow $(33 \%, \mathrm{n}=3)$ had similar abundance in the three surveyed segments. The 4-6 km transect segments are characterized by a higher abundance of larger animals and preferred game (Table 5.1).

Table 5.1: Average body mass $(\mathrm{kg})$ of the game species and the distance segment in which they were most abundant around Las Marías.

\begin{tabular}{|l|c|c|c|}
\cline { 2 - 4 } \multicolumn{1}{c|}{} & \multicolumn{3}{c|}{ Distance from the village $(\mathrm{km})$} \\
\cline { 2 - 4 } \multicolumn{1}{c|}{} & $0-2$ & $2-4$ & $4-6$ \\
\hline Tapir & & & 240 \\
\hline White-lipped peccary & & 34 & 34 \\
\hline White-tailed deer & & 34 & 34 \\
\hline Red brocket deer & 22 & & \\
\hline Collared peccary & 8 & & \\
\hline Paca & & 5 & \\
\hline Armadillo & & & 5 \\
\hline Coati & 4 & & \\
\hline Agouti & 4 & 4 & 4 \\
\hline Great currassow & & 2 & \\
\hline Crested guan & & \\
\hline
\end{tabular}

*Average body mass measurements taken from Reid (1997) for all mammals, and from Stiles and Skutch (1989) for birds

Table 5.1 provides the average body mass for each species in the distance segment where it was most abundant. For example, the tapir was more abundant in the 4-6 km 
segments than in the other segments; its body mass was therefore used in this section to calculate the total average body mass index for that segment. While not without exceptions, the general trend is that average body mass tends to increase with distance away from the village. The most likely explanation for this is the depletion of the larger, highly preferred game animals that are also more vulnerable species because they have lower reproductive rates.

In view of the results obtained in this study, we can conclude that the Pech and Miskito hunt at greater intensity at close proximity from the village than at farther distances, a spatial hunting characteristic shared by several subsistence hunting groups (e.g., Stearman 1990; Vickers 1991; Stearman 1992; Townsend 1995; Alvard et al. 1997; Sirén et al. 2004; Dunn 2004; Smith 2008). Several studies have noted that subsistence hunters reduce the abundance of large bodied mammals and birds as they are frequently the preferred game species (Thiollay 1986; Peres 1990; Fitgibon et al. 1995; Peres 1999, Carrillo et al. 2000, Robinson and Bennet 2000; Peres 2001; Peres and Lake 2003). The relatively low abundance of large game species in the first few kilometres around Las Marías would certainly support this statement. This is also supported by the fact that all ungulates, apart from the collared peccary, were significantly less abundant in the non-hunted area.

5.3 Geographical distribution of wildlife in the hunted territory.

The participatory map-making process used for this study proved to be effective. As mentioned above, many people in the village were reluctant to openly talk about their 
hunting activities. Preparing a map of the hunting grounds, therefore, required working with people with whom there was mutual rapport, and who were willing and enthusiastic about the project.

All participants in the delimitation of the hunting zone had some familiarity with maps and had an excellent sense of orientation in the forest. While I relied heavily on the compass for direction in the forest, they always knew which direction to take to reach a point, even when they had to go around steep hills or cross rivers. Although this sense of orientation can be explained by their familiarity with the surroundings near Las Marías, they demonstrated the same skills in the unfamiliar areas of the nucleus zone. Although some villagers did not understand the metric system very well, all appear to have an innate sense of scale; reproducing life scale data on paper sheets was therefore not a major challenge for them. The person who had worked on a previous mapping project took the lead in the group. He knew how to read a topographic map and could, because of his excellent knowledge of the area, visualize the topographic elements present on the map. Therefore, he was able to explain to his colleagues what the map represented. Once the other participants understood the meaning of contour lines, hill-tops and rivers on the topographic maps, they were also able to pinpoint specific areas on the map.

This participatory exercise allowed a group of villagers to cooperate on a subject they knew well and produce something they all agreed upon. It is not to say that no challenges or disagreement between the participants were encountered during the process. One participant, for example, did not believe we should include agricultural lands in the hunting territory. But since he agreed that animals were still killed for food in these areas, we 
decided to include them anyway. Another wanted to incorporate territories used in multiday expeditions, but all agreed in the end to stick to the principal hunting grounds.

One important point that came out of this exercise was that the Pech and Miskito of Las Marías are fast learners who can quickly learn modern cartography. The participants appeared proud of their work and were happy to see on paper something they thought of as conceptual. The fact that one of the villagers was able to retain what he had learned for more than a decade and to transmit his knowledge to his peers demonstrates that once modern mapping techniques are learned they can be retained for a long time. More importantly, this participatory process showed that, when given the opportunity, the villagers can cooperate on subjects that touch their cultural identity and produce results that correspond to "their" reality. This exercise supported the argument that local people can combine their local knowledge with modern knowledge and take leading roles in wildlife management.

The delineation of the $107 \mathrm{~km}^{2}$ hunting zone presented here represents the principal hunting grounds of Las Marías that are used regularly by day-hunters. However, hunting is a dynamic and opportunistic activity; villagers will therefore follow an animal even if this means going outside these principal boundaries. Multi-day hunting activities occur occasionally and go beyond the boundaries provided here. According to villagers, these outings are becoming rarer and seem almost reserved to younger hunters who take this opportunity to discover the region and bond with their group. Since this study focuses on wildlife abundance, it is assumed that rare hunting trips would have little comparative effects on game population and were therefore not included in the map. Villagers more commonly go on multi-day fishing expeditions, during which time opportunistic hunting 
also occurs. Such trips may even happen within the nucleus zone, but none of the people I spoke with said that this occurs.

As Pech and Miskito are riverain peoples who use canoes as their principal mode of transportation, we expected the distribution of the principal hunting grounds of the village to be along the Plátano River rather than perpendicular to it. However, they are laid out in a north-south direction, perpendicular to the Plátano River. Due to the nature of hunting, which depends on factors such as prey availability, hunters' preferences, topography, and soil quality, I expected some form of irregularity in the shape of the hunting territory. The results, however, were surprising because the territory seemed to be separated into two distinct areas: a relatively small area on the north bank of the River and a large area on the southern bank. More surprisingly perhaps, was that the village was expected to be at the centre of the hunting lands and it was not. These results differ from those of other studies (e.g., Dunn 2004; Smith 2008) which seem to indicate that the geographical space occupied by hunting activities radiates away from the village. Apart from the opportunistic hunting done in agricultural fields, the activity of hunting is purposeful in the sense that people go to specific locations in search of their prey rather than hunt in random directions away from the village. Hunting in Las Marías is done on foot and people tend to walk in the direction of or along the principal secondary rivers, such as Batiltuk, when in search of game. The game animals they encounter are carried back to the village on their shoulders. The mass of the animal, therefore, can be a factor in prey selection. Some hunters, for example, have mentioned not having killed tapir far from the village because they could not carry it back home. Sometimes, hunters do a second trip to get the rest of their kill. Because hunting is a cost-opportunity activity, people concentrate their activities where they believe they have a 
greater opportunity to encounter game, and where they will spend less energy to do so. Hunting in valleys and along rivers seems to bring back the greatest return for hunters in Las Marías as they tend to concentrate their efforts in these areas. The hunting territory appears related to topography; much of the hunting territory is located in areas that are comparatively flat and easy to walk through. Villagers also attest that agricultural areas are where they most frequently kill game.

\subsection{Effectiveness of the Cultural Zone of the Biosphere Reserve at protecting biodiversity.}

For more than two decades, conservationists and cultural anthropologists have argued about whether or not local people, and in particular indigenous peoples, should be allowed to extract natural resources, including wildlife, from protected areas. Viewed through a different lens, this debate has been on whether lands inhabited by indigenous peoples are suitable as protected areas. Either way, the idea that indigenous people are inherent conservationists has been dismissed for some time now (Redford 1991). There are numerous examples demonstrating overharvesting by native peoples (Redford 1991; Robinson and Redford 1991; Alvard et al 1997; Bodmer et al 1997; Terborgh 1999; Bennet et al. 2000; Chicchón 2000; Redford and Sanderson 2000) and that "conservation by indigenous communities should be seen not as exceptional but rather as the rule" (Hunn et al. 2003: S99). Moreover, as Posey explains (cited in Ridley 1996: 217): "Any evidence of ecologically unsound activities by indigenous and traditional peoples undermines their basic 
rights to land, resources, and cultural practice." The refusal to accept that native peoples occasionally overharvest their resources, therefore, seems to be more politically oriented than based on unbiased observations. This is not to say that indigenous peoples have no ecological conscience. In fact, it is readily accepted that indigenous groups generally manage natural systems in a much more sustainable way than do people of European descent (Redford and Robinson 1987; Nietschmann 1992; Borgerhoff et al. 2005). This research simply acknowledges that sustainable management of natural resources by indigenous group is not a fait accompli.

Protected areas are a major point of contention between those who prioritize the preservation of cultural values and those who focus primarily on biodiversity conservation. While some conservationists advocate for the relocation of people outside protected areas (e.g., Terborgh 1999), some cultural anthropologist argue that the management of protected areas should give "equal emphasis to the cultural aspects of ecosystems" (Bridgewater 2002:9), and that "strict preservation could destroy biodiversity and the indigenous knowledge needed for ecosystem management" (Woods 1995:124).

In some ways, biosphere reserves have constructively fed the debate over the use of resources by indigenous people in protected areas by putting in place a worldwide system that incorporates the conservation of cultural values with the protection of biological and natural resources. The nucleus zones of the biospheres are areas of strict biological conservation, and the surrounding cultural and buffer zones are areas where human communities use natural resources in ecologically sustainable ways. Whether or not the cultural zone of the biosphere reserves are truly managed in a sustainable way is an important question. As Nations (2001: 1232) explains: “A biosphere reserve's core zone 
serves as a global benchmark of ecological health, setting the standard for comparison with the effects of human uses occurring elsewhere in the reserve". This study uses this "benchmark" to assess subsistence hunting in the cultural zone of the biosphere.

The results of this study indicate that the abundance of several species are reduced within the cultural zone of the biosphere reserve. Furthermore, the number of observations for all species together was $42 \%$ higher in the nucleus zone, and $60 \%$ of the species observed were significantly more abundant. This trend was even more pronounced for game species as $73 \%$ of those were significantly lower in the cultural zone. The fact that game abundance is significantly lowered by hunting within a particular area, however, does not necessarily translate into unsustainable hunting. While hunting undeniably reduces game populations, it does not necessarily lead to extirpation if the hunted area is surrounded by sufficiently large areas that do not experience hunting that allow, through a source-sink mechanism, the replenishment of the harvested area. According to the metapopulation theory, the diversity of habitat patches created by landscape heterogeneity can lead to source-sink dynamics when individuals from the same populations occupy habitat patches which produce different birth, death, immigration and emigration rates within the same landscape (Pulliam 1988). Better habitats produce better birth rates, creating emigration sources towards suboptimal areas (sinks), which would go extinct without the immigration from the source area (Pulliam 1988). Because hunting can create spatial differences in mortality, patches subjected to intense harvest can be considered as sink (Novaro et al. 2005). Therefore, what one should consider when intending to protect biodiversity is the global conservation status of the animals to be protected. Temporarily and locally overhunting a common and adaptable species may not affect its global population, but 
harvesting a rare or vulnerable species can seriously affect its long-term survival ability. Out of the twenty species selected for this study, seven were considered at risk in terms of conservation (ie: classified as near-threatened, endangered, or critically endangered by the IUCN Red List 2009; Table 5.2). Of those, three were game species and four are not.

All game species considered at risk, namely the Baird's tapir, the white-lipped peccary and the great curassow, were significantly less abundant in the hunted zone, suggesting they may be overhunted. Abundance was similar for three (ie: jaguar, margay and giant anteater) of the four non-game species considered at risk.

The only non-game species considered at risk significantly less abundant around the village was the Central American spider monkey, which is suspected to have been extirpated in the past because of hunting. 
Table 5.2: IUCN Classification for Game and Non-game Species and Hunting Level around the Village of Las Marías.

\begin{tabular}{|c|c|c|c|c|}
\hline & Common Name & Scientific Name & $\begin{array}{l}\text { Significantly } \\
\text { lower } \\
\text { abundance }\end{array}$ & $\begin{array}{l}\text { IUCN Red List } \\
\text { Category (2009) }\end{array}$ \\
\hline \multirow{11}{*}{ 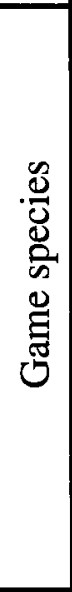 } & Baird's tapir & Tapirus bairdii & $\bar{x}$ & Endangered \\
\hline & Collared peccary & Tayassu tajacu & & Least Concern \\
\hline & White-lipped peccary & Tayassu pecari & $\mathrm{x}$ & Near Threatened \\
\hline & White-tailed deer & Odocoileus virginianus & $\mathrm{x}$ & Least Concern \\
\hline & Red brocket deer & Mazama Americana & $\mathrm{x}$ & Data Deficient \\
\hline & Nine-banded armadillo & Dasypus novemcinctus & $\mathrm{x}$ & Least Concern \\
\hline & White-nosed coati & Nasua narica & & Least Concern \\
\hline & Paca & Agouti paca & $\mathrm{x}$ & Least Concern \\
\hline & Agouti & Dasyprocta puntata & $\mathrm{x}$ & Least Concern \\
\hline & Great curassow & Crax rubra & $\mathrm{x}$ & Near Threatened \\
\hline & Crested guan & Penelope purpurascens & & Least Concern \\
\hline \multirow{10}{*}{ 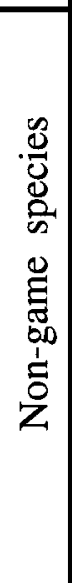 } & $\begin{array}{l}\text { Central American Spider } \\
\text { monkey }\end{array}$ & Ateles geoffroyi vellerosus & $\mathrm{x}$ & $\begin{array}{l}\text { Critically } \\
\text { Endangered }\end{array}$ \\
\hline & White-faced capuchin & Cebus capucinus & & Least Concern \\
\hline & Mantled howler monkey & Alouatta palliata & $\mathrm{x}$ & Least Concern \\
\hline & Jaguar & Pantera onca & & Near Threatened \\
\hline & Puma & Puma concolor & $\mathrm{x}$ & Least Concern \\
\hline & Ocelot & Leopardus pardalis & $\mathrm{x}$ & Least Concern \\
\hline & Margay* & Leopardus wiedii & & Near Threatened \\
\hline & Jaguarundi* & Herpailurus yaguaoundi & & Least Concern \\
\hline & Giant anteater & Myrmecophaga tridactyla & & Near Threatened \\
\hline & Northern tamandua & Tamandua mexicana & & Least Concern \\
\hline
\end{tabular}

* Since these two species were grouped into a single category called small felids their individual relative abundance cannot be assumed. However, no significant difference was found for the group "small felids".

Is wildlife sustainably harvested around Las Marías? The result of this study indicates that the majority of game species are significantly less abundant around the village. More importantly, the populations of species that are considered at risk nationally and internationally are also significantly reduced in the cultural zone of the reserve, putting extra weight on the global population of these species. While localized depletion of common species may not put entire populations at risk, harvest species at risk may seriously affect 
their long term survival. On a positive note, however, non-hunted species that are considered at risk, such as the margay, giant anteater and jaguar, had similar abundance in the two zones, indicating that the Pech and Miskito of Las Marías have managed to conserve the ecosystem these species require.

Hunting is a necessity for many of the villagers in Las Marías. While this activity may be important culturally, it is also a needed source of protein for an impoverished population. Honduras is the second-poorest country in Latin America (Central Intelligence Agency 2009), the Moskitia is the poorest region of the country, and Las Marías is one of the poorest villages in the Moskitia. Because of the remoteness of the area, basic necessities are more expensive than elsewhere. For example, gas, which is needed for transportation and the building of houses and canoes, costs twice as much than as in the rest of the country. Forest resources, therefore, are needed. This thesis recognizes this reality and in no way intends to judge hunting by Pech and Miskito on their territory. However, it illustrates, through an empirical process, that the abundance of some species are significantly reduced on their territory.

This study recommends that stakeholders work together to develop conservation measures for Baird's tapir, white-lipped peccaries and great curassow - which could include stopping the hunting of these species. All three are at risk throughout the region and are possibly overhunted around the village. The RPBR is an important source of conservation because it is part of the Mesoamerican wildlife, which essentially enables wildlife movement between the north and south of Central America. Fragmenting populations of species at risk can only have a serious impact on their overall populations. More research should be done on brocket deer outside the region in order to assess whether or not special 
conservation measures are needed for this species. But because it is found principally in primary broadleaf forests, which are limited in Honduras, It would be recommended that hunting this species be suspended until further studies are conducted. Collared peccary would be a good alternative prey to these four species for the hunters of Las Marías; the collared peccary is one of their preferred game species, has a high reproductive rate, is adaptable and common throughout the region, and is found at higher density around the village than in the nucleus zone. The white-tailed deer, paca, agouti and nine-banded armadillo are also less abundant in the hunted zone, but these species have a relatively high reproductive rate and are relatively common throughout Central America. Their overall population, therefore, does not seem at risk.

Is the cultural zone of the RPBR protecting biological diversity effectively? Apart from the four species mentioned above I would argue that yes, the cultural zone of the biosphere helps in protecting biological diversity. Overhunting may be happening for some species, but this is a problem that can be resolved in cooperation with the population of Las Marías. In general, villagers truly appreciate nature and are concerned about preserving it. Furthermore they are increasingly generating revenue from tourism and understand that wildlife is an important draw for visitors. Without empirical studies illustrating problems of overhunting for particular species, villagers may not be aware that it is occurring.

The region around Las Marías still hosts healthy ecosystems. Apart from the Central American Spider monkey, all species found in the nucleus zone were also present in the cultural zone. This area hosts six species considered at risk, including the giant anteater, the most endangered species of Central America. In addition, the region is home to more than 500 Pech and Miskito, who depend on the natural resources this area provides for survival. 
It can be concluded that the cultural zone around the village of Las Marias is an important area for wildlife conservation, but without occasional monitoring and control of harvesting, this region is at risk to lose a number of important elements of its biodiversity. 


\section{Chapter 6:}

\section{Conclusion}

\subsection{Conclusion and Summary}

Most protected areas in Latin America have been created on lands inhabited by indigenous people because these are where the last remaining tracks of biologically rich environments deemed suitable for conservation are found (Alcorn 1994; Herlihy 1997). However, the relationships between indigenous groups with their natural surroundings are changing and some of the factors that have helped indigenous groups in conserving wild resources have been eroding for many years (Redford 1992). The adoption of modern hunting technologies and more sedentary lifestyles, the increase in population and their greater demand for market goods may be affecting the ability of some indigenous people to conserve wildlife in the long-run (Robinson and Redford 1991). This thesis examines the abundance of wildlife in the Río Plátano Biosphere Reserve to investigate the effects of indigenous subsistence hunting on wildlife in a protected area.

The delineation of the principal hunting grounds shows that the villagers of Las Marías use $107 \mathrm{~km}^{2}$ of land around their settlement for subsistence livelihoods. Hunting also occurs beyond these boundaries, but at very low rates. Hunters tend to hunt inland and on foot, towards the deep forest rather than along the Plátano River, and direct their search mainly towards larger species. This research provides evidence that hunting by the Pech and Miskito villagers has reduced wildlife abundance around Las Marìas, particularly in the immediate vicinity of their settlement (within 2 kilometres), but also at farther distances. 
The abundance of game species examined here, for example, was sixty percent greater in the 4-6 kilometer distances than immediately around the village.

The comparison between the hunted and non-hunted areas shows that most game species are less abundant around indigenous settlements. Of the 11 game species studied, eight were significantly less abundant in the hunted area than in the non-hunted area, indicating that the area around the village provides less protection for these species than the nucleus zone. Also of concern is the fact that hunting includes species considered at risk, like the Baird's tapir, the white-lipped peccary and the great curassow. Furthermore, the quantitative findings, together with anecdotal evidence from villagers have led me to believe that hunting has extirpated the Central American spider monkey from around the village of Las Marías.

In conclusion, this thesis suggests that subsistence hunting can have a detrimental effect on the conservation of some wildlife populations within protected areas, although more research is needed to determine whether the lowered abundance of game species is a significant threat to their survival, or whether reduced populations may be stable over long periods of time. Parks and protected areas that allow hunting should not be considered equivalent to other protected areas in terms of conservation value because they do not offer the same level of protection. Rather than acting as wildlife sources for areas outside the park, they may act as sink for areas that are strictly protected.

In no way does this research intend to reduce the rights of indigenous people to hunt within their territories. After all, the current need to protect biological diversity was not caused by indigenous peoples' mismanagement of their environments, but rather by the environmental mismanagement and deforestation outside these areas. In fact, protected 
areas on indigenous lands remain of tremendous social, cultural and ecological importance. They are the ancestral homes of indigenous peoples, they provide them with much needed resources, including food, and they remain important habitats for many plant and animal species. The presence of the endangered giant anteater in this zone highlights the importance of these areas for wildlife conservation. Protected areas which permit subsistence activities, however, provide a lower level of protection to wildlife than fully protected areas.

\subsection{Key Recommendations}

This research showed that subsistence hunting can have a detrimental effect for the long-term conservation of wildlife in protected areas. However, this does not imply that hunting should be abolished in protected areas inhabited by indigenous peoples. Due to historic and cultural factors, indigenous communities are often found on the economic margins of society and are as a result dependent upon the natural resources offered by their environments. The right of indigenous peoples to use natural resources within their territory is therefore not contested. Furthermore, imposing resource use bans in indigenous territories on the premise that lands outside their territories were poorly managed is both unethical and paternalistic.

The key recommendations made in this thesis are addressed to conservation organizations and government agencies responsible for wildlife protection. Protected areas in Latin America are often subjected to different types of land use that range from total 
conservation to varying degrees and types of use, including agriculture, timber harvesting, human settlements, and hunting. Too often, however, all lands subjected to some form of protection are classified under the sole label of "protected areas." As is illustrated in this thesis, human activities can seriously reduce a park's ability to conserve biological resources for future generations. Including protected areas which allow for activities that are detrimental to the long-term conservation of wild resources, therefore, can grossly overestimate the area of land that is actually protecting wildlife. For example, only $2 \%$ of the Cerro Azul Meámbar National Park in Honduras is fully protected; the rest consists of fragmented landscapes subjected to various forms of land use including banana, coffee and pineapple plantations and cattle ranching among others. Yet, the whole area is usually presented as a protected area, misleading the public. Therefore, there is a need to increase the number of protected areas or improve the level of protection of current "protected areas" in order to effectively protect wildlife resources for future generations.

Important biological resources within the RPBR should be more frequently monitored. Over the three-month field season, no park authority from the federal forest agency was ever seen. Monitoring wildlife could be done at low cost using the same techniques used for this research. Furthermore it could be done with the help of the local inhabitants so as to provide employment, generate good will, and improve wildlife conservation awareness.

Comparative analysis of relative abundance suggested that eight game species were significantly lower in the cultural zone. However, based on the current conservation status and reproductive rate of each species, this research would recommend that three species the Baird's tapir, white-lipped peccary and the great curassow - should not be hunted until more is known on the populations of these species within the reserve. Too few observations 
of red brocket deer were made to allow making inferences. It is recommended that research on the population status of this species in the greater region should be done so as to better understand the effects of hunting on this species. The white-tailed deer, armadillo, paca, and agouti are also significantly less abundant in the hunted area, but since these species are not under any conservation threat at the broader scale and because they have relatively high reproductive rates, hunting is likely not a significant threat to their persistence in the region. The population of crested guan was found at similar abundance in both the hunted and nonhunted areas, suggesting that this species can withstand current extraction rates. Conversely, other game species, such as the collared peccary and white-nosed coati, were more abundant in the hunted zone. These species are not threatened over their range and have relatively high reproductive rates; they could therefore be hunted at greater rates in the cultural zone. It is believed that spider monkeys have disappeared from the village because of past hunting activities. Should this species re-colonize the hunted zone, it is recommended to protect this species from hunting.

\subsection{Future Research}

This thesis is part of a growing body of research on indigenous wildlife use in the neotropics. Its findings underline the importance of wildlife as source of food for traditional peoples, but demonstrate that subsistence hunting can have important implications for the long-term viability of wildlife around indigenous settlements. It shows that protected areas where subsistence hunting is practiced can have a lower value in terms of conservation, but 
can still provide important habitat, including for rare and endangered species; it also illustrates the importance of cultural zones in biosphere reserves for indigenous subsistence activities.

Understanding of the impacts of indigenous communities on wildlife populations in protected areas remains a difficult task. It remains too often assumed, on the basis that many indigenous groups have managed to maintain their territories in apparently good ecological conditions over innumerable generations, that indigenous groups are naturally inclined to wildlife conservation. More research is needed on this subject if we want to avoid or minimize conflicts and misunderstandings between conservationists, government agencies and indigenous peoples. The majority of the larger parks in Latin America are inhabited, yet we do not know how much of these protected lands are providing effective protection for vulnerable wildlife species. A clear framework of what defines a protected area for wildlife conservation should be developed with this in mind.

Understanding the spatial distribution of indigenous hunting is key to understanding the patterns of wildlife extraction on indigenous territories; yet, this subject has been greatly overlooked by the research community. While studies have started to define where people hunt around indigenous settlements, we still do not know what defines a good hunting territory and why hunters choose one area over another. It is unclear, for example, how topography, vegetation, or hydrology influence hunting. Answering these kinds of questions could help in better understanding the patterns of subsistence hunting, and their impacts on wildlife over time and from place to place.

This thesis only touches the surface of what needs to be understood to ensure longterm protection of wildlife in the RPBR and protect the cultural rights of the Pech and 
Miskito to subsistence activities in the cultural zone. Better knowledge of metapopulation dynamics, minimum viable population sizes, and source-sink dynamics applicable to the species of the RPBR would allow to better understanding the sustainability of subsistence hunting in the reserve. This thesis focused on wildlife abundance. Research on what and how much wildlife is extracted would help determine how sustainable current levels of extraction are, and to understand the needs and preferences of hunters. 


\section{$\underline{\text { References cited }}$}

Abreu, K.C., P. F. Moro-Rios, J.E. Silva-Pereira, J.M.D. Miranda, E.F. Jablonski, and F.C. Passos. 2008. Feeding habits of ocelot (Leopardus pardalis) in southern Brazil. Mammalian Biology (73): 407-411.

Alcorn, J.B. 1993. Indigenous peoples and conservation. Conservation Biology 7: 424-426.

Alcorn, J.B. 1994. Noble savage or noble state? Northern myths and southern realities in biodiversity conservation. Ethnoecologica, 2(3): 6-19.

Alencar, A.A., L.A. Solorzano, and D. Nepstad. 2004. Modeling forest understory fires in an eastern Amazonian landscape. Ecological Applications 14: 139-149.

Aliaga-Rossel, E., Moreno R. S., Kays R. W., and J. Giacalone. 2006. Ocelot (Leopardus pardalis) predation on agouti (Dasyprocta punctata). Biotropica 38(5): 691-694.

Alvard, M.S. 1993. A test of the "ecologically noble savage hypothesis": interspecific prey choices by neotropical hunters. Human Ecology 21: 355-387.

Alvard, M.S. 1994. Conservation by native people: prey choice in a depleted habitat. Human Nature 5: 127-154.

Alvard, M.S. 1995. Intraspecific prey choice by Amazonian hunters. Current Anthropology 36: 789-818.

Alvard, M.S. 2000. The impact of traditional subsistence hunting and trapping on prey populations: data from Wana horticuluralists of upland central Sulawesi, Indonesia. In Bennet, E.L., and J. G. Robinson (eds.). Hunting for Sustainability in Tropical Forests. Columbia University Press, New York. Pp. 214-232.

Alvard, M.S. and H. Kaplan. 1991. Procurement technology and prey mortality among indigenous neotropical hunters. In M. Stiner (ed.). Human Predators and Prey Mortality. Westview Press, Boulder, Colorado. Pp. 79-104.

Alvard, M.S., J. Robinson, K. Redford, and H. Kaplan. 1997. The sustainability of subsistence hunting in the Neotropics. Conservation Biology 11(4): 977-982.

Andresen, E. 2000. Ecological roles of mammals: The case of seed dispersal. In Entwistle, A., and N. Dunstone (eds.). Priorities for the Conservation of Mammalian Diversity: Has the Panda Had its Day? Cambridge University Press, Cambridge, UK. Pp. 11-25. 
Atkinson, I. 1989. Introduced animals and extinctions. In D. Western and M.C. Pearl (eds.). Conservation for the twenty first Century. Oxford University Press, Oxford. Pp. 54-69.

Ayres, J.M., C. Ayres. 1979. Aspectos da caça no alto rio Aripuana. Acta Amazonica 9: 287-298.

Ayres, J. M., D. M. Lima, E. Martins, and J.L.K. Barreiros. 1991. On the track of the road: Changes in subsistence hunting in a Brazilian Amazonian Village. In J. G. Robinson and K. H. Redford (eds.). Neotropical Wildlife Use in Conservation. University of Chicago Press, Chicago. Pp. 82-92.

Bailey, J.A. 1984. Principles of Wildlife Management. New York: John Wiley and Sons 373 pp.

Baksh, M. 1995. Changes in Machiguenga quality of life. In Sponsel, L. E. (ed.). Indigenous Peoples and the Future of Amazonia: An Ecological Anthropology of an Endangered World.Arizona Studies in Human Ecology, University of Arizona Press, Tuscon, Arizona. Pp. 187-205.

Balée W. 1992. People of the fallow: a historical ecology of foraging in lowland South America. In K. H. Redford, C. Padoch (eds.). Conservation of Neotropical Forests: Working from Traditional Resource Use.Columbia University Press, New York. Pp. 35-57.

Barrett C.B., K. Brandon, C Gibson, and H. Gjertsen. 2001. Conserving tropical biodiversity amid weak institutions. BioScience 51(6): 497-502.

Beck, H., A.Taber, M. Altrichter, A Keuroghlian and R. Reyna. 2008. Pecari tajacu. In IUCN 2009. IUCN Red List of Threatened Species. Version 2009.1. Retrieved August 21, 2009, from http://www.iucnredlist.org. [Internet Website].

Becker, E.F. 1991. A terrestrial furbearer estimator based on probability sampling. Journal of Wildlife Management 55: 730-737.

Bello, J., R. Reyna, and J. Schipper. 2008. Mazama temama. In IUCN 2009. IUCN Red List of Threatened Species. Version 2009.1. Retrieved on August 28, 2009, from http://www.iucnredlist.org. [Internet Website].

Benitez-Malvido, J.,and M. Martinez-Ramos. 2003. Impact of forest fragmentation on understory plant species richness in Amazonia. Conservation Biology 17: 389-400.

Bennett, E.L., A.J. Nyaoi and J. Sompud. 2000. Saving Borneo's bacon: the sustainability of hunting in Sarawak and Sabah. In J.G. Robinson and E.L. Bennett (eds.). Hunting for Sustainability in Tropical Forests. Columbia University Press, New York. Pp. 305324. 
Bennett, E.L., J.G. Robinson. 2000. Hunting for the Snark. In J.G. Robinson and E.L. Bennett (eds.). Hunting for Sustainability in Tropical Forests. Columbia University Press, New York. Pp. 1-9.

BirdLife International 2008a. Crax rubra. In IUCN 2009. IUCN Red List of Threatened Species. Version 2009.1. Retrieved on September 10, 2009, from http://www.iucnredlist.org. [Internet Website].

BirdLife International 2008b. Penelope purpurascens. In IUCN 2009. IUCN Red List of Threatened Species. Version 2009.1. Retrieved on September 10, 2009, from http://www.iucnredlist.org. [Internet Website].

Blake E.R. 1977. Manual of Neotropical Birds. University of Chicago Press, Chicago. 676 pp.

Bodmer, R.E. 1990. Responses of ungulates to seasonal inundations in the Amazon floodplain. Journal of Tropical Ecology 6:191-201.

Bodmer, R.E. 1991. Strategies of seed dispersal and seed predation in Amazonian Ungulates. Biotropica 23(3): 255-261.

Bodmer, R. E. 1994. Managing wildlife with local communities: The case of the Reserva Comunal Tamshiyacu-Tahuayo. In D. Western, M. Wright and S. Strum (eds.). Natural Connections. Island Press, Washington, DC. Pp. 113 -134.

Bodmer, R.E. 1995. Succeptibility of mammals to overhunting in Amazonia. In J. Bissonette and P. Kraussman (eds.). Integrating People and Wildlife for a Sustainable Future. Pp. 292-295.

Bodmer, R. E., Fang, T. G., Luis, L. and Gill, R. 1994. Managing wildlife to conserve Amazonian forests: Population biology and economic considerations of game hunting. Biological Conservation. 67: 29-35.

Bodmer, R.E., and L.K. Sowls. 1993. The collared peccary (Tayassu tajacu). In W. Oliver (ed.) Pigs, Peccaries and Hippos Action Plan: Status Survey and Conservation Action Plan. IUCN, Gland, Switzerland, pp. 7-13.

Bodmer, R.E., J.F. Eisenberg and K.H. Redford. 1997. Hunting and the likelihood of extinction of Amazonian mammals. Conservation Biology 11: 460-466.

Borgerhoff Mulder, M. and P. Coppolillo. 2005. Conservation: Linking Ecology, Economics and Culture. Princeton University Press. Princeton. 440 pp. 
Boyce, M.S. 1989. The Jackson Hole Elk Herd. Cambridge University Press, Cambridge, UK. 324 pp.

Brandon, K., and S.E. Anderson, (eds.). 1998. Parks in Peril: People, Politics and Protected Areas. Island Press, Washington, D.C. 532pp.

Bridgewater, P.B. 2002. Biosphere reserves: special places for people and nature. Environmental Science and Policy 5(1): 9-12.

Brooks, D.M. 2006. The utility of hotspot identification for forest management: cracids as bioindicators. Acta Zoologica Sinica 52: 199-201.

Brooks, D.M. and S.D. Strahl. 2000. Curassows, guans and chachalacas. Status, survey and conservation action plans for cracids 2000-2004. IUCN/SSC Cracid Specialist Group. IUCN, Gland, Switzerland and Cambridge UK.

Bruner, A.G., R.E. Gullison, R.E. Rice and G.A.B. da Fonseca. 2001. Effectiveness of Parks in Protecting Tropical Biodiversity. Science 291: 125-128.

Buckland, S.T., D.R. Anderson, K.P. Burnhamand J.L. Laake. 1993. Distance Sampling: Estimating Abundance of Biological Populations. Chapman and Hall. 446 pp.

Bush, M.B. 1996. Amazonian Conservation in a Changing World. Biological Conservation 76(3): 219-228.

Caro, T.M. 1999. Conservation monitoring: estimating mammal densities in woodland habitats. Animal Conservation 2:305-315.

Carrillo, E., J. C. Saenz and T.K. Fuller. 2002. Movements and activities of white-lipped peccaries in Corcovado National Park, Costa Rica. Biological Conservation 108: $317-$ 324.

Carrillo, E., G. Wong and A.D Cuarón. 2000. Monitoring mammal populations in Costa Rican protected areas under different hunting restrictions. Conservation Biology 14: $1580-1591$.

Caso, A., C. Lopez-Gonzalez, E. Payan, E. Eizirik, T. de Oliveira, R. Leite-Pitman, M. Kelly, C. Valderrama and M Lucherini ${ }^{\mathrm{a}}$. 2008. Puma concolor. In IUCN 2009. IUCN Red List of Threatened Species. Version 2009.1. Retrieved September 22, 2009, from http://www.iucnredlist.org. [Internet Website].

Caso, A., C. Lopez-Gonzalez, E. Payan, E. Eizirik, T. de Oliveira, R. Leite-Pitman, M. Kelly, C. Valderrama and M Lucherini ${ }^{\mathrm{b}}$. 2008. Leopardus pardalis. In IUCN 2009. IUCN Red List of Threatened Species. Version 2009.1 Retrieved September 22, 2009, from http://www.iucnredlist.org. [Internet Website]. 
Caso, A., C. Lopez-Gonzalez, E. Payan, E. Eizirik, T. de Oliveira, R. Leite-Pitman, M. Kelly, C. Valderrama ${ }^{c}$. 2008. Puma yagouaroundi. In IUCN 2009. IUCN Red List of Threatened Species. Version 2009.1. Retrieved September 22, 2009, from http://www.iucnredlist.org. [Internet Website].

Castellanos, A., C. Foerester, D.J. Lizcano, E. Naranjo, E Cruz-Aldan, I Lira-Torres, R. Samudio, S. Matola, J. Schipper, and J. Gonzalez-Maya. 2008. Retrieved September 18, 2009, from http://www.iucnredlist.org. [Internet Website].

Caughley, G. and A.R.E. Sinclair. 1994. Wildlife Ecology and Management. Blackwell Science, Cambridge, MA. 634 pp.

Causado, J., A.D. Cuarón, A. Shedden, E.Rodríguez-Luna, and P.C. de Grammont. 2008. Cebus capucinus. In IUCN 2009. IUCN Red List of Threatened Species. Version 2009.1. Retrieved September 19, 2009, from http://www.iucnredlist.org. [Internet Website].

Central Intelligence Agency 2009. The World Fact Book: Honduras. Retrieved March 7, 2010, from https://www.cia.gov/library/publications/the-world-factbook/geos/ho.html. [Internet Website].

Chalfoun AD, F.R. Thompson, M.J. Ratnaswamy. 2002. Nest predators and fragmentation: a review and meta-analysis. Conservation Biology 16:306-318.

Chapman C.A. 1989. Spider monkey sleeping sites: uses and availability. American Journal of Primatology 18: 53-60.

Chapman C.A., and L.J. Chapman. 1995. Survival without dispersers: seedling recruitment under parents. Conservation Biology 9: 675-678.

Chiarello, A.G. 2000. Density and population size of mammals in remnants of Brazilian Atlantic Forest. Conservation Biology 14: 1649-1657.

Chicchón, A. 2000. Conservation theory meets practice. Conservation Biology 14(5): 13681369

Cochran, D.M.Jr. 2005. The sustainability of Shifting Cultivation in Rain Forest Conservation: Participatory Mapping in the Cultural Geography of Native Peoples in the Río Plátano Biosphere Reserve, Honduras. Ph. D. Thesis. University of Kansas, Kansas. 
Cochrane, M.A., and W.F. Laurance. 2002. Fire as a large-scale edge effect in Amazonian forests. Journal of Tropical Ecology 18: 311-325.

Cochrane, M.A., D.L. Skole, E.A.T. Matricardi, C. Barber, and W. Chomentowski. 2002. Interaction and synergy between selective logging, forest fragmentation and fire disturbance in tropical forests: case study Mato Grosso, Brazil. CGCEO/RA03-02/w. Michigan State University, East Lansing, Michigan.

Colchester, M. 2000. Indigenous peoples and biodiversity conservation. Sector review for the Biodiversity Support Program, Washington, DC.

Colding, J. and C. Folke. 1997. The Relations among Threatened Species: Their Protection, and Taboos. Conservation Ecology. Retrieved on January 5, 2010, from http://www.consecol.org/vol1/iss1/art6. [Internet Website].

Constantino, P., L. Fortini, F. Kaxinawa, A. Kaxinawa, E. Kaxinawa, A. Kaxinawa, L. Kaxinawa, J. Kaxinawa, and J. Kaxinawa. 2008. Indigenous collaborative research for wildlife management in Amazonia: The case of the Kaxinawá, Acre, Brazil.

Biological Conservation 141: 2718-2729.

Cox, P.A. and T. Elmqvist. 1991. Indigenous control of tropical rainforest reserves: an alternative strategy for conservation. Ambio 20: 317-321.

Cracid Specialist Group. 2009. Why are they important? Retrieved on September 15, 2009, from http://www.cracids.org/why.php. [Internet Website].

Cuarón ${ }^{\text {a }}$, A.D., A. Morales, A. Shedden, E. Rodriguez-Luna, and P.C. de Grammont. 2008. Ateles geoffroyi. In IUCN 2009. IUCN Red List of Threatened Species. Version 2009.1. Retrieved on September 15, 2009, from http://www.cracids.org/why.php. [Internet Website]

Cuarón ${ }^{\text {b }}$ A.D., A. Shedden, E. Rodríguez-Luna, P.C. de Grammont, and A. Link. 2008. Alouatta palliata ssp. palliata. In: IUCN 2009. IUCN Red List of Threatened Species. Version 2009.1. ? Retrieved on September 15, 2009, from http://www.cracids.org/why.php. [Internet Website]

Cullen, L.J., R.E. Bodmer, and C. Valladares Pádua. 2000. Effects of hunting in habitat fragments of the Atlantic forests, Brazil. Biological conservation 95: 49-56.

Currier, M.J.P. 1983. Felis concolor. Mammalian Species 200: 1-7.

Cushman, S.A. 2006. Effects of habitat loss and fragmentation on Amphibians: A review and prospectus. Biological Conservation 128: 231-240. 
Da Silva, M.N.F., G.H. Shepard Jr., and D.W. Yu. 2005. Conservation implications of primate hunting practices among the Matsigenka of Manu National Park, Peru. Neotropical Primates 13: 31-36.

Daily, G.C., G. Ceballos, J. Pacheco, G. Suzan, and A. Sanchez-Azofeifa. 2003. Countryside biogeography of neotropical mammals: conservation opportunities in agricultural landscapes of Costa Rica. Conservation Biology 17: 1814-1826.

Davis, S.H., and A. Wali. 1993. Indigenous territories and tropical forest management In Latin America. Policy Research Working Paper. The World Bank, Washington DC.

Delfín-Alfonso, C., S. Gallina, and C.A. López-González. 2009. Evaluación del hábitat del venado cola blanca utilizando modelos espaciales y sus implicaciones para el manejo en el centro de Veracruz, México. Tropical Conservation Science Vol.2 (2):215-228.

_DeScola, P. 1986. La Nature Domestique. Symbolisme et Praxis dans l'écologie des Achuar. Reprinted in Cambridge University Press 1994 as in the Society of Nature. A Native Ecology in Amazonia. Cambridge University Press, Cambridge. 372pp.

Diamond, J.M. 1980. Patchy distributions of tropical birds. In M.E. Soulé and B.A. Wilcox (eds.). Conservation biology: An evolutionary-ecological perspective. Sinauer Associates, Sunderland, Massachusetts. Pp. 57-74.

Diamond, J., and T.J. Case. 1986. Overview: Introductions, extinctions, extirminations, and invasions. In J. Diamond and T.J. Case (eds.). Community Ecology. Harper and Row: New York. Pp. 65-79.

Dice, L.R. 1941. Methods for estimating populations of animals. Journal of Wildlife Management. 5: 398-407.

Dillon, A., and M.J. Kelly. 2007. Ocelot Leopardus pardalis in Belize: the impact of trap spacing and distance moved on density estimates. Oryx 41(4): 469-477.

Dirzo, R., and A. Miranda. 1991. Altered patterns of herbivory and diversity in the forest understory: a case study of the possible consequences of contemporary defautnation. In P.W. Price, P.W. Lewilnsolhn, G.W. Fernandes, and W.W. Benson (eds.). PlantAnimal Interactions: Evolutionary Ecology in Tropical and Temperate Regions. Wiley, New York. 635pp.

Duckworth, J.W. 1998. The difficulty of estimating population densities of nocturnal forest mammals from transect count of animals. Journal of zoology 246: 443-486.

Dunn, M. 2004. Re-Interpreting the Impacts of Indigenous Hunting: A Participatory Geographic Analysis of Miskito Wildlife Use in Eastern Honduras. Master's thesis, Carleton University, Ontario, Canada. 
Emmons, L.H. 1984. Geographic variation in densities and diversities of non-flying mammals in Amazonia. Biotropica 16: 210-222.

Emmons LH, Sherman P, Bolster D, Goldizen A, Terborgh J. 1989. Ocelot behavior in moonlight. In K.H Redford and J.F. Eisenberg (eds). Advances in Neotropical Mammalogy. Brill, Leiden. Pp 233-242

Engeman, R.M. and L. Allen. 2000. Overview of a passive tracking index for monitoring wild canids and associated species. Integrated Pest Management Reviews 5: 197-203.

Escamilla, A., M. Sanvicente, M. Sosa, and C. Galindo Leal. 2000. Habitat mosaic, wildlife availability, and hunting in the tropical forest of Calakmul, Mexico. Conservation Biology 14: 1592-1601.

Fedigan, L. M., L. M. Rose, and R. Morera Avila. 1998. Growth of Mantled Howler Groups in a Regenerating Costa Rican Dry Forest. International Journal of Primatology 19(3): 405-432.

FitzGibbon, C.D., H. Mogaka, and J.H. Fanshawe. 1995. Stubsistence hunting in ArabukoSokoke Forest, Kenya, and its effects on mammal populations. Conservation Biology 9: $1116-1126$.

FitzGibbon C.D., H. Mogaka, and J.H. Fanshawe. 2000. Threatened mammals, subsistence harvesting, and high human population densities: a recipe for disaster. In J.G. Robinson and E.L. Bennett (eds.). Hunting for Sustainability in Tropical Forests. Columbia University Press, New York. pp 154-67.

Foerster, C.R. and C. Vaughan. 2002. Home range, habitat use, and activity of Baird's tapir in Costa Rica. Biotropica 34: 423-437.

Food and Agriculture Organization. 1993. Forest Resources Assessment 1990: Tropical Countries. FAO, Forestry Paper 112, Rome, Italy.

Food and Agriculture Organization. 2005. The State of the World's Forest. Food and Agriculture Organization of the United Nations. Rome. $166 \mathrm{pp}$.

Fragoso, J.M. 1987. The habitat preference and social structures of tapirs. M.Sc. Thesis. University of Toronto, Ontario, Canada.

Fragoso, J.M. 1991. The effect of hunting on tapirs in Belize. In J.G. Robinson and K. H. Redford (eds.). Neotropical wildlife use and conservation. University of Chicago Press, Chicago, Illinois. Pp. 154-162.

Fragoso, J.M.V. 1998. Integrating Scientific and Indigenous Wildlife Management Approaches in Indigenous Areas: Status Evaluation and Management of Hunted 
Wildlife Population in the Rio das Mortes Xavante Reserve, Mato Grosso, Brazil. Report to World Wildlife Fund, Brazil.

Freese, C.H. and C.J. Saavedra. 1991. Prospects for wildlife management in Latin America and the Caribbean. In J.G. Robinson and K.H. Redford (eds.). Neotropical wildlife use and conservation. University of Chicago Press: Chicago, Illinois, USA. Pp. 430-444.

Freese, C.H., P,G. Heltne, N. Castro, and G. Whitesides. 1982. Patterns and determinants of monkey densities in Peru and Bolivia, with notes on distributions. International Journal of Primatology 3: 53-90.

Galetti, M. 2001. Indians within conservation units: Lessons from the Atlantic forest. Conservation Biology 15: 798-799

Gallina, S., and H. Lopez Arevalo. 2008. Odocoileus virginianus. In IUCN 2009. IUCN Red List of Threatened Species. Version 2009.1. Retrieved on August 28, 2009, from http://www.iucnredlist.org. [Internet Website].

Garber P.A., A. Estrada, M.S.M. Pavelka. 2006. New perspective in the study of Mesoamerican Primates: concluding comments and conservation priorities. In Estrada A., P.A. Garber, M.S.M. Pavelka, and M. Luecke (eds.). New perspective in the study of Mesoamerican primates: distribution, ecology, behaviour and conservation. New York: Springer. Pp. 563-584.

Gascon, C., B.G. Williamson, G.AB. da Fonseca. 2000. Receding forest edges and vanishing reserves. Science 288: 1356-1358.

Glanz, W. E. 1991. Mammalian densities at protected versus hunted sites in central Panama. In J.G. Robinson, and K.H. Redford (eds). Neotropical Wildlife Use and Conservation. Chicago University Press, Chicago. Pp. 163-173.

Gonzales-Kirshner, J. P., and M. Sainz de la Maza. 1998. Primates hunting by Guayami Amerindians in Costa Rica. Human Evolution 13(1): 15-19.

Gonzalez, S., and J.M. Duarte. 2007. Non invasive methods for genetic analysis applied to ecological and behavioral studies in Latino-America. Revista Brasileira de Zootecnía 36: $89-92$.

Goulart F.V.B., N.C. Cáceres, M.E. Graipel, M.A. Tortato, I.R Ghizoni, L.G.R. OliveiraSantos. 2009. Habitat selection by large mammals in a southern Brazilian Atlantic forest. Mammalian Biology 74(3): 182-190.

Haines, A. M., J.E. Janecka, M.E. Tewes, L.I. Grassman, and P. Morton. 2006. The importance of private lands for ocelot Leopardus pardalis conservation in the United States. Oryx 40(1): 1-5. 
Hames, R. 1979. A comparison of the efficiencies of the shotgun and the bow in Neotropical forest hunting. Human Ecology 7: 219-252.

Hames, R. 1980. Game depletion and hunting zone rotation among the Ye'kwana and Yanomano Indians of Amazonian Venezuela. In R. Hames and K.M. Kessinger (eds.). Working Papers on South American Indians. Bennington, Vermont. Pp. 24-62.

Hames, R.B. and W.T. Vickers. 1982. Optimal diet breadth theory as a model to explain variability in Amazonian hunting. American Ethnologist 9: 358-378.

Harmon, D. 1998. The other extinction crisis: declining cultural diversity and its implications for protected area management. In N.W.P. Munro and J.H.M. Willison (eds.). Linking protected areas with working landscapes, conserving biodiversity. Science and Management of Protected Areas Association, Wolfville, Nova Scotia. Pp. 352-359.

Hart, J.A. 2000. Impact and sustainability of indigenous hunting in the Ituri forest, CongoZaire: a comparison of unhunted and hunted duiker populations. In J.G. Robinson and E.L. Bennett (eds.). Hunting for Sustainability in Tropical Forests. Columbia University Press, New York. Pp.106-153.

Haugaasen, T., and C.A. Peres. 2005. Mammal assemblage structure in Amazonian flooded and unflooded forests. Journal of Tropical Ecology 21: 133-145.

Helms, M.W. 1971. Asang: Adaptations to Culture Contact in a Miskito Community. University of Florida Press, Gainesville. 268pp.

Hennemann, W.W. 1983. Relationship among body mass, metabolic rate and the intrinsic rate of natural increase in mammals. Oecologia 56: 104-108.

Herlihy, P.H. 1997. Indigenous Peoples and Biosphere Reserve Conservation in the Mosquitia Rain Forest Corridor, Honduras. In S. F. Stevens (ed.). Conservation Through Cultural Survival. Island Press, Washington D.C. Pp. 99-129.

Herlihy, P.H. 1999. Participatory Research Zoning of the Río Plátano Biosphere Reserve in the Honduran Moskitia. In Gesellschaft für Agrarprojekte (ed.). Natural Resource Management Between Poverty Alleviation and Nature Conservation: Experiences from Development Projects in Asia, Latin America and Africa. Wissenschaftsverlag Vauk Kiel KG: Hamburg, Germany. Pp. 225-243.

Herlihy, P.H. 2001. Indigenous and Ladino Peoples of the Río Plátano Biosphere Reserve, Honduras. In S.C. Stronich (ed.). Endangered Peoples of Latin America: Struggles to Survive and Thrive. Greenwood Press, Westport, Connecticut. Pp.100-120.

Herlihy, P.H. 2003. Participatory Research Mapping of Indigenous Lands in Darién, Panama. Human Organization 62 (4): 315-331. 
Herlihy, P.H. and G. Knapp. 2003. Maps of, by, and for the Peoples of Latin America. Human Organization 62(4): 303-314.

Herlihy, P.H., and A.P. Leake. 1997. Participatory Research Mapping of Indigenous Lands in the Honduran Moskitia. In A.R. Pebley and L. Rosero-bixby (eds.). Demographic Diversity and Change in the Central American Isthmus. Rand books, Santa Monica, California. Pp. 707-736.

Herrera-MacBryde, O. 1995. North-east Honduras and Río Plátano Biosphere Reserve. Department of Botany, Smithsonian Institution, Washington, D.C. Retrieved September 28, 2007, from http://botany.si.edu/projects/cpd/ma/ma15.htm. [Internet Website].

Herrenás-Diego, Y., M. Quesada, K.E. Stoner, J.A. Lobo, Y Hernandez-Flores, and G.S. Montoya. 2008. Effects of forest fragmentation on fruit and seed predation of the tropical dry forest tree Ceiba aesculifolia. Biological Conservation 141: 241-248.

Hill, K., and K. Hawkes. 1983. Neotropical hunting among the Aché of eastern Paraguay. In R. Hames and W. Vickers (eds.). Adaptive Responses of Native Amazonians. Academic Press, New York. Pp. 139-188.

Hill, K., G. McMillan, and R. Fariña. 2003. Hunting-related changes in game encounter rates from 1994 to 2001 in the Mbacarayu reserve, Paraguay. Conservation Biology 17(5): 1312-1323.

Hill, K. and J. Padwe. 2000. Sustainability of Aché hunting in the Mbaracayu reserve, Paraguay. In J.G. Robinson and E.L. Bennet (eds.). Hunting for Sustainability in Tropical Forests. Columbia University Press, New York. Pp 79-105.

Holdridge, L.R. 1967. Life Zone Ecology. Tropical Science Center, San José, Costa Rica. $206 \mathrm{pp}$.

Holmes, B.R., and J.W. Laundré. 2006. Use of open, edge and forest areas by pumas Puma concolor in winter: are pumas foraging optimally? Wildlife Biology 12(2): 201-209.

House, P., and T.M. Mejía. 2002. Mapa de Ecosistemas Vegetales de Honduras: Manual de Consulta. P.A.A.R: Tegucigalpa, Honduras.

Hunn, E. S., Johnson, D., Russell, P., and Thornton, T. F. (2003). Huna Tlingit Traditional Environmental Knowledge, Conservation, and the Management of a "Wilderness" Park. Current Anthropology 44: S79-S103.

Hurtado-Gonzales, J.L., and R.E. Bodmer. 2004. Assessing the sustainability of brocket deer hunting in the Tamshyiacu-Tahuayo Comunal Reserve, northeastern Peru. Biological Conservation 116: 1-7. 
International Union for Conservation of Nature and Natural Resources (IUCN). 2009. 2009 IUCN Red List of Threatened Species. IUCN Species Survival Commission, Gland, Switzerland. Retrieved on September 25, 2009, from http://www.iucnredlist.org. [Internet Website]

Irvine, D. 1987. Resource management by the Runa indians of the Ecuadorian Amazon. Ph.D. dissertation, Department of Anthropology, Stanford University.

Janson, C.H., J. Terborgh, and L.H. Emmons. 1981. Non-flying mammals as polllinating agents in the Amazonian rainforest. Reproductive Botany 14: 1-16.

Janzen, D.H. 1974. Tropical blackwater rivers, animals and mast fruiting by the Dipterocarpaceae. Biotropica 6: 69-103.

Jerozolimski, A., Peres, C.A. 2003. Bringing home the biggest bacon: a cross-site analysis of the structure of hunter-kill profiles in Neotropical forests. Biological Conservation 111: 415-425.

Jorgenson, J.P. 2000. Wildlife conservation and game harvest by Maya hunters in Quintana Roo, Mexico. In Robinson, J.G. and E.L. Bennett (eds.). Hunting for sustainability in tropical forests. Columbia University Press: New York. Pp. 251-266.

Jorgenson, J.P. and Redford, K.H. 1993. Humans and big cats as predators in the neotropics. In N. Dunstone and M.L. Gorman (eds.). Mammals as predators. Oxford Science Publications, London. 485pp.

Joshi, N.V. and M. Gadgil. 1991. On the role of refugia in promoting the prudent use of biological resources. Theoretical Population Biology. 40: 211-229.

Julia, J.P., and E. Richard. 1999. Estado de conservación de las corzuelas (Mazama spp.) en el noreste argentino. In Fang, T., O. Montenegro, and R. Bodmer (eds.). 1999. Manejo y Conservación de Fauna Silvestre en America Latina. La Paz, Bolivia. Pp. 447-552.

Kaplan, H. and K. Kopischke. 1992. Resource use, traditional technology, and change among native peoples of lowland South America. In Redford, K.H., and C. Padoch (eds.). Conservation of Neotropical Forests: Working from Traditional Resource Use, Columbia University Press, New York. Pp. 83-107.

Karr, J.R. 1982. Avian extinction on Barro Colorado Island, Panama: A reassessment. American Naturalist 119: 20-39.

Kemf, E. 1993. In search of a home: people living in or near protected areas. In E. Kemf, (ed.). Indigenous peoples and protected areas. The law of Mother Earth. Earthscan: London. Pp. 3-11. 
Keuroghlian, A., P.D. Eaton, and W.S. Longland. 2004. Area use by white-lipped and collared peccaries (Tayassu pecari and Tayassu tacaju) in tropical forest fragment. Biological Conservation 120: 415-429.

Koster, J. 2008a. The impact of hunting with dogs on wildlife harvests in the Bosawas Reserve, Nicaragua. Environmental Conservation 35(3): 211-220.

Koster, J.M. 2008b. Kills of giant anteaters (Myrmecophaga tridactyla) by hunters with dogs in the Bosawas Biosphere Reserve, Nicaragua. The Southwestern Naturalist 53: $414-416$.

Laundré, J.W., J.L. Salazar, L. Hernández, D. Nuñez López, and U Breitenmoser. 2009. Evaluating Potential Factors Affecting Puma Puma concolor Abundance in the Mexican Chihuahuan Desert. Wildlife Biology 15(2):207-212.

Laurance, W.F. 1990. Comparative responses of five arboreal marsupials to tropical forest fragmentation. Journal of Mammalogy 71: 641-653.

Laurance, W.F. 1991. Ecological correlates of extinction proneness in Australian tropical rain forest mammals. Conservation Biology 5: 7989.

Laurance, W. F., J. Rankin-de Merona, A.C.S. Andrade, S.G. Laurance, S.A. D'Angelo, T.E. Lovejoy, and H. Vasconcelos. 2003. Rain forest fragmentation and the phenology of Amazonian tree communities. Journal of Tropical Ecology 19: 343-347.

Lee, R.J. 2000. Impact of subsistence hunting in North Sulawesi, Indonesia, and conservation options. In J.G. Robinson and E.L. Bennett Hunting for Sustainability in Tropical Forests (eds.). Columbia University Press, NewYork. Pp. 375-394.

Leeuwemberg, F.J., and J.G. Robinson. 2000. Traditional management of hunting by a Xavante community in central Brazil: the search for sustainability. In Bennet, E.L., and J.G. Robinson (eds). 2000. Hunting for Sustainability in Tropical Forests. New York: Columbia University Press. Pp. 375-394.

Leeuwenberg, F.J. 1997. Edentata as a food resource: Subsistence hunting by Xavante Indians, Brazil. Edentata (3): 4-5.

Leni, R., 1999. Aprovechamiento de la fauna silvestre en una comunidad de agricultores: Los guaranies de Akae. Santa Cruz. Bolivia. In In Fang, T., O. Montenegro, and R. Bodmer (eds.). 1999. Manejo y Conservación de Fauna Silvestre en America Latina. La Paz, Bolivia. Pp. 147-157.

Linares, O. 1976. Garden hunting in the American tropics. Human Ecology 4: 331-49.

Linares, O.F. 1984. Book review: Peoples and resources in the tropics. Adaptive responses of native Amazonians, by R.B. Hamer and W.T. Vickers. Science 226(4677): 962-964. 
Lira-Torres, I., E.J. Naranjo-Piñera, D.M. Güiris-Andrade, and E.Cruz Aldán. 2004. Ecología de Tapirus bairdii (perissodactyla: tapiridae) en la Reserva de la Biosfera El Triunfo (Polígono I), Chiapas, México. Acta Zoologica Mexicana 20: 1-21.

Lizcano, D.J. and J. Cavelier. 2000. Densidad poblacional y disponibilidad de hábitat de la danta de montaña (Tapirus pinchaque) en los Andes Centrales de Colombia. Biotropica 32(1): 165-173.

Lopes, M.A. And S.F. Ferrari. 2000. Effects of human colonization on the abundance and diversity of mammals in eastern Brazilian Amazonia. Conservation. Biology 14: 16581665.

Ludlow, M.E and M.E. Sunquist. 1987. Ecology and Behaviour of Ocelot in Venezuela. National Geographic Research 3(4): 447-461.

MacArthur R.H, E.R Pianka. 1966. On the optimal use of a patchy environment. American Naturalist 100 (916): 603-609.

Mace, G.M and J.D. Reynolds. 2001. Exploitation as a conservation issue. In J.D. Reynolds, G.M. Mace, K.H. Redford, and J.G. Robinson (eds.). Conservation of Exploited Species. Cambridge University Press, Cambridge. Pp 4-15.

Mainka, S.A. 2002. Biodiversity, poverty and hunger: where do they meet? In Mainka, S.A., and M. Trivedi (eds.). Links Between Biodiversity Conservation Likelihoods and Food Security: The Sustainable Use of Wild Species for Meat. IUCN, Gland, Swittzerland and Cambridge UK. Pp 11-19.

Mandujano, S. 2005. Track count calibration to estimate density of white-tailed deer (Odocoileus virginianus) in Mexican dry tropical forest. The Southwestern Naturalist 50(2): 223-229.

Marchak, P.M. 1995. Logging the Globe. Montreal, QC: McGill-Queen's University Press. Pp. 404.

Marten, G.C. 1972. Censusing mouse populations by means of tracking. Ecology 53: 859867.

Martínez-Kú, D.H. 2007. Importancia de las aguadas para los mamíferos de talla mediana y grande en Calakmul, Campeche, México. Tesis de licenciatura. Facultad de Ciencias Químico Biológicas. Universidad Autónoma de Campeche, Campeche, México.

Matsuda, I., and K. Izawa. 2008. Predation of wild spider monkeys at La Macarena, Colombia. Primates 49: 65-68.

McCain, C.M. 2001. First evidence of giant anteaters (Myrmecophaga tridactyla) in Honduras. Southwestern Naturalist 46: 252-254. 
Mccann, C., K. Williams-guillén, F. Koontz, A.A. Roque-Espinoza, J.C. Martínez-Sánchez, and C. Koontz. 2003. Shade coffee plantations as wildlife refuge for mantled howler monkeys (alouatta palliata) in Nicaragua. In L. Marsh (ed.). Primates in Fragments. Kluwer Academic/Plenum Publishers, New York. Pp. 321-341.

McDonald, D. R. 1977. Food Taboos: A Primitive Environmental Protection Agency (South America). Anthropos 72(516): 734-748.

McSweeney, K. 2004. The dugout canoe trade in Central America's Mosquitia: Approaching rural livelihoods through systems of exchange. Annals of the Association of Geographers 94(3): 638-661.

McKinney, M.L., 1997. Extinction vulnerability and selectivity: combining ecological and paleontological views. Annual Review of Ecology and Systematics 28, 495-516.

Medellín, R. A. and M. Equihua. 1998. Mammal species richness and habitat use in rainforest and abandoned agricultural fields in Chiapas, Mexico. Conservation Biology 35: 13-23.

Mena, P., J.R. Stallings, J. Regalado, and L. Cueva. 2000. The sustainability of current hunting practices by the Huaorani. In E.L. Bennet and J.G. Robinson (eds.). Hunting for sustainability in Tropical Forests. Columbia University Press, New York. Pp. 5778.

Méndez-Carvajal, P.J. 2005. Population Survey of the Azuero Howler Monkey (Alouatta palliata trabeata) in Herrera Province, Republic of Panama. Neotropical Primates 13(3): 1-6.

Meritt, D., R. Samudio, and Members of the IUCN SSC Edentate Specialist Group 2008. Tamandua mexicana. In IUCN 2009. IUCN Red List of Threatened Species. Version 2009.1. Retrieved September 26, 2009, from http://www.iucnredlist.org. [Internert Website]

Milner-Gulland, E.J., and E.L. Bennett. 2003. The SCB 2002 Annual Meeting Wild Meat Group. Wild meat: the bigger picture. Trends in Ecology and Evolution 18: 351-357.

Mittermeier, R.A. 1991. Hunting and its effect on wild primate populations in Suriname. In Robinson, J.G., and K.H. Redford (eds.). Neotropical Wildlife Use and Conservation. University of Chicago Press, Chicago, Illinois. Pp. 93-107.

Mooty, J.J., P.D. Karns, and D.M. Heisey. 1984. The relationship between white-tailed deer track counts and pellet-group surveys. Journal of Wildlife Management. 48: 275-279. 
Moreno, R.S., R.W. Kays, and R. Samudio. 2006. Competitive release in diets of ocelot (Leopardus pardalis) and puma (Puma concolor) after jaguar (Panthera onca) decline. Journal of Mammalogy 87(4): 808-816.

Murcia, C. 1995. Edge effects in fragmented forests: implications for conservation. Trends in Ecology and Evolution 10: 58-62.

Myers, N. 1988. Tropical forests and their species: Going, going...? In E.O. Wilson and F.M. Peter (ed.). Biodiversity. National Academy Press: Washington, DC. Pp. 28-35.

Naranjo, P. E. 1995. Hábitos de alimentación del tapir (Tapirus bairdii) en un Bosque tropical húmedo de costa Rica. Vida Silvestre Neotrop 4:32-37

Naranjo, E.J. 2009. Ecology and Conservation of Baird's tapir in Mexico. Tropical Conservation Science 2(2): 140-158.

Naranjo, EJ and R.E. Bodmer. 2007. Source-sink systems and conservation of hunted ungulates in the Lacandon Forest, Mexico. Biological Conservation 138: 412-420.

Naranjo, E.J. and J.E. Bolanos, and M.M. Guerra, and R.E. Bodmer. 2004. Hunting sustainability of ungulate populations in the Lacandon forest Mexico. In Silvius, K.M. and R.E. Bodmer, and J.M.V. and Fragoso (eds.). People in Nature: wildlife conservation in South and Central America. Columbia University Press, New York. Pp. 324-343.

Nations, J.D. 2004. Biosphere Reserves. International Encyclopedia of the Social \& Behavioral Sciences. Pp 1231-1235.

Naranjo, E.J., R.E. Bodmer. 2007. Source-sink systems and conservation of hunted ungulates in the Lancadon Forest, Mexico. Biological Conservation 138: 412-420.

Naughton-Treves, L. 2002. Wild animals in the garden: conserving wildlife in Amazonian agroecosystems. Annals of the Association of American Geographers 92(3): 488-506.

Naughton-Treves L., J.L. Mena, A. Treves, N. Alvarez N., and V. C. Radeloff. 2003. Wildlife Survival Beyond Park Boundaries: the Impact of Slash-and-Burn Agriculture and Hunting on Mammals in Tambopata, Peru. Conservation Biology 17(4): 11061117.

Nepstad, D., S. Schwartzman, B. Bamberger, M. Santilli, D. Ray, P. Schlesinger, P. Lefebvre, A. Alencar, E. Prinz, G. Fiske, and A. Rolla. 2006. Inhibition of Amazon deforestation and fire by parks and indigenous lands. Conservation Biology 20: 65-73.

Nietschmann, B. 1972. Hunting and Fishing Focus Among the Miskito Indians, Eastern Nicaragua. Human Ecology 1(1): 41-67. 
Nietschmann, B. 1973. Between Land and Water. Seminar Press, New York. 279 pp.

Nietschmann, B. 1992. The Interdependence of Biological and Cultural Diversity. Occasional paper \#21. Center for Indigenous Studies. Olympia, WA.

Novack, A. 2003. Impacts of subsistence hunting on the foraging ecology of jaguar and puma in the Maya Biosphere Reserve, Guatemala. M.Sc. Thesis. University of Florida.

Novack, A.J., M.B. Main, M.E. Sunquist, and R.F. Labisky. 2005. Foraging ecology of jaguar (Panthera onca) and puma (Puma concolor) in hunted and non-hunted sites within the Maya Biosphere Reserve, Guatemala. Journal of Zoology. 267: 167-178.

Novaro, A.J., K.H. Redford, and R.E. Bodmer. 2000. Effect of hunting in source-sink systems in the Neotropics. Conservation. Biology.14: $713-721$.

Novaro A.J, Funes M.C., and Walter R.S. 2005. An empirical test of source-sink dynamics induced by hunting. Journal of Applied Ecology 42: 910-920.

Nowell, K., and P. Jackson (eds.). 1996. Wilds Cats Status Survey and Conservation. IUCN: Switzerland. 279pp.

Ohl-Schacherer, J., G.H. Shepard Jr., H. Kaplan, C.A. Peres, T. Levi, and D.W. Yu. 2007. The sustainability of subsistence hunting by Matsigenka native communities in Manu National Park, Peru. Conservation Biology 21(5): 1174-1185.

Ojasti, J. 1996. Wildlife Utilization in Latin America: Current Situation and Prospects for Sustainable Management. (FAO Conservation Guide - 25). Food and Agriculture Organization of the United Nations - FAO, Rome. 250pp.

Orejuela, J.E. 1992. Traditional productive systems of the Awa (Cuaiquer) Indians of Southwestern Colombia and neighboring Ecuador. In K.H. Redford, and C. Padoch (eds.). Conservation of Neotropical Forests: Working from Traditional Resource Use, Columbia University Press, New York. Pp. 58-82.

Padilla, A., O.E. Munguía, and Y. Contreras. 2003. Case study on the site consolidation process: Río Plátano Man and Biosphere Reserve, Honduras. Technical document for the Parks in Peril Program. Tegucigalpa, Honduras.

Painter, R. L. E., Wallace R. B., and D. Pickford. 1995. Relative abundances of peccaries in areas of different human pressures within the Beni Biosphere Reserve, Bolivia. IBEX J.M.E. 3: 49-52.

Paviolo, A., Y.E. Di Blanco, C. De Angelo, and M.S. Di Bitetti. 2009. Protection Affects the Abundance and Activity Patterns of Pumas in the Atlantic Forest. Journal of Mammalogy 90(4): 926-934. 
Payan, E., E. Eizirik, T. de Oliveira, R. Leite-Pitman, M. Kelly, and C. Valderrama. 2008. Leopardus wiedii. In IUCN 2009. IUCN Red List of Threatened Species. Version 2009.1. Retrieved on September 24, 2009, from http://www.iucnredlist.org. [Internet Website].

Peres, C.A. 1990. Effects of hunting on western Amazonian primate communities. Biological Conservation 54: 4759.

Peres, C.A. 1991. Humbolts wooly monkey decimated by hunting in Amazonia. Oryx 25: 89-95.

Peres, C.A. 1993. Biodiversity Conservation by Native Amazonians: a Pilot Study in the Kaxinawá Indigenous Reserve of Rio Jordão, Acre, Brazil. Report for the World Wildlife Fund- US, Washington, DC.

Peres, C.A. 1994. Indigenous reserves and nature conservation in Amazonian forests. Conservation Biology 8: 586-588.

Peres, C.A. 1995. Population status of white-lipped Tayassu pecari and collared peccaries T. tajacu in hunted and non-hunted Amazonian forests. Biological Conservation 77: 115123.

Peres, C.A. 1996. Population status of white-lipped Tayassu pecari and collared peccaries $T$. tajacu in hunted and unhunted Amazonian forests. Biological Conservation 77: 115123.

Peres, C.A. 1999. Nonvolant mammal community structure in different Amazonianforest types. In J.F. Eisenberg and K.H. Redford (eds.). Mammals of the neotropics: the Central Neotropics. University of Chicago Press, Chicago, Illinois. pp. 564-581.

Peres, C.A. 2000a. Effects of subsistence hunting on vertebrate community structure in Amazonian forests. Conservation Biology. 14: 240-253.

Peres, C.A. 2000b. Evaluating the impact and sustainability of subsistence hunting at multiple Amazonian forest sites. In Robinson, J.G., and E.L. Bennett. (eds.). Hunting for Sustainability in Tropical Forests. Biology and Resource Management Series, Columbia University Press, New York. Pp. 31-56.

Peres, C.A. 2001. Synergistic effects of subsistence hunting and habitat fragmentation on Amazonian forest vertebrates. Conservation Biology 15: 1490-1505.

Peres, C.A., and I.R. Lake. 2003. Extent of non-timber resource extraction in tropical forests: accessibility to game vertebrates by hunters in the Amazon basin. Conservation Biology 17: 521-535. 
Peres, C.A., and E. Palacios. 2007. Basin-wide effects of game harvest on vertebrate population densities in Amazonian forests: implications for animal-mediated seed dispersal. Biotropica 39: 304-315.

Peres, C.A., and J.W. Terborgh. 1995. Amazonian nature reserves: an analysis of the defensibility status of existing conservation units and design criteria for the future. Conservation Biology 9: 34-46.

Peres, C.A., and M.G.M. Van Roosmalen. 1996. Avian dispersal of mimetic seeds in Ormosia lignivalvis (Leguminosae: Papilionaceae): deceit or mutualism? Oikos 75: 249-258

Peres, C.A., and B. Zimmerman. 2001. Perils in parks or parks in peril? Reconciling conservation in Amazonian reserves with and without use. Conservation Biology 15: $793-797$.

Peters, R.H., and K. Wassembgerg. 1983. The effect of body size on animal abundance. Oecologia 60: 89-96.

Peterson, R.T., and E.L. Chalif. 1973. Peterson Field Guide to Mexican Birds: Mexico, Guatemala, Belize, El Salvador. Houghton Mifflin Co., Boston. 320 pp.

Porini, G., A.B. Rylands, R. Samudio, and Members of the IUCN SSC Edentate Specialist Group 2008. Myrmecophaga tridactyla. In: IUCN 2009. IUCN Red List of Threatened Species. Version 2009.1. Retrieved on September 26, 2009, from http://www.iucnredlist.org. [Internet Website].

Posey, D.A. 1992. Interpreting and applying the "reality" of indigenous concepts: what is necessary to learn from the natives? In Redford, K.H., and C. Padoch. (eds.). Conservation of Neotropical Forests: Working from Traditional Resource Use. Columbia University Press, New York. Pp. 21-34.

Prescott-Allen, C. and R. Prescott-Allen. 1982. What's wildlife worth? Economic contributions of wild plants and animals to developing countries. An Earthscan Paperback, 92 pp.

Pulliam, H.R. 1988. Sources, sinks, and population regulation. American Naturalist 132: 652-661.

Ramos-Fernandez, G., L.G. Vick, F. Aureli, C.A. Schaffner, and D.M. Taub. 2003. Behavioral ecology and conservation status of spider monkeys in the Otoch Ma'ax Yetel Kooh protected area. Neotropical Primates 11(3): 155-158.

Redford, K.H. 1991. The ecologically noble savage. Orion 9:24-29.

Redford, K.H. 1992. The Empty Forest. BioScience 42(6): 412-422. 
Redford, K.H. 1993. Hunting in Neotropical forests: a subsidy from nature. In C.M. Hladik, A. Hladik, 0.F. Linares, H. Pagezy, A. Semple, and M. Hadley (eds.). Tropical Forests, People and Foods: Biocultural Interactions and Applications to Development. United Nations Educational, Scientific and Cultural Organization: Paris. Pp. 227-246.

Redford, K.H., and J.G. Robinson. 1987. The game of choice: patterns of Indian and colonist hunting in the Neotropics. American Anthropologist 89: 650-667.

Redford, K.H., and J.G. Robinson. 1991. Subsistence and commercial uses of wildlife in Latin America. In Robinson, J.G., and Redford, K.H. (eds.). Neotropical Wildlife Use and Conservation, University of Chicago Press, Chicago, Illinois. Pp. 6-23.

Redford, Kent H. and C. Padoch 1992. Conservation of Neotropical Forests. Working from Traditional Resource Use. Columbia University Press, New York. Pp. 475.

Redford, K.H., and S.E. Sanderson. 2000. Extracting humans from nature. Conservation Biology 14: 1362-1364.

Redford, K.H., and A.M. Stearman. 1993. Forest-dwelling native Amazonians and the conservation of biodiversity: interests in common or in collision? Conservation Biology 7: 248-255.

Reichel-Dolmatoff, G. 1971. Amazonian Cosmos: The Sexual and Religious Symbolism of the Tukano Indians. University of Chicago Press: Chicago. 290 Pp.

Reichel-Dolmatoff, G. 1996. The Forest Within: The World-View of the Tukano Amazonian Indians, Themis Books, Totnes, Devon. 256Pp.

Reid, F.A. 1997. A Field Guide to the Mammals of Central America and Southeast Mexico. Oxford University Press: New York. Pp. 334.

Reid, W.V. 1992. How many species will there be? In T.C. Whitmore and J.A. Sawyer (eds.). Tropical Deforestation and Species Extinction. Chapman and Hall: London. Pp. 55-73.

Reyna-Hurtado, R., and G.W. Tanner. 2005. Habitat preferences of ungulates in hunted and non-hunted areas in the Calakmul forest, Campeche, Mexico. Biotropica 37(4): 676685 .

Reyna-Hurtado, R., and G.W. Tanner. 2007. Ungulate relative abundance in hunted and non-hunted sites in the Calakmul forest (Southern Mexico). Biodiversity and Conservation 16: 743-756. 
Reyna-Hurtado, R., A. Taber, M. Altrichter, J. Fragoso, A. Keuroghlian, and H. Beck. 2008. Tayassu pecari. In IUCN 2009. IUCN Red List of Threatened Species. Version 2009.1. Retrieved on August 25, 2009, from http://www.iucnredlist.org. [Internet Website].

Ridley M. 1996. The Origins of Virtue. London: Viking, Penguin. 304 pp.

Rivas, R.D. 2000. Pueblos Indígenas y Garifuna de Honduras: Una Caracterizacion. Guaymuras: Tegucigalpa, Honduras. 492 Pp.

Robinson, J.G. 1993. The limits to caring: sustainable living and the loss of biodiversity. Conservation Biology 7: 20-28.

Robinson, J.G., 1996. Hunting wildlife in forest patches: an ephemeral resource. In Schellas, J., and R. Greenberg (eds.). Forest Patches in Tropical Landscapes. Island Press, Washington DC. Pp. 111-130.

Robinson, J.G., and E.L. Bennett. 2000. Carrying capacity limits to sustainable hunting in tropical forests. In: Robinson, J.G., and E.L. Bennett (eds.). Hunting for Sustainability in Tropical Forests. Columbia University Press: New York. Pp. 13-30.

Robinson, J.G., and E.L. Bennett. 2004. Having your wildlife and eating it too: an analysis of hunting sustainability across tropical ecosystems. Animal Conservation 7: 397-408.

Robinson, J.G., and R.E. Bodmer. 1999. Tropical forest wildlife management. Journal of Wildlife Management 63(1): 1-9.

Robinson, J.G., and Redford, K.H. 1991. Sustainable harvest of neotropical forest mammals. In Robinson, J.G., and K.H. Redford (eds.). Neotropical Wildlife Use and Conservation, University of Chicago Press: Chicago, Illinois. Pp. 415-429.

Robinson, J.G., and B. Richter. 1999. Conservation of biodiversity in a world of use. Conservation Biology 13: 1246-1256.

Rudle, K. 1970. The hunting technology of the Maraca Indians. Anthropologica 25: 21-63. Ruddle, K. and W. Manshard. 1981. Renewable natural resources and the environment. Tycooly Internationa: Dublin. 396 pp.

Saffirio, G. and R. Scaglion. 1982. Hunting Efficiency in Acculturated and Unacculturated Yanomama Villages. Journal of Anthropological Research 38(3): 315-327.

Salas, L.A., and J.B. Kim. 2002. Spatial factors and stochasticity in the evaluation of sustainable hunting of tapirs. Conservation Biology 16: 86-96.

Sánchez-Rojas, G., C. Aguilar-Miguel, and E. Hernández-Cid. 2009. Estudio poblacional y uso de hábitat por el Venado Cola Blanca (Odocoileus virginianus) en un bosque 
templado de la Sierra de Pachuca, Hidalgo, México. Tropical Conservation Science Vol.2(2): 204-214.

Sanderson, E.W., K.H. Redford, C.B. Chetkiewicz, R.A. Medellin, R.A. Rabinowitz, J.G. Robinson, and A.B. Taber. 2002. Planning to save a species: the jaguar as a model. Conservation Biology 16: 1-15.

Schutt, A. and C. Vaughan. 1995. Incorporating wildlife into development: The case of the Curu Wildlife Refuge and Farm, Costa Rica. In J. Bissonette and P. Krausmann (eds.). Integrating people and wildlife for a sustainable future. The Wildlife Society, Bethesda, Maryland. Pp. 250-254.

Schwartzman, S., A. Moreira, and D. Nepstad. 2000. Rethinking tropical forest conservation: perils in parks. Conservation Biology 14: 1351-1357.

Shepard Jr., G.H.. 2002. Primates in Matsigenka subsistence and worldview. In A. Fuentes and $\mathrm{L}$. Wolfe (eds). Primates face to face: the conservation implications of human and nonhuman primate interconnections. Cambridge University Press, Cambridge, United Kingdom. Pp. 101-136.

Silva, J.L., and S.D. Strahl. 1991. Human impact on populations of chachalacas, guans, and curassows (Galliformes: Cracidae). In J.G. Robinson and K.H. Redford (eds.). Neotropical Wildlife Use and Conservation. Chicago University Press, Chicago. Pp. $37-52$.

Silveira L. 2004. Ecologia comparada e conservação da onça-pintada (Panthera onca) e onça-parda (Puma concolor), no Cerrado e Pantanal. Ph.D. thesis, Univ. de Brasília, Brasília, Brazil.

Sirén, A., P. Hambäck, and J. Machoa. 2004. Including Spatial Heterogeneity and Animal Dispersal When Evaluating Hunting: a Model Analysis and an Empirical Assessment in an Amazonian Community. Conservation Biology 18 (5): 1315-1329.

Skole, D., and C. Tucker. 1993. Tropical deforestation and habitat fragmentation in the Amazon: satellite data from 1978 to 1988. Science 260: 1905-1911.

Smith, D.A. 2003. Participatory Mapping of Community Lands and Hunting Yields among the Buglé of Western Panama. Human Organization 62 (4): 332-343.

Smith, D.A. 2005. Garden game: shifting cultivation, indigenous hunting and wildlife ecology in western Panama. Human Ecology 33: 505-537.

Smith, D.A. 2008. The spatial patterns of indigenous wildlife use in western Panama: Implications for conservation management. Biological Conservation 141: 925-937. 
Smith, J. 1978. Optimization theory in evolution. Annual Review of Ecology and Systematics 9: 31-56.

Snarr, K. and K. Edwards. 2005. Primate abundance and behaviour, Cusuco National Park, Honduras. Final report for the University of Nottingham/Operation Wallacea Forest Projects. Tegucigalpa, Honduras.

Sorensen, T., and L.M. Fedigan. 2000. Distribution of three monkey species along a gradient of regenerating tropical dry forest. Biological Conservation 92: 227-240.

Souza-Mazurek, R., T. Pedrinho, F. Xinymy, H. Waraié, G. Sanapyty, and M. Ewepe. 2000. Subsistence hunting among the Waimiri Atroari Indians in central Amazonia, Brazil. Biodiversity and Conservation 9: 579-596.

Sowls L.K. 1997. Javelinas and other Peccaries - Their biology, management and use. 2nd ed. Texas A and M University Press: College Station, Texas. 352pp.

Sponsel, E.L. 1986. Amazon ecology and adaptation. Annual Review of Anthropology 15: 67-97.

Stearman, A.M. 1990. The effects of settler incursion on fish and game resources of the Yuquí, a native Amazonian society of eastern Bolivia. Human Organization 49: 373385.

Stearman, A.M. 1992. Neotropical indigenous hunters and their neighbors: Sirionó, Chimane, and Yuquí hunting on the Bolivian frontier. In Redford, K.H., C. Padoch (eds.). Conservation of Neotropical Forests: Working from Traditional Resource Use. Columbia University Press: New York. Pp. 108-128.

Stearman, A.M. 2000. A Pound of Flesh: Social Change and Modernization as Factors in Hunting Sustainability among Neotropical Indigenous Societies. In Robinson, J.G. and E.L. Bennett (eds.). Hunting for Sustainability in Tropical Forests. New York, Columbia University Press. Pp. 233-250.

Stearman, A.M., K.H. Redford. 1995. Game management and cultural survival: the Yuquí ethno-development project in lowland Bolivia. Oryx 29: 29-34.

Stiles, F., A. Skutch. 1989. A Guide to the Birds of Costa Rica. Ithaca, New York: Comstock Publishing Associates. $656 \mathrm{pp}$.

Stoner, K.E. 1996. Habitat Selection and Seasonal Patterns of Activity and Foraging of Mantled Howling Monkeys (Alouatta palliata) in Northeastern Costa Rica. International Journal of Primatology 17(1): 1-30.

Suazo-Euceda, J.P. 2005. Perception y Uso de la Vida Silvestre: Tawahkas y Ladinos en el Corredor Mesoamericano. Guaymuras: Tegucigalpa, Honduras. Pp. 225. 
Tabanez, A.J., and V.M. Viana. 2000. Patch structure within Brazilian Atlantic forest fragments and implications for conservation. Biotropica 32: 925-933.

Tapir Specialist Group. 2009. The World's Tapirs - The Baird's Tapir (Tapirus bairdii). Retreived on August 19, 2009, from http://www.tapirs.org/tapirs/bairds.html. [Internet Website].

Terborgh, J. 1974. Faunal equilibria and the design of wildlife preserves. In Golley, F.B., and E. Medina (eds.). Tropical Ecological Systems. Springer-Verlag, New York. Pp. 369-380.

Terborgh, J. 1983. Five new world primates: a study in comparative ecology. Princeton University Press, Princeton, New Jersey. 280 pp.

Terborgh, J. 1999. Requiem for nature. Island Press: Washington, D.C. 254 pp.

Terborgh, J. 2000. The fate of tropical forests: a matter of stewardship. Conservation Biology 14: 1358-1361.

Terborgh. J., L.H. Emmons, and Y.C. Freese. 1986. La fauna silvestre de la Amazonia: el despilfarro de un recurso renovable. Boletín de Lima 46.

Terborgh, J., G. Nuñez-Iturri, N.C.A. Pitman, F.H.C. Valverde, P. Alvarez, V. Swamy, E.G. Pringle, and C.E.T. Paine. 2008. Tree recruitment in an empty forest. Ecology 89: $1757-1768$.

Terborgh, J., and C.A. Peres. 2002. The problem of people in parks. In J. Terborgh, C. van Schaik, L. Davenport, and M. Rao (eds.). Making parks work. Island Press, Washington, D.C. Pp. 307-319.

Terborgh, J., and C. van Schaik. 2002. Why the world needs Park. In J. Terborgh, C. van Schaik, L. Davenport, and M. Rao (eds.). Making Parks Work: Strategies for Preserving Tropical Nature. Island Press. Pp. 3-14.

Terborgh, J., and B. Winter. 1978. Some causes of extinction. In M. Soulé and. B.A. Wilcox (eds.). Conservation biology. Pp. 119-133.

Thiollay, J.M. 1986. Structure comparée du peuplement avien dans trois sites de foret primaire en Guyane. Revue d'Ecologie 41: 59-105.

Thomas-Slayter, B. 1995. A brief history of participatory methodologies. In R. Slocum, L. Wichhart, D. Rocheleau and B. Thomas Slayter (eds.). Power, Process and Participation: Tools for Change. Intermediate Technology Publications, London. Pp. 9-16. 
Thompson, W.L. 2004. Sampling Rare or Elusive Species: Concepts, Designs, and Techniques for Estimating Population Parametres. Island Press, Washington, D.C. 429 pp.

Thompson, W.L, G.C. White, and C. Gowan. 1998. Monitoring Vertebrate Populations. Academic Press, San Diego. 365pp.

Tobler, M.W. 2002. Habitat use and diet of Baird's tapir (Tapirus bairdii) in a montane cloud forest of the Cordillera de Talamanca, Costa Rica. Biotropica 34(3): 468-474.

Townsend, W. 1995. Living on the edge: Sirionó hunting and fishing in lowland Bolivia. Ph.D. thesis, University of Florida.

Townsend, W.R. 2000. The Sustainability of Subsistence Hunting by the Sirionó Indians of Bolivia. In Robinson, J.G. and E.L. Bennett (eds.). Hunting for Sustainability in Tropical Forests. Columbia, New York. Pp. 267-281.

Tresierra, J.C. 1997. Derechos de uso de los recursos naturales por los groupos indígenas en el bosque tropical. Banco Interamericano de Desarrollo: Washington DC. Pp. 46.

UNEP-WCMC. 2002. Río Plátano Biosphere Reserve, Honduras. Retrieved on September 20, 2007, from http://www.unep-wcmc.org/sites/wh/pdf/Rio\%20Platano.pdf [Internet Website]

UNESCO 2007. MAB Biosphere Reserves Directory. Retrieved on September 5 2008, from http://www.unesco.org/mabdb/br/brdir/directory/biores.asp?mode=allandcode [Internet Website].

Van den Berg, L.J.L., J.M. Bullock, R.T. Clarke, R.H.W. Langston, R.J. Rose RJ. 2001. Territory selection by the Dartford warbler (Sylvia undata) in Dorset, England: the role of vegetation type, habitat fragmentation and population size. Biological Conservation 101: 217-228.

Van Dyke, W.D., R.H. Broke, and H.G. Shaw. 1986. Use of road track counts as indices of mountain lion presence. Journal of Wildlife Management 50: 102-109.

Van Hulle, M., and C. Vaughan. 2009. The Effect of Human Development on Mammal Populations of the Punta Leona Private Wildlife Refuge, Costa Rica. Revista de Biología Tropical 57(1-2): 441-449.

Van Shaik, C. P., J.W. Terborgh, and S.J. Wright. 1993. The phenology of tropical forests: Adaptive significance and consequences for primary consumers. Annual Review of Ecology and Systematics 24: 353-377.

Vaughan, C., and K. Weiss. 1999. Neotropical dry forest wildlife waterhole use and management. Regional Wildlife Program. Universidad Nacional Heredia: Costa Rica. 
Vaughan, C., and M. Rodriguez. 1991. White-tailed deer management in Costa Rica. In J.G. Robinson and K.H. Redford (eds.). Neotropical Wildlife Use in Conservation. University of Chicago Press, Chicago. Pp. 288-299.

Ventocilla, J. 1992. Cacería y Subsistencia en Cangandi, una Comunidad de los Indígemas Kunas (Comarca Kuna Yala). Ediciones Abya-Yala: Quito, Ecuador.

Ventocilla, J. 1995. Terrestrial Fauna. In Ventocilla, J., H. Herrera and V. Núñez (eds.). Plants and Animals in the Life of the Kuna. University of Texas Press: Austin. Pp. 3042.

Vickers, W. 1984. The faunal components of lowland South American hunting kills. Interciencia 9: 366-376.

Vickers, W. 1991. Hunting yields and game composition over ten years in an Amazonian village. In J. G. Robinson and K.H. Redford (eds.). Neotropical Wildlife Use in Conservation. University of Chicago Press, Chicago. Pp. 53-81.

Vié, J.C., C. Hilton-Taylor, and S.N. Stuart (eds.). 2009. Wildlife in a Changing World-An Analysis of the 2008 IUCN Red List of Threatened Species. Gland, Switzerland: IUCN. $180 \mathrm{pp}$.

Weber, M. 2000. Effects of hunting on tropical deer populations in Southeastern México. M.Sc. Thesis, Royal Veterinary College, University of London: London, United Kingdom.

Webster, G.S. 1986. Optimization Theory and Pre-Columbian Hunting in the Tehuacan Valley. Human Ecology 14(4): 415-435.

Wilcove DS, C.H. McLellan, and A.P. Dobson. 1986. Habitat fragmentation in the temperate zone. In M.E Soulé (ed.). Conservation Biology. Sinauer, Sunderland, Massachusset. Pp. 237-56.

Wilkie, D.S. and J.T. Finn. 1990. Slash-burn cultivation and mammal abundance in the Ituri Forest, Zaire. Biotropica 22: 90-99.

Williams, H. E., and C. Vaughan. 2001. White-faced monkey (Cebus capucinus) ecology and management in neotropical agricultural landscapes during the dry season. Revista de Biología Tropical 49(3-4): 1199-1206.

Williams, K. 1984. The Central American tapir in northwestern Costa Rica. Ph.D. dissertation. Michigan State University: East Lansing, Michigan.

Wolfheim, J.H. 1983. Primates of the World. University of Washington Press, Seattle. 807pp. 
Wood, D. 1995. Conserved to death: Are tropical forests being over-protected from people? Land Use Policy 12 (2): 115-135.

World Bank. 2005. Project Brief on a Proposed Grant from the Environment Facility Trust Fund in the Amount of \$US 12 Million to the Central American Commission of Environment and Development for the Nicaragua/Honduras Corazón Transboundary Biosphere Reserve. RP 438. Retrieved on September 10, 2008, from http://wwwwds.worldbank.org/external/default/WDSContentServer/WDSP /IB/2006/06/05/000160016 20060605155012/Rendered/PDF/RP4380P0854881Marco deProcesoFinal.pdf. [Internet Website].

Wright, S.J. 2003. The myriad consequences of hunting for vertebrates and plants in tropical forests. Perspectives in Plant Ecology. Evolution and Systematics 6(1-2): 73-86.

Wright, S.J., M.E. Gompper, and B. DeLeon. 1994. Are large predators keystone species in neotropical forests? The evidence from Barro Colorado Island. Oikos 71: 279-294.

Wright, S.J., H. Zeballos, I. Dominguez, M.M. Gallardo, M.C. Moreno, R. Ibanez. 2000. Poachers alter mammal abundance, seed dispersal and seed predation in a Neotropical forest. Conservation Biology 14: 227-239.

Yost, J.A. and P.M. Kelley. 1983. Shotguns, Blowguns, and Spears: The Analysis of Technological Efficiency. In Hames, R.B. and W.T. Vickers. Adaptive Responses of Native Amazonians. Academic Press, New York. Pp. 189-222.

Zimmerman, B., C.A. Peres, J.R. Malcolm, and T. Turner. 2001. Conservation and development alliances with the Kayapó of south-eastern Amazonia, a tropical forest indigenous people. Environmental Conservation 28: 10-22. 